\title{
The Eventification of Exhibiting Architecture
}

by

Daniela Mandarano

A thesis submitted to the Faculty of Graduate Postdoctoral Affairs

in partial fulfillment of the requirements for the degree of

\author{
Master of Architecture
}

Carleton University

Ottawa, Ontario, Canada

(c) 2020

Daniela Mandarano 


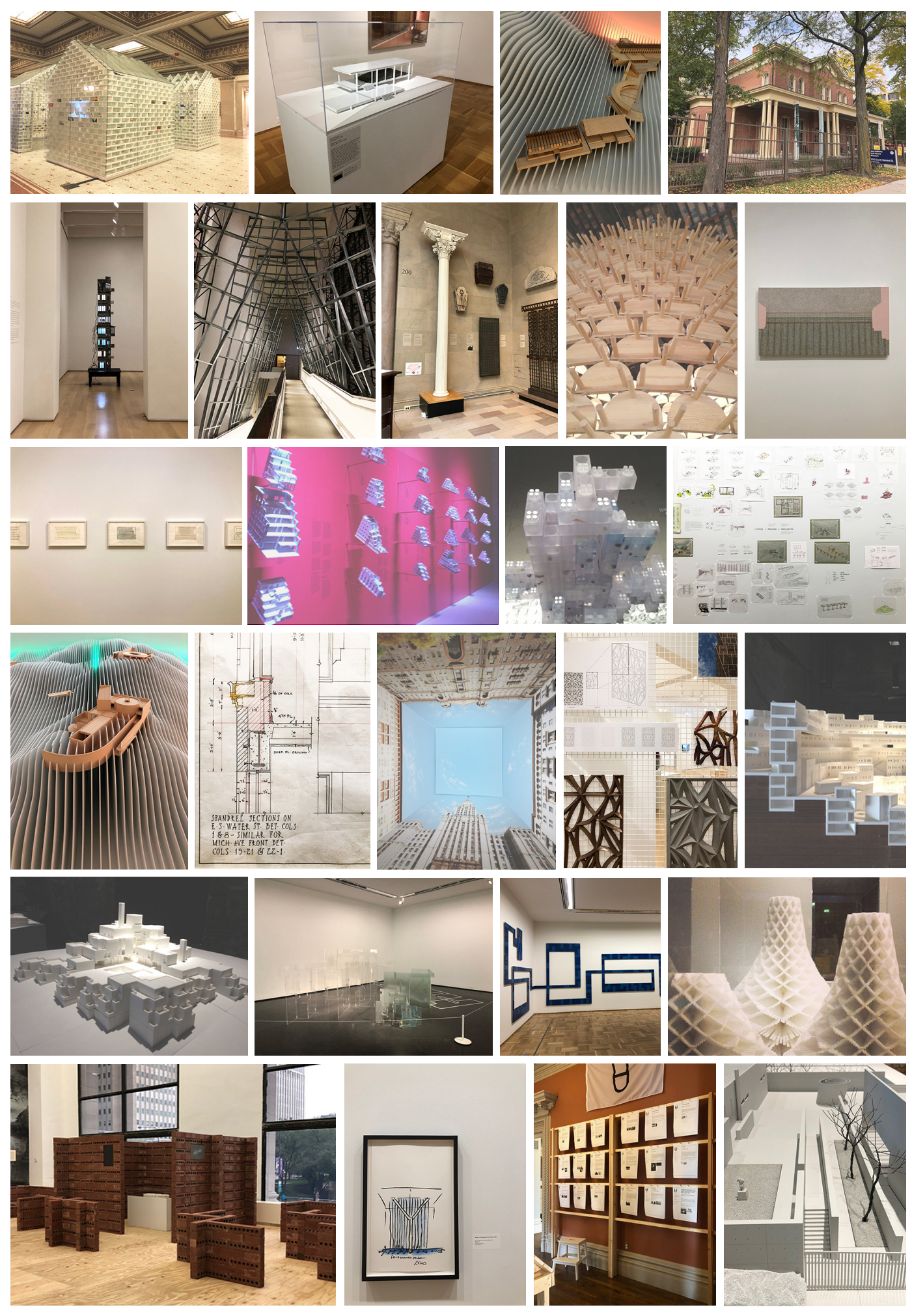


"Architecture is, by its very nature, in the world', in both spatial and temporal terms: buildings are concrete and tangible elements of our everyday life-world. Yet, also architectural designs, urban plans, utopian schemes or paper architecture are 'in the world': they might not define the way things work, but they do change the way we think about how they work, or should work. It is this peculiar, myriad beingin-the-world-ness of architecture that raises fundamental questions about how architecture enacts, how it performs, and consequently, how it might 'act otherwise' or lead to other possible futures."

Doucet, Cupers, Agency in Architecture:

Rethinking Criticality in Theory and Practice, 1. 
This thesis is dedicated in memory of my Babcia Sophie for teaching me about the true joys in life.

Your spirit continues to guide me throughout my journey. 


\section{Abstract}

Why do we exhibit architecture when we are enveloped by it every day? Architecture exhibitions have become increasingly popular and relevant over the last two decades. This is evident in the recognition and influence demonstrated by international organizations such as the Venice Architecture Biennale (Venice, Italy), Chicago Architecture Biennial (Chicago, IL., USA) and Storefront for Art and Architecture (New York, NY., USA). Placing architecture on display activates the curatorial practice of the convergence between art and architecture. This thesis sets out to explore the integration and overlap of artistic expression within architecture and how it informs the function of a space. The notion of curation and its practices will be researched to delve further into how visual and creative practices influence how architects develop, discuss and advocate their work. The final curatorial project will explore how art can be utilized as a catalyst to bridge purely pragmatic physical elements of a structure with artistic forms, seeking to enrich the relationships between the public and the (built) environment. 


\section{Acknowledgments}

To my advisors, Roger Connah and Yvan Cazabon, for your wealth of knowledge, inspiration and guidance in the development of this thesis.

To my colleagues, whose friendships have made this experience more fruitful than I could have imagined. Your work continues to inspire and motivate me to do better.

To my parents, Val and Larry, for your unconditional love and support throughout my entire academic career. Without your sacrifices, I would not be who I am or where I am today. This accomplishment is as much yours as it is mine.

To my sister, Tatjana, for your countless advice and listening ear when I needed it most.

To Jake, for your endless encouragement, positivity and thoughtful acts of love, no matter the distance. 


\section{Contents}

Dedication iv

Abstract $\quad v$

Acknowledgments

Contents vii

Glossary viii

List Of Figures $x$

Introduction xiii

The Brief 16

Curare / Curator / Curation 18

The Role Of The Exhibition In Architectural Discourse 20

How Is Architecture Curated? 25

Representation

Experiential Investigation

Original Context

Curating Architecture Through The Vitrine 36

The Exhibition $\quad 40$

Exhibiting Architecture: Case Studies $\quad 41$

Chicago Architecture Biennial

Storefront For Art And Architecture

Wrightwood 659

Curating Spaces For Events

Site(s) For Events $\quad 56$

The (Un)Curated Event 59

$\begin{array}{ll}\text { Postscript } & 76\end{array}$

Endnotes $\quad 78$

Glossary (Sources) 80

Bibliography $\quad 81$

Figures (Sources) 83

Appendix 89 


\section{Glossary}

Agency

An action or event that produces an effect. ${ }^{1}$

Architecture Exhibition

A spatial condition evolving from the curation of architectural production that catalyzes an event to occur.

Architectural Production

The modality of architectural discourse as it pertains to its discipline, practice, theory and research.

\section{Curation}

A derivative of the word curator, is "the action or process of selecting, organizing, and looking after the items in a collection or exhibition."2

\section{Eventification}

An experience of events that are measured on the multiplicity of their occurrence.

\section{Content}

The events, physical detail, and information in a work of art: the architect as cultural producer. ${ }^{3}$

\section{Space}

A boundless two- or three-dimensional extent in which objects and events inhabit, based on a relative position and direction. ${ }^{4}$

\section{Exhibition}

An architecture within its context, where its program has changed from its original intent and is now preserved for display. 


\section{Exhibitionist}

An architecture that functions as per its original intent and finds its program curated through a didactical design of architectural elements that perform as spatial events.

Vitrine

A glass showcase. ${ }^{5}$

The vitrine is used as a subject throughout the thesis as it creates a continuous dialogue between the various spatial conditions that are related to the curation of architecture.

\section{Urban Vitrine}

An interstice between interior and exterior where the convergence of art and architecture emerges within the urban fabric of a city.

\section{Urban Fabric}

The physical aspects of urbanism emphasizing open spaces and streetscapes but excluding the built environment. ${ }^{6}$

Art

An artistic expression developed through skill, creativity and imagination that produces a product with aesthetic intention.

\section{Event}

In relation to Bernard Tschumi's theory of "there is no space without event". An event is a spatial condition consisting of time, action and movement that is activated by the human body. ${ }^{7}$

\section{Viewer}

One who participates in viewing events that take place. The viewer can also become the subject of viewing.

Subject

A person, spatial condition or object involved in the experience of an event. 


\section{List Of Figures}

Figure 01: Architecture Within Its Context, Winnipeg Art Gallery, Winnipeg, MB. 13

Figure 02: Architecture Removed From its Context, Winnipeg Art Gallery, Winnipeg, MB. 13

Figure 03: Architecture Relocated in the Museum, Winnipeg Art Gallery, Winnipeg, MB. 13

Figure 04: White Box Diagram 14

$\begin{array}{ll}\text { Figure 05: Matrix } & 17\end{array}$

Don't Miss a Sec', Monica Bonvicini, 2004

Snake, Richard Serra, 2005

Realizing An Anthropometry, Yves Klein, 1960

Splitting, Gordon Matta-Clark, 1974

Falling Clock, Daniel Arsham, 2011

Withdrawing Room, Elizabeth Diller, 1987

Imponderabilia, Marina Abramovic \& Ulay, 1977-2017

Marsyas: Anish Kapoor, 2002

Figure 06: Kunstkammer, (1636) painted by Frans II Fracken 18

Figure 07: Comparison Diagram: Narratives of a Curator and an Architect 19

Figure 08: The Evolution of Exhibiting Architecture 21

1932: Display at Bullocks-Wilshire Department Store, Los Angeles, CA., USA:

Modern Architecture International Exhibition - Philip Johnson and Henry-Russell

Hitchcock

1938: December 7, 1938-January 30, 1939. Photographic Archive.

The Museum of Modern

Art Archives, New York. Photographs by Soichi Sunami

1941: The Ecole Des Beaux-Arts And Architectural Education by Paul P. Cret

1957: Berlin Interbau (1957) Postcard

Berlin Inter - Aerial photo of the Hansaviertel District, 1962

Berlin Inter - Orientation sign for the new buildings in the Hansaviertel

1980: Façades of the Strada Novissima at the 1980 Biennale Architettura

1982: Opening night of Performance A to Z, first event hosted at Storefront

2005: Bi-City Shenzhen Biennale of Urbanism / Architecture 8th edition to run 2019. titled Urban Space and Technological Innovation

2007: Trienal de Arquitectura de Lisboa 5th edition to run 2019, titled The Poetics of Reason

2015: Chicago Architecture Biennial. First biennial to be established in North America 3rd edition to run 2019, titled ...And Other Such Stories

2019: Bauhaus in Greece International conference to take place in Athens for the 100th anniversary of the foundation of Bauhaus at The Athens School of Fine Arts 2019: Bienal de Arquitectura Latinoamericana 
Figure 09: John A. Russell Architecture Building (1959), University of Manitoba, Winnipeg, MB. 23

Figure 10: 2019 Thesis Work exhibited in the Lightroom Gallery, Carleton University 24

Figure 11: Anticipating The Architectural Outcome Exhibition at Chicago Art Institute 26

Figure 12: Cabinet of Architectural Representations $\quad 27$

Figure 13: Softscape (2011) by SPMB at RAW Gallery, Winnipeg, MB. 28

Figure 14: Diorama of the (Un)Ordinary $\quad 29$

Figure 15: Farnsworth House (1951) by Mies van der Rohe, Plano, IL., USA 30

Figure 16: Centre Pompidou (1971-77) by Renzo Piano \& Richard Rogers, Paris, France 31

Figure 17: The Authentic Self $\quad 32$

Figure 18: Deconstructed Layers of Each Curation Method 33

Figure 19: Curating Architecture Diagram: Inspired by Sculpture In The Expanded Field by 34 Rosalind Krauss

Figure 20: Unfolding Spatial Conditions $\quad 35$

Figure 21: Deconstructing the Binary Vitrine $\quad 37$

Figure 22: Thresholds $\quad 39$

Figure 23: Chicago Cultural Center 11897), Chicago IL., USA 41

Figure 24: Teeter-Totter Wall by Rael Sam Fratello (2018), on the border between Sunland Park, 42 NM., USA \& Ciudad Juarez, Mexico.

Figure 25: Gallery facade (1993) by Vito Acconci \& Steven Holl for Storefront for Art and 43 Architecture, New York, NY. USA

Figure 26: Wrightwood 659 (2018) by Tadao Ando Architect and Associates, Chicago, IL., USA 44

Figure 27: Wrightwood 659 (2018) by Tadao Ando Architect and Associates, Chicago, IL., USA 45

Figure 28: Architectural Didactics - Stairs At Play 47

Figure 29: Architectural Didactics - Stairs At Play Deconstructed Layers of the Drawing 48

Figure 30: The Ceiling display from the 2014 Venice Architecture Biennale: Fundamentals in 50 Venice, Italy.

Figure 31: Index of Architectural Elements (Exhibition/Exhibitionist)

From The Knees Of My Nose To The Belly Of My Toes: Alex Chinneck, 2013

Crystal Houses: MVRDV, 2016

Umbrella Street: Quartier Petit Champlain, 2019

Yi Chen And Muchen Zhang: Guanglian Licc Cloud Center, 2019

Corridor House: Mos Architects, 2015

Red River College Princess Campus-Roblin Centre: Cibinel Architecture, 2011

Passages: Do Ho Suh

Best Products Company, Inc.: Site

'Untitled (Stairs)' : Rachel Whiteread, 2001

Vessel: Thomas Heatherwick, 2019

Richard Serra

Marsyas: Anish Kapoor, 2002

Passages: So-Il, 2015

The Why Factory Is (W)Ego: MVRDV, 2017 
Off The Cuff: Diller Scofidio + Renfro, 2017

Al Fayah Park: Thomas Heatherwick, 2010

The Future Was Then: Daniel Arsham, 2016

The Collage House: S+Ps Architects, 2015

Wastelandscape: Architect Clémence Eliard And Artist Elise Morin, 2011

Superkilen: Brash Danish Architects Big In Collaboration With German

Landscape Architects Topotek 1 And Superflex, 2013

Massimo Uberti: Neon Light Installation, 2014

Hh59 Zurich: Meyer Dudesek Architekten, 2015

Figure 32: Cohesion Element Diagram

Figure 33: Vessel (2019) by Thomas Heatherwick in New York City, NY., USA 53

Figure 34: Crystal Houses (2016) by MVRDV, Amsterdam, Netherlands 54

Figure 35: From the Knees of my Nose to the Belly of my Toes (2013) by Alex Chinneck, Kent, UK. 54

Figure 36: Site Plan - Centretown, Ottawa, ON.

Figure 37: Existing Site Conditions $\quad 57$

Figure 38: Exploration of Site Activity $\quad 58$

Figure 39: North Narrative Section $\quad 61$

Figure 40: Teeter-Totter Floor $\quad 62$

Figure 41: Threshold of a Floor $\quad 63$

Figure 42: East Narrative Section $\quad 64$

Figure 43: Stairs In Action $\quad 65$

Figure 44: Peek-A-Boo on the Stairs 66

Figure 45: Thresholds of a Door $\quad 67$

Figure 46: The Extending Window $\quad 68$

Figure 47: Interstice of Floors $\quad 69$

Figure 48: Bounce in Every Step $\quad 70$

Figure 49: West Narrative Section $\quad 71$

Figure 50: Swiveling from Interior to Exterior Conditions $\quad 72$

Figure 51: The Buffer-less Corridor $\quad 73$

Figure 52: Depths of a Wall $\quad 74$

Figure 53: Sitting on a Wall $\quad 75$

Figure 54: Supplementary Sketches and Explorations 89

Figure 55: Supplementary Sketches and Explorations 90

Figure 56: Supplementary Sketches and Explorations 91

*See Figures on page 83 for image sources. 


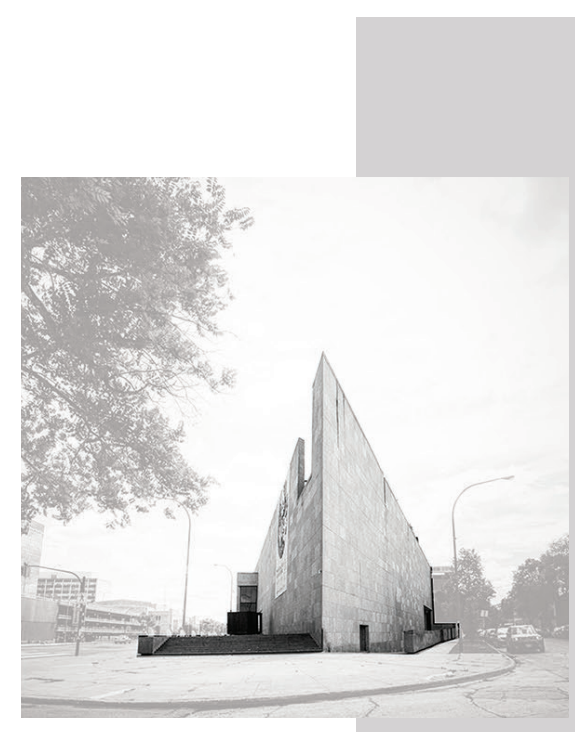

Fig 1 Architecture Within Its Context,

Winnipeg Art Gallery, Winnipeg, MB.

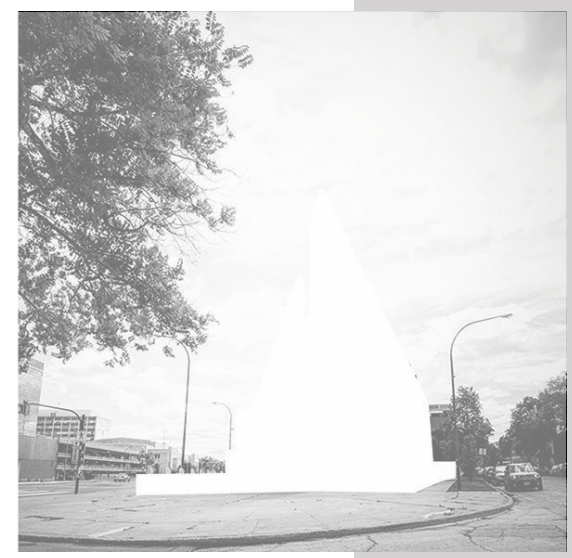

"Architecture is always somewhere else - in the city

or the landscape

but never in the exhibition."

Zardini, Exhibiting and Collecting Ideas: A Montreal Perspective, 81.

Fig 2 Architecture Removed From Its

Context, Winnipeg Art Gallery, Winnipeg, MB.

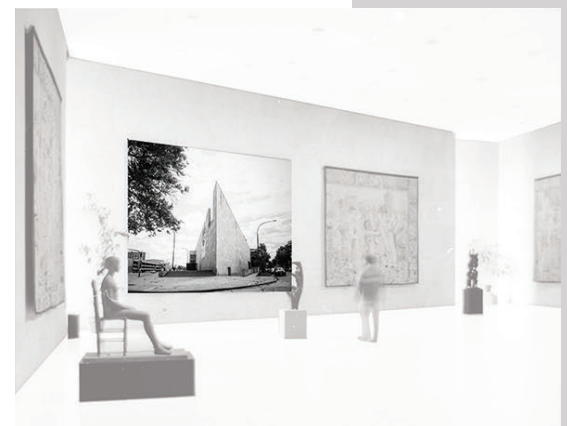

Fig 3 Architecture Relocated in the Museum, Winnipeg Art Gallery, Winnipeg, MB. 


\section{Introduction}

The word architecture can be somewhat confusing. As writer and curator Alison Hugill explains in Curating Architecture: The Architecture of Estrangement, "architecture has become ambiguous, producing a defamiliarizing effect when strategically used out of context. While generally referring to any complex structure, the term 'architecture' has come to represent, among other things, the conceptual framework and logical organization of systems."1 Architecture is one of the few disciplines that plays a varying role in many other disciplines. Its utilitarian nature subjects it to a versatility of endeavours at the risk of becoming lost in translation within its own discipline. Most people relate architecture to buildings and an architect as one who designs buildings. The most basic definition of the term architecture according to the MerriamWebster Dictionary is "the art or practice of designing and constructing building structures." ${ }^{2}$ For those outside of the field, this is possibly the extent of their understanding. If so, how does the subject of architecture - as significant and commonplace in our daily lives - remain so poorly understood?

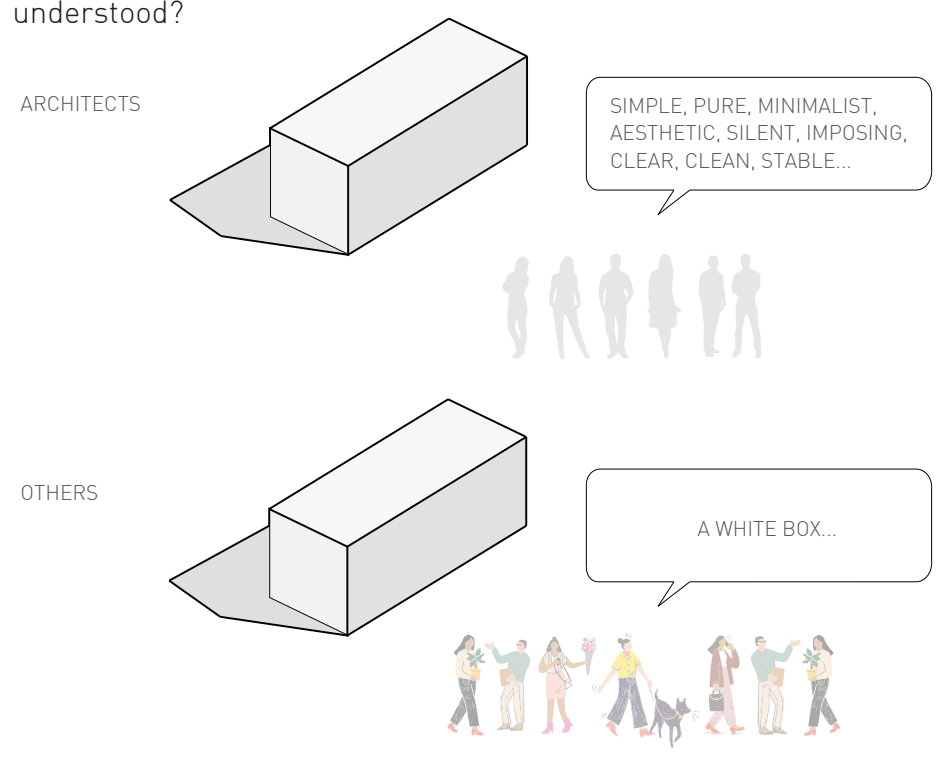

Fig 4 White Box Diagram illustrating the juxtaposition in the perception between architects and the public

The Eventification of Exhibiting Architecture 
Perhaps society's misconception of architecture has to do with its portrayal in how film and media. ${ }^{3}$ In certain instances it is used as a device to defamiliarize our experience of something which can consequently affect our perception of it. Quite often the role of the architect is glamourized, and according to architectural writer Mark Lamster, is "captivated by certain dreams, ideals, and even fantasies that have come to characterize the architect's image - the mystique of the profession to those outside the discipline and sometimes even, against considerable odds, to practitioners themselves." 4 Does this misconception translate into the way architecture is exhibited? If so, does it confuse or clarify the role of architecture within society (to the public) and within the discipline (in collaboration between practitioners)?

This thesis aims to explore how the agency of curatorial practices can be used to represent and misrepresent architecture. Firstly, does an architecture exhibition become an apparatus to challenge our preconceived ideas of architecture? Secondly, what turns the curatorial object into a pedagogical inquiry of how architecture is created, experienced and discussed? ${ }^{5}$ Studying the relationship between curation and architecture could offer us a better understanding of how to develop a future thoughtful spatial practices.

In the beginning periods of curating architecture, it can be presumed that the exhibition was a product of architectural production. With the ubiquitous architectural biennials and triennials emerging all over the world today, it prompts us to wonder if the future of architectural production will be a biproduct of the architectural exhibition. How, then can we discuss an architecture that continuously disrupts and challenges our perception of and relationship to space and place?

\section{Agency}

An action or event that produces an effect. ${ }^{1}$

Architecture Exhibition A spatial condition evolving from the curation of architectural production that catalyzes an event to occur.

Architectural Production The modality of architectural discourse as it pertains to its discipline, practice, theory and research. 


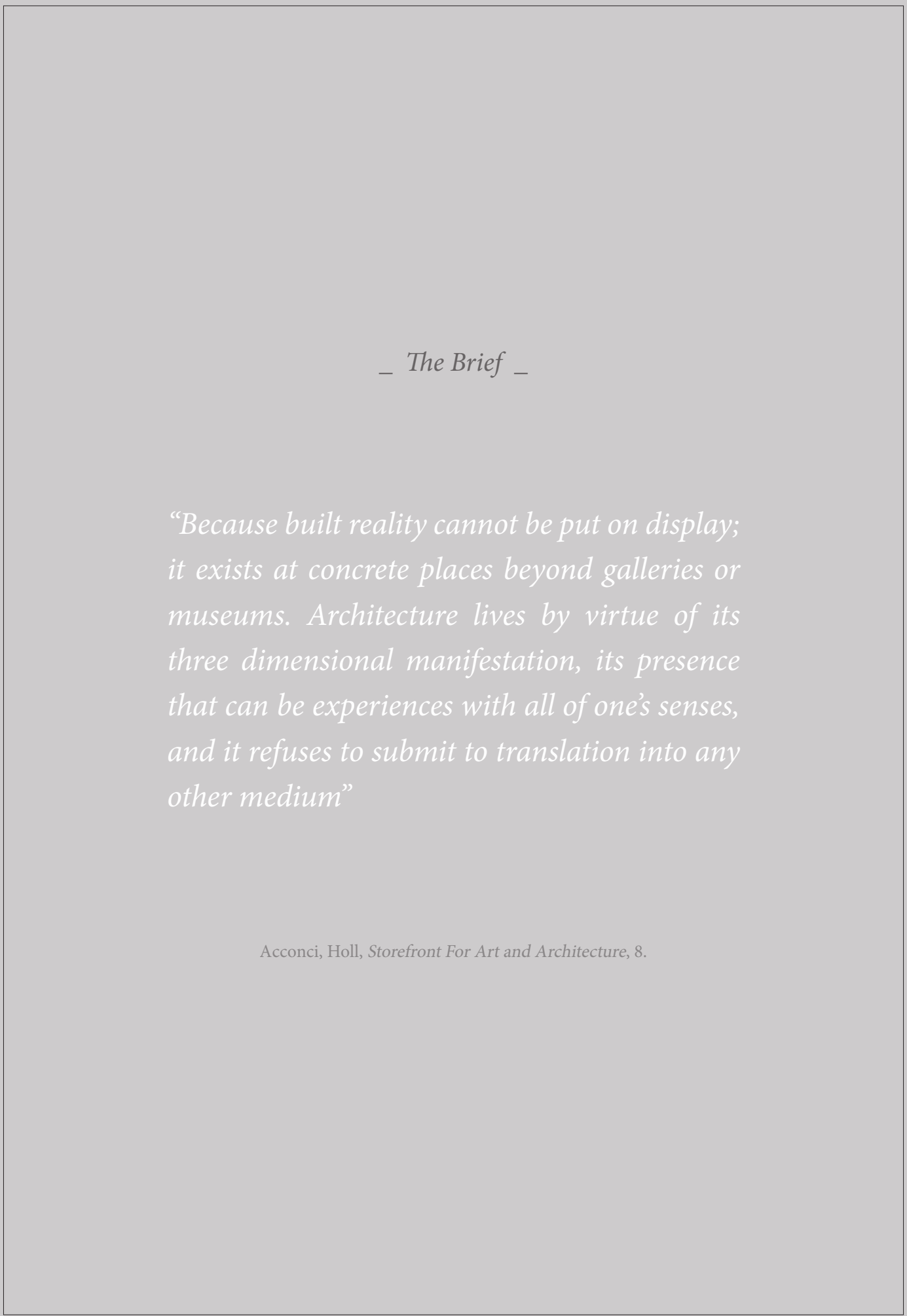

The Eventification of Exhibiting Architecture 


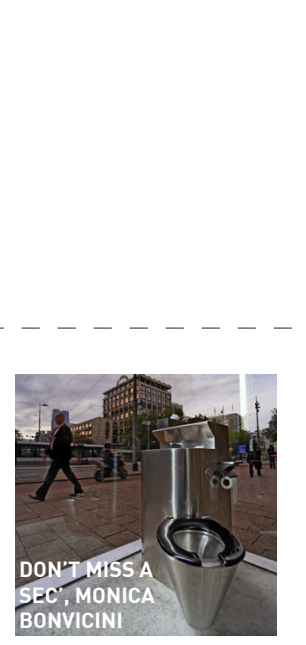

What is an architecture exhibition?

\section{BONVICINI}

“Space is...a dialectical

phenomenon that cannot be thought out or defined...it exists even without architecture." (Acconci, Holl, 12)
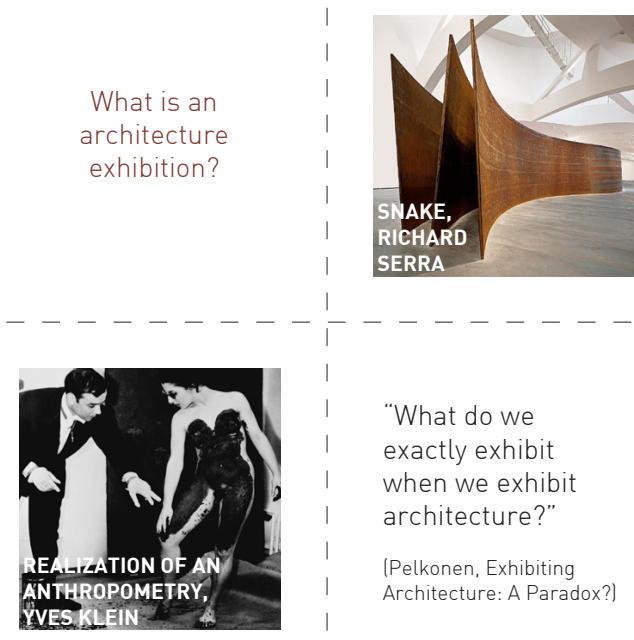

What is or is

not achieved by removing architecture from its original context and situating it somewhere else?

"What do we exactly exhibit when we exhibit architecture?"

(Pelkonen, Exhibiting Architecture: A Paradox?]

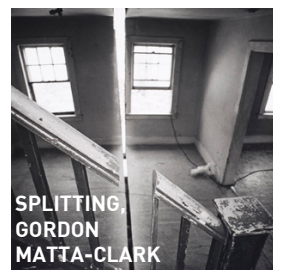
images"

(Shklovsky, Art, As Device, 157)

\section{FALLING CLOCK,}

DANIEL ARSHAM

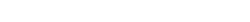

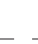

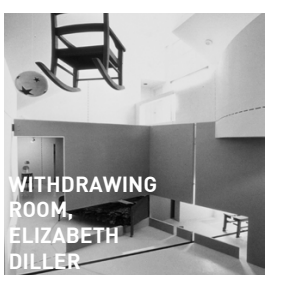

How can

architecture be at once the object and the context of display?

architecture exhibition?
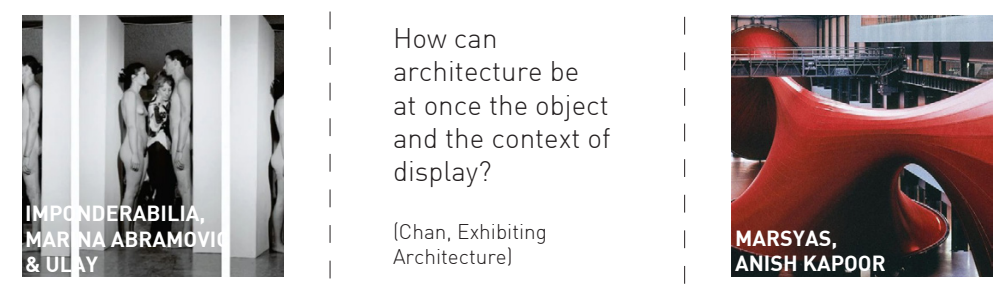

(Chan, Exhibiting Architecture)

What is an architecture exhibition?

Fig 5 Matrix

I A collection of several well-known artists or I artist-architects whose works challenge the notion of architectonic components, space and the body in architecture. 


\section{Curare / Curator / Curation}

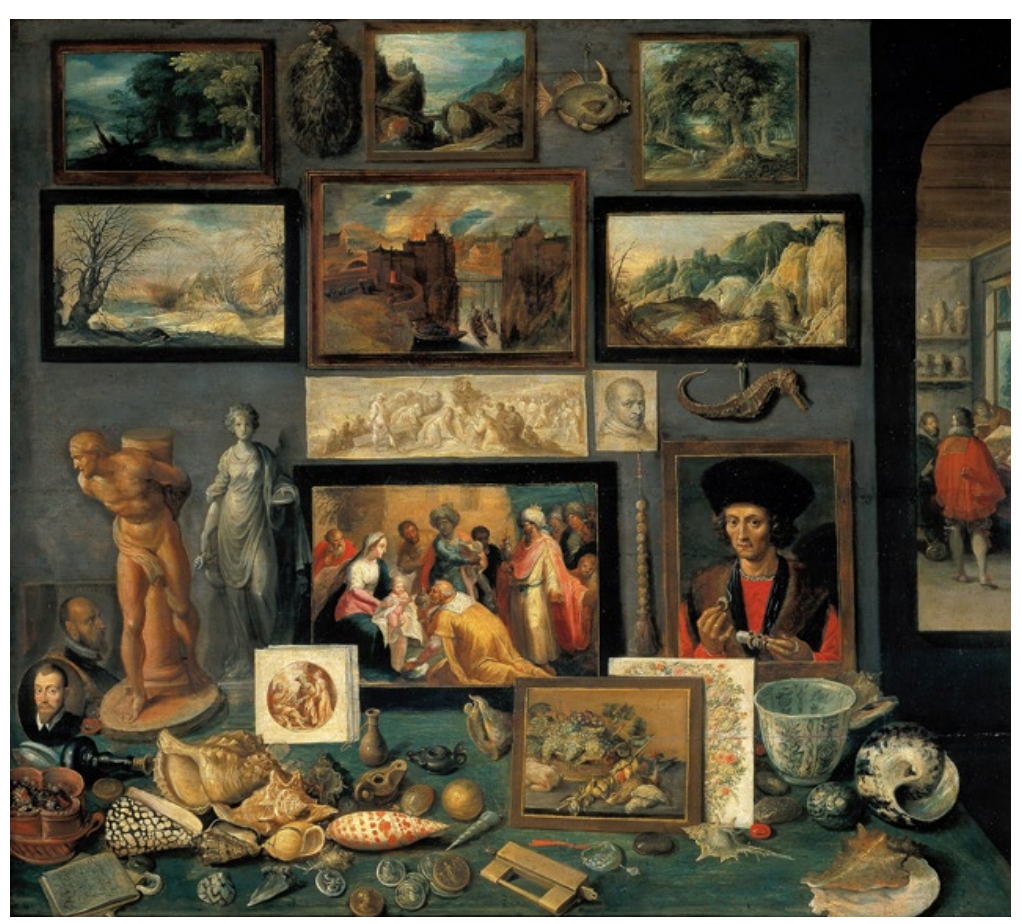

To understand the role curation plays in architecture, the origin and etymology of the word must first be considered. The word curator stems from the Latin verb curare, and dates back to the mid-1 $4^{\text {th }}$ century where it was used to define the role of an overseer, manager or guardian in relation to the collection of objects. ${ }^{1}$ These collections would be housed in rooms known as Cabinets of Curiosities and would range in artworks, carving, geological samples, antiques and so forth (fig. 6). ${ }^{2}$ Throughout the $18^{\text {th }}$ and $19^{\text {th }}$ centuries collections began to emerge more officially in museums and consequently the role of the curator began to evolve from a collector to an expert in visual cultural taste or to an interpreter of works. ${ }^{3}$
Fig 6 Kunstkammer (1636) A cabinet, painted by Frans II Francken which exhibits a range of Baroque-era connoisseurship.

\section{Curation}

A derivative of the word curator, is "the action or process of selecting, organizing and looking after the items in a collection or exhibition." 2 
What are the relationships between the role of a curator and an architect? Are their narratives more similar than we think?

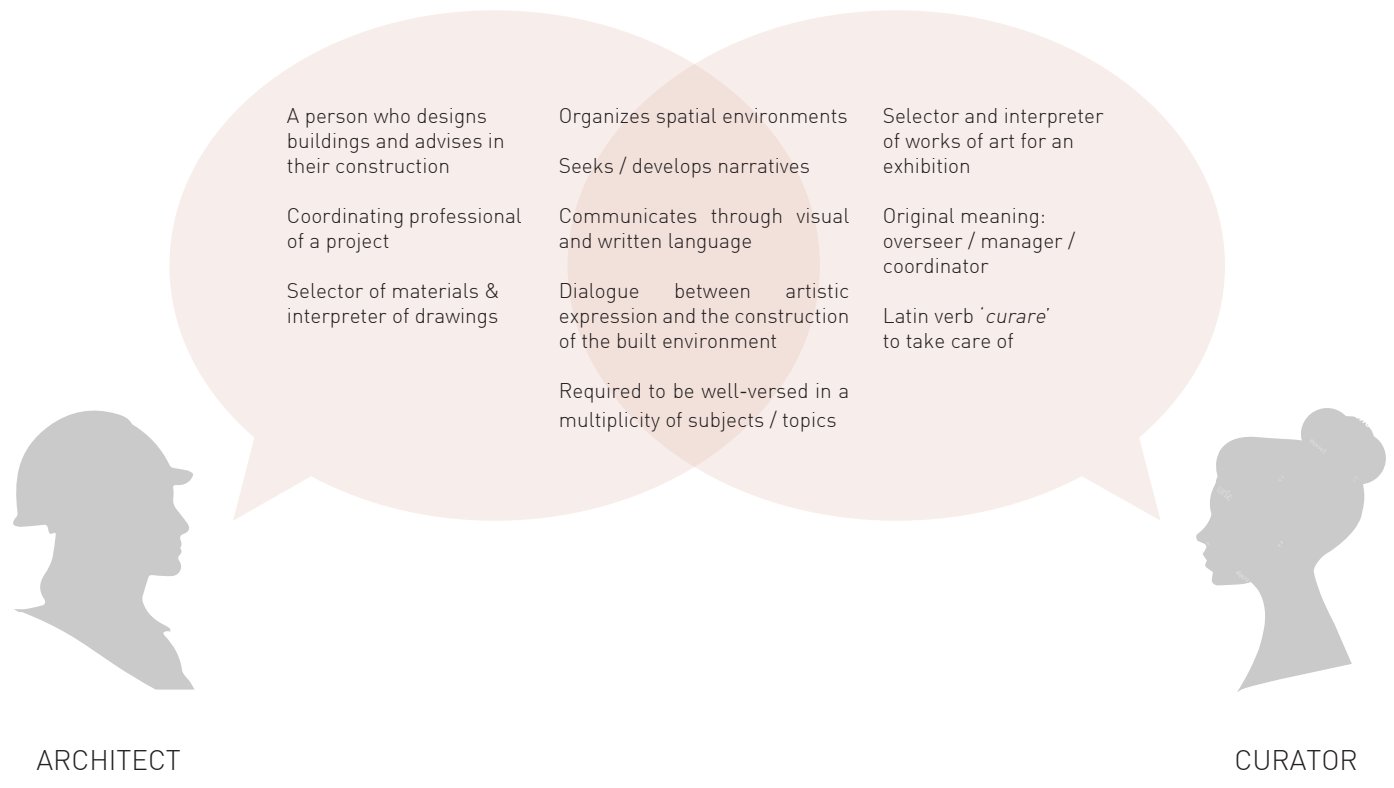

We can find many similarities between the role of a curator and an architect through their professional narratives. Both roles design spatial conditions that consist of a constant dialogue between artistic expression and the construction of the built environment. The nature of their work requires them to interpret, manage and convey copious amounts of knowledge to produce a final product. The scales of their work may vary but the multiplicity of subjects and topics they encounter are boundless. This thesis will focus on the history of curation and its role as it relates to architecture. It will not, however, delve further into the history of museology and its participation in colonial expansion as it relates to artworks.

Fig 7 Comparison Diagram

Narrative of a Curator and an Architect 


\section{The Role Of The Exhibition In Architectural Discourse}

Curation has played a role in architecture as early as the 1930s. In 1932, the world's first curatorial department dedicated to architecture and design was established by The Museum of Modern Art (MoMA) in New York, NY., USA. In 1980 the Venice Biennale of Architecture was founded in Venice, Italy, and shortly after, Storefront for Art and Architecture in New York, NY., USA, was created in 1982. Over the last two decades, architecture exhibitions have multiplied all over the world (fig. 8). In 2015, the Chicago Architecture Biennial in Chicago, IL., USA. was developed and is currently the largest architecture and design exhibition in North America. Why is it, even after some decades of various organizations exhibiting architecture that we still find ourselves asking questions such as,

"How do you explain architecture? How do you communicate architecture, and what kind of action do you need to make to an architectural object in order to explain architecture to someone else?"4

It is uncertain if the role of curation has further enhanced the public's understanding of architecture beyond its built form or whether it has complicated it. One outcome that has developed in the plethora of exhibiting architecture is how it enables architecture to be structured as an event beyond its built environment. Considering the effects architecture exhibitions play on architectural discourse, has curating architecture led to the eventifcation of architectural production? ${ }^{5}$

\footnotetext{
Eventification

An experience of events that are measured on the multiplicity of their occurrence.
} 


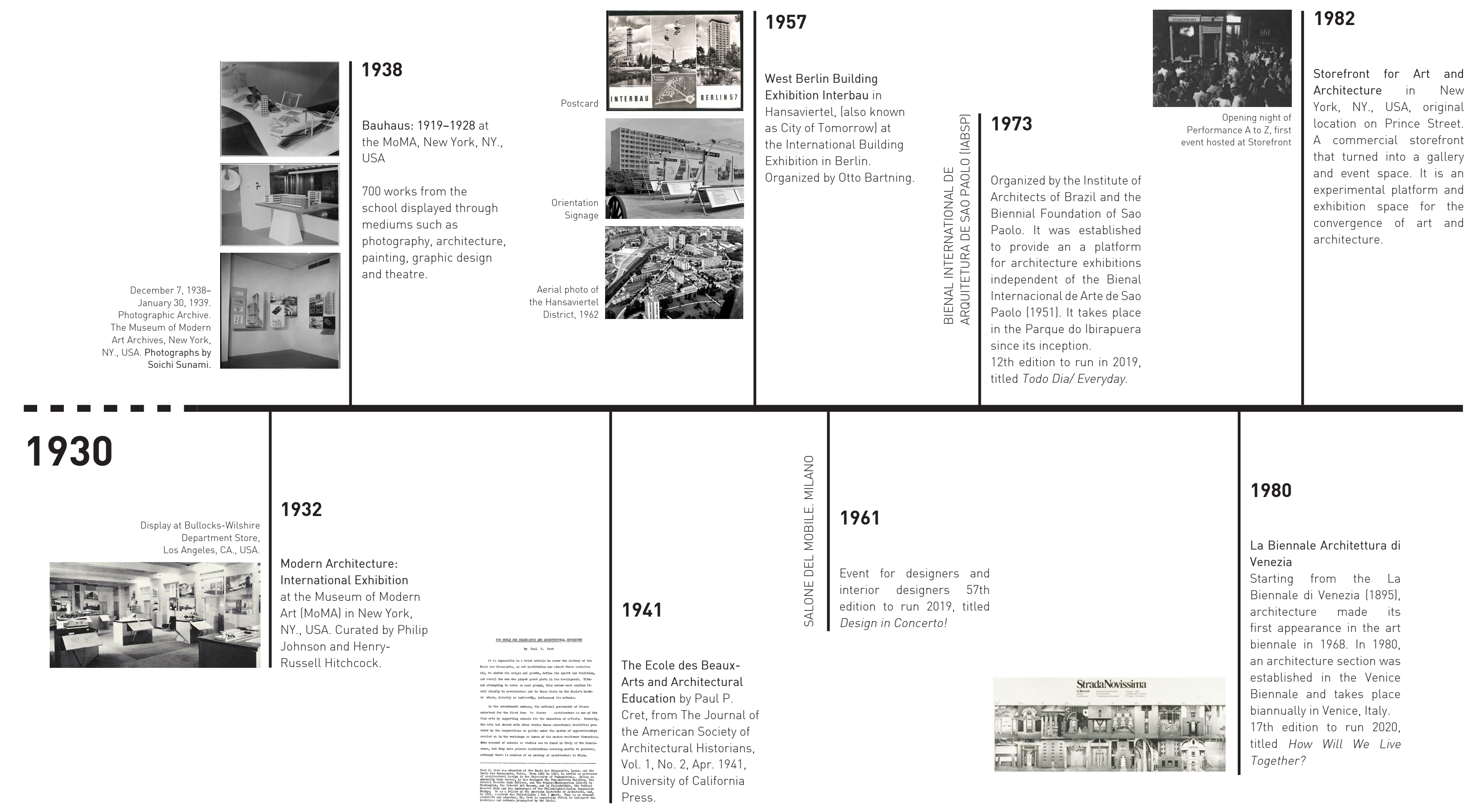

Fig 8 The Evolution of Exhibiting Architecture 


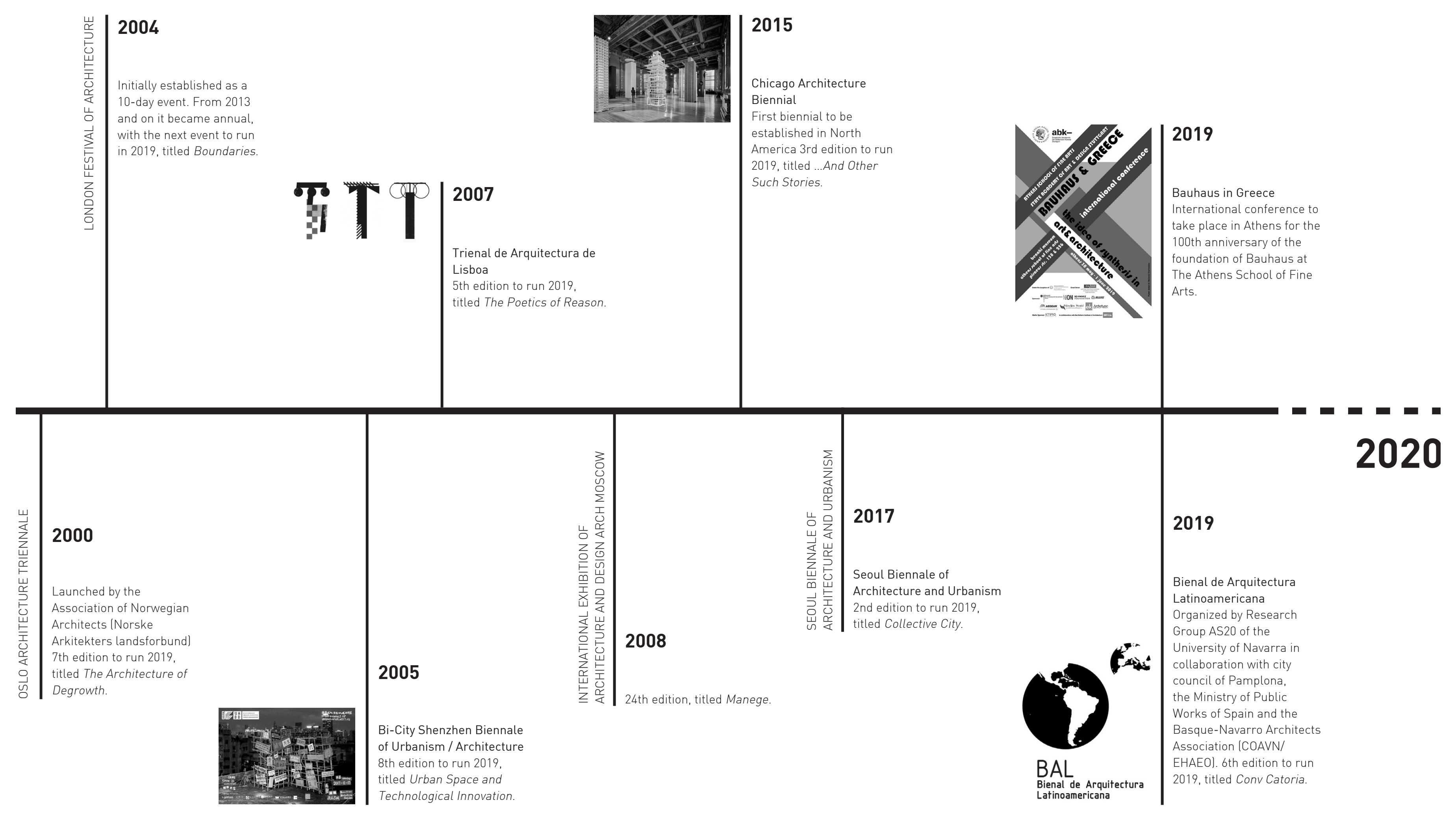




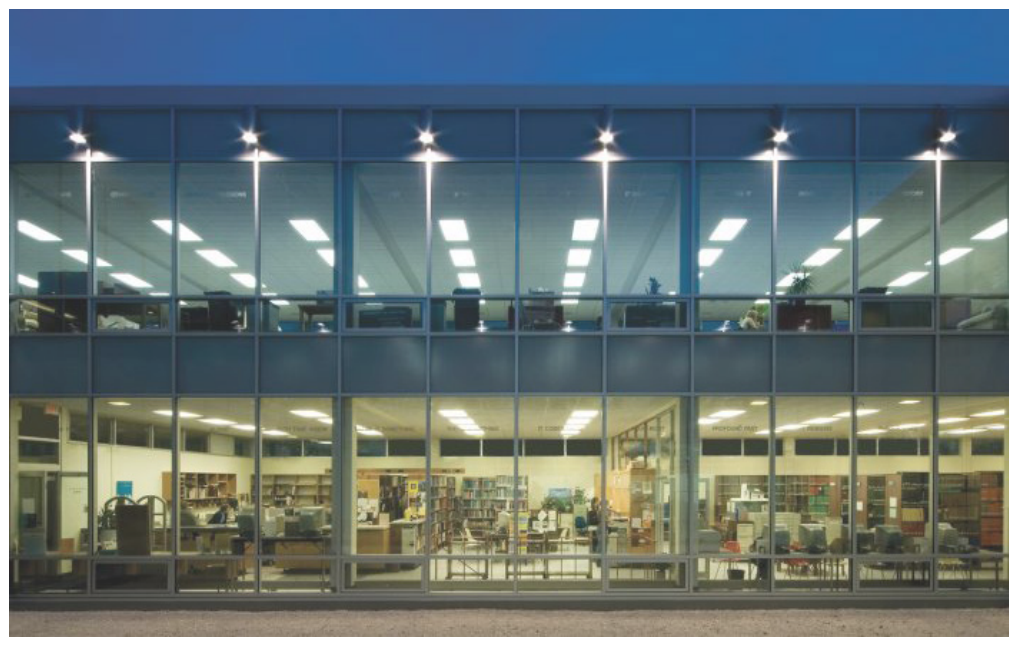

The act of curation is taught indirectly to architecture students from the beginning of their academic career. This is evident in the way students are instructed to exhibit their architectural theories, investigations and work for advice and constructive critique through various modes of representation. The methodology in how their content is presented adopts similar characteristics and nuances to that of an exhibition setting in a museum's gallery space. The architecture school itself is designed with characteristics similar to that of a gallery. An example of this is the John A. Russell Architecture Building at the University of Manitoba in Winnipeg, Manitoba (fig. 9). We can interpret the interior of the building as an exhibition space through its intentional use of materiality in all interior finishes. Walls are lined with corkboard substrates painted white to allow every square foot of surface to be covered with bodies of work. The windows are situated at a higher elevation plane to allow for maximum wall space to display work. Selected rooms are divided by moveable partitions to create a more versatile space to cater to different occupancies and functions. The curation of architectural projects, including student work, is a means by which project authors can communicate the process of their work from pedagogic inquiry to a proposed outcome. This leads us to ask, has the expanding interest in curating architecture throughout the world influenced the role of exhibitions in academic institutions as a pedagogical resource and platform for experimental research?
Fig 9 John A. Russell Building (1959), University of Manitoba, Winnipeg, MB.

Content

The events, physical detail, and information in a work of art: the architect as cultural producer. $^{3}$ 


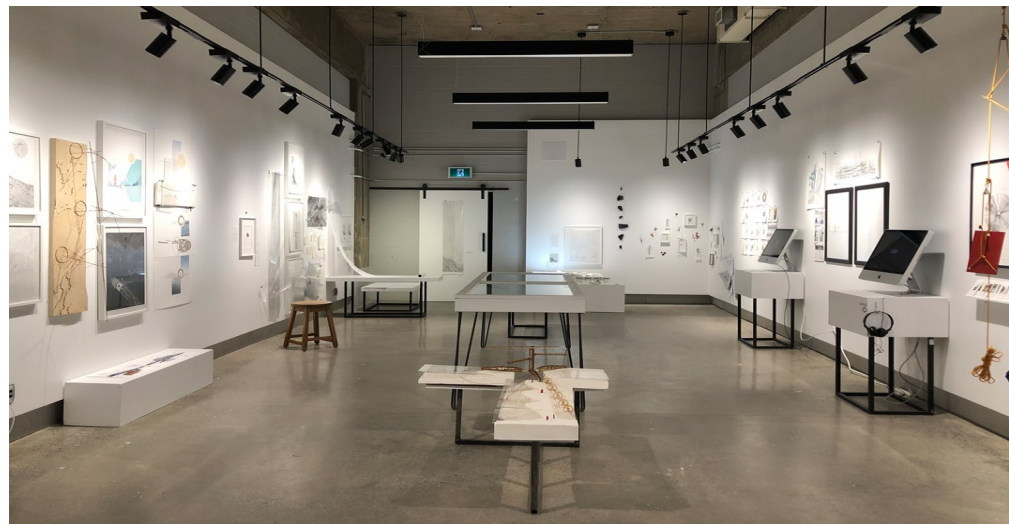

The act of curation is clearly used as a device to organize the physical manifestations of work in a cohesive manner. As a result, the art of curation may have (in)directly altered the design process within academia. Through curatorial practices, styles of production begin to formulate and enhance the overall comprehension and spatial philosophy of the work within its academic context. This is observed during an architectural presentation where the student body presents their work through various modes of representation, elucidating the design process in the resulting final physical manifestation (fig. 10). Several styles of production include representation and experiential investigations which can be comprised of drawings, renderings, physical and BIM modelling, dioramas and so on. As architectural production transitions into new modes of representation through technological advances (CNC laser cutting machine, threedimensional printer and BIM software), the design process and how it is curated evolves with it symbiotically. It is these archetypes that will now be addressed in the following section as we discuss the ways in which architecture has and continues to be curated in academia and throughout the discipline.
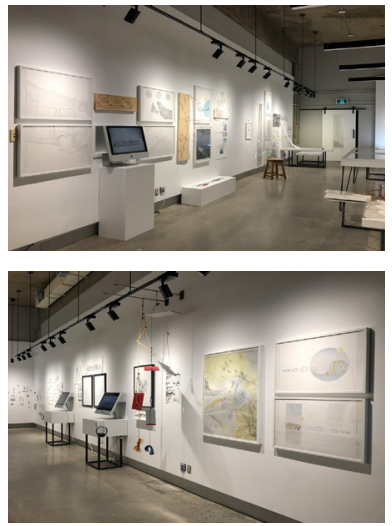

Fig 102019 Thesis Work exhibited in the Lightroom Gallery Room 234 Architecture Building, Carleton University, Ottawa, ON. 


\section{How Is Architecture Curated?}

The evident paradox in curating architecture is the reality that architecture cannot be displayed in any other form or context other than its original state. Even replicating the form is limited to the scale of the environment in which it will be reproduced and exhibited. What, then, is or is not achieved by removing architecture from its original context and situating it somewhere else, for example by exhibiting architecture?

In Storefront for Art and Architecture, artist Vito Acconci and architect Steven Holl explain the challenge in exhibiting architecture "lies in the fact that it always requires both reflection on the absence of architecture and the acceptance of this as a prerequisite of itself. Because built reality cannot be put on display; it exists at concrete places beyond galleries or museums. Architecture lives by virtue of its three dimensional manifestation, its presence that can be experiences with all of one's senses, and it refuses to submit to translation into any other medium." 6 For this reason, we can argue that architecture is prone to being curated in three ways:

Representation

Experiential Investigation

Original Site Context 


\section{Representation}

Architecture can be presented through representation in the form of multiple mediums and reproductive techniques such as photography, scale models, drawings (plan, section, elevation, rendering), videography and mock-ups that are expressed through a format in a gallery setting. This is evident in Anticipating The Architectural Outcome featuring Kisho Kurokawa's drawing "Perspective and Axonometric Floor Plan", which showcase the architectural process of perspective and axonometric drawing technique (fig. 11).

More often than not, the public's first interaction with a building is its final product. "In order to envision potential outcomes, architects employ various representational tools to analyze and communicate their ideas and proposals."7 By exhibiting representational techniques used to communicate a physical manifestation, it is then considered that the viewer develops a deeper understanding of the project beyond its built form, through the design and representation process.

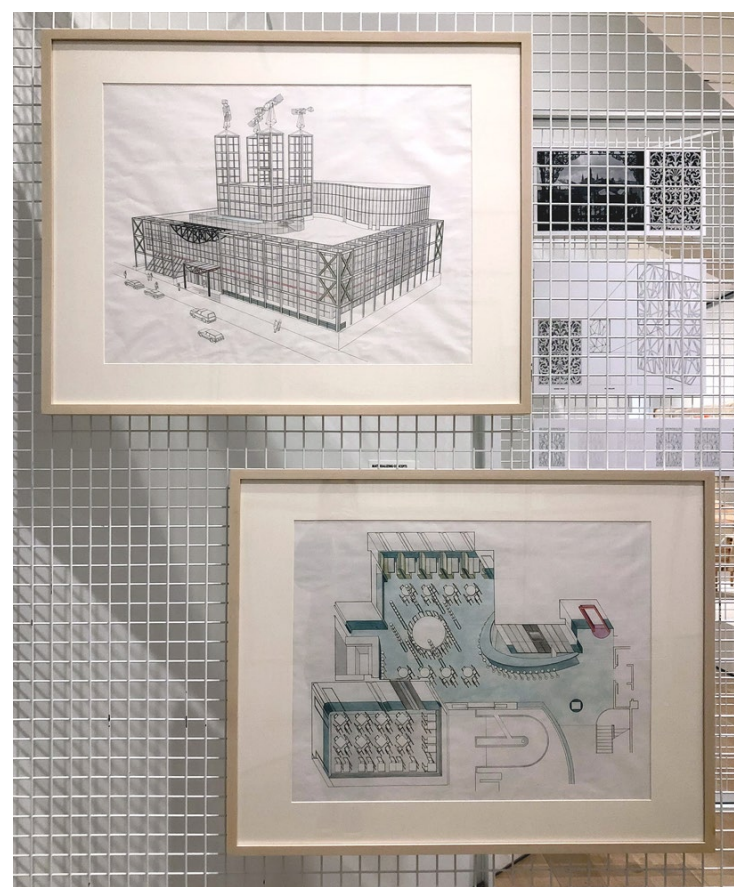

Fig 11 Anticipating The Architectural Outcome Exhibition at Chicago Art Institute. "Perspective and Axonometric Floor Plan" completed in 1988/90 by Kisho Kurokawa on Illinois Center Sporting Club in Chicago, Il.., USA. 
Representation [plan, section, elevation, rendering, modeling]

expressed through

Format [shape, size \& makeup of a manifestation]

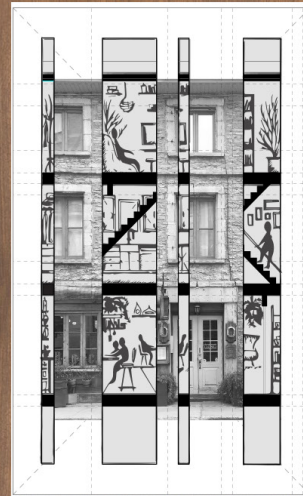

$$
\text { SECTION }
$$

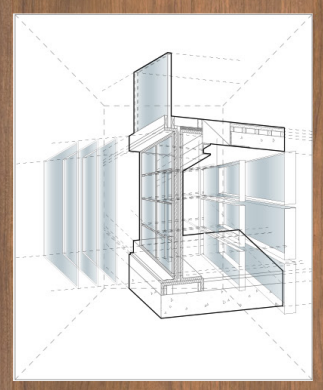

EXPLODED AXONOMETRIC

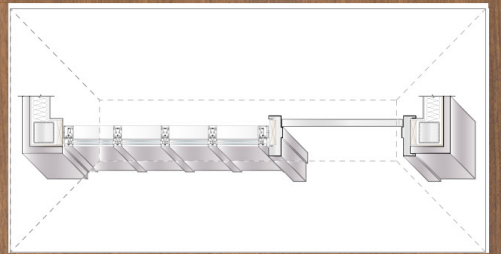

PERSPECTIVAL PLAN DETAIL

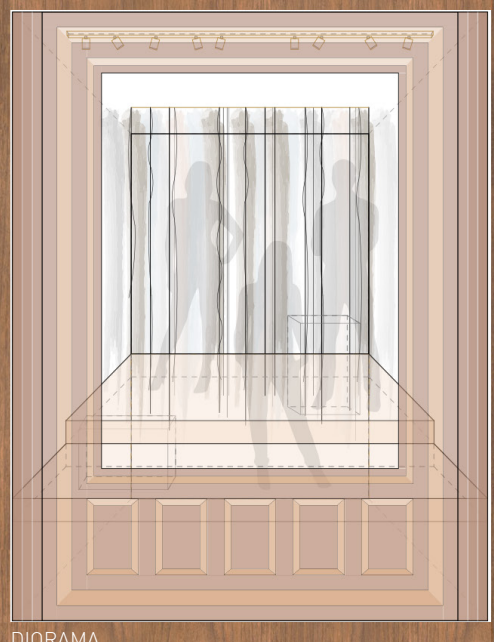

DIORAMA

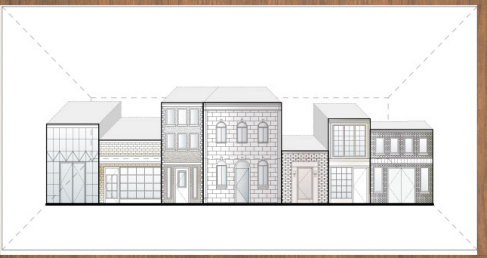

ELEVATION

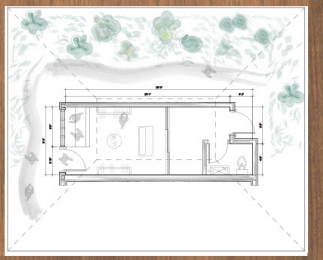

FLOOR PLAN

Fig 12 Cabinet of Architectural Representations: Inspired by the notion of Cabinets of Curiosities, the illustration is a collection of architectural representations commonly experienced in academia, exhibition and within the profession. Each representation is a means to create a dialogue about a built or fictitious subject. 


\section{Experiential Investigation}

An experiential investigation is an idea that is manifested in the form of an installation or a three-dimensional environment - presenting technological advancements, experimentation and material research in architecture within the built environment or urban fabric of a city. This is evident in Softscape which "engage[s] the body in participatory and contemplative ways by accentuating the focus on the visitor's experience rather than simply understanding the architecture as an isolated object (fig. 13)."8 The visitor becomes a participant within the exhibition, engaging all senses to experience the impermanent spatial environment and its relationship to the permanent built form. Where the installation begins and ends is blurred by its continuous surface which fosters a dialogue between the visitor and architectural discourse, installation and the existing built environment, space and place and - most significantly between the visitors themselves.
Space

A boundless two- or threedimensional extent in which objects and events inhabit, based on a relative position and direction. ${ }^{4}$
Fig 13 Softscape (2011) by SPMB at RAW Gallery, Winnipeg, MB

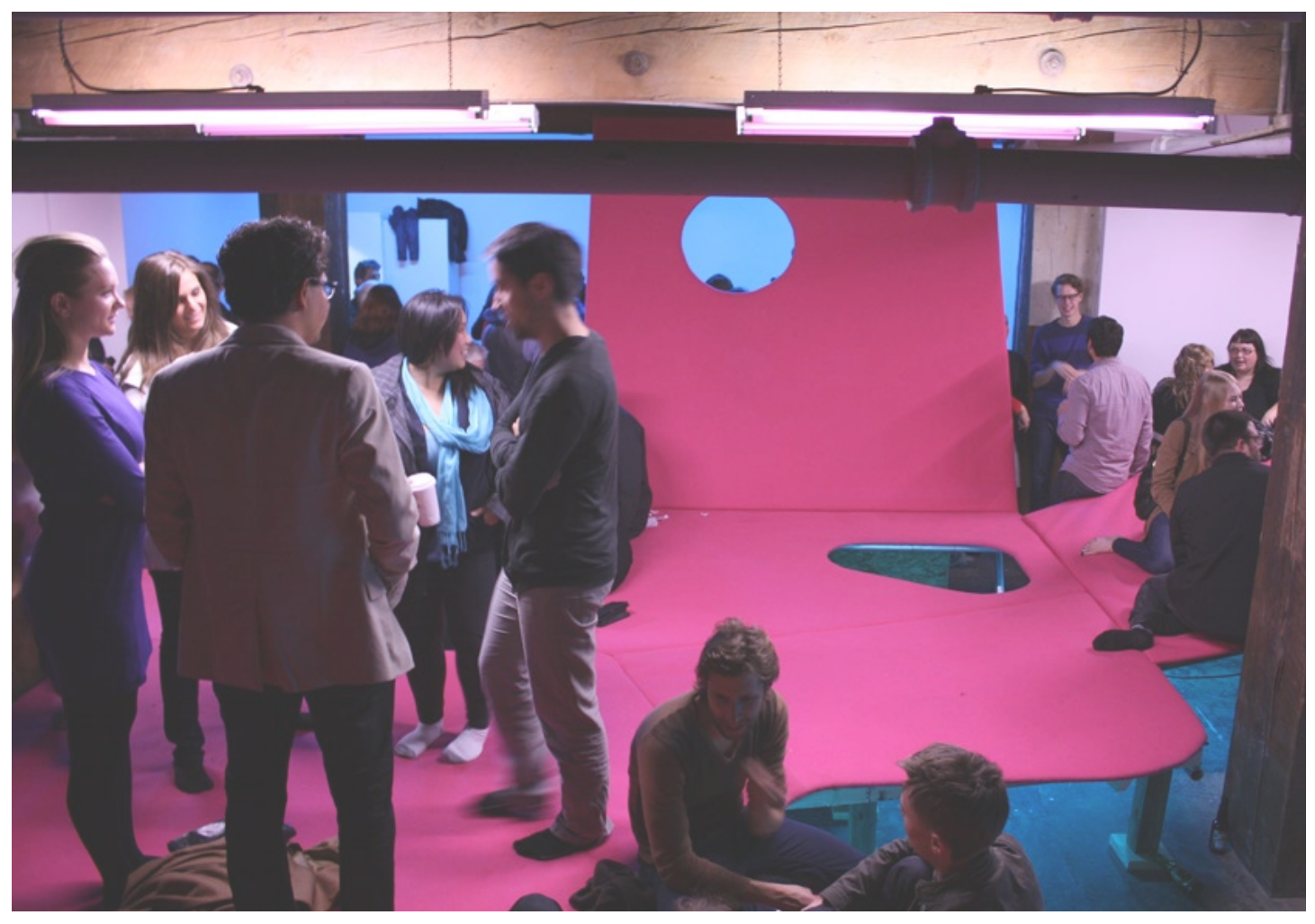




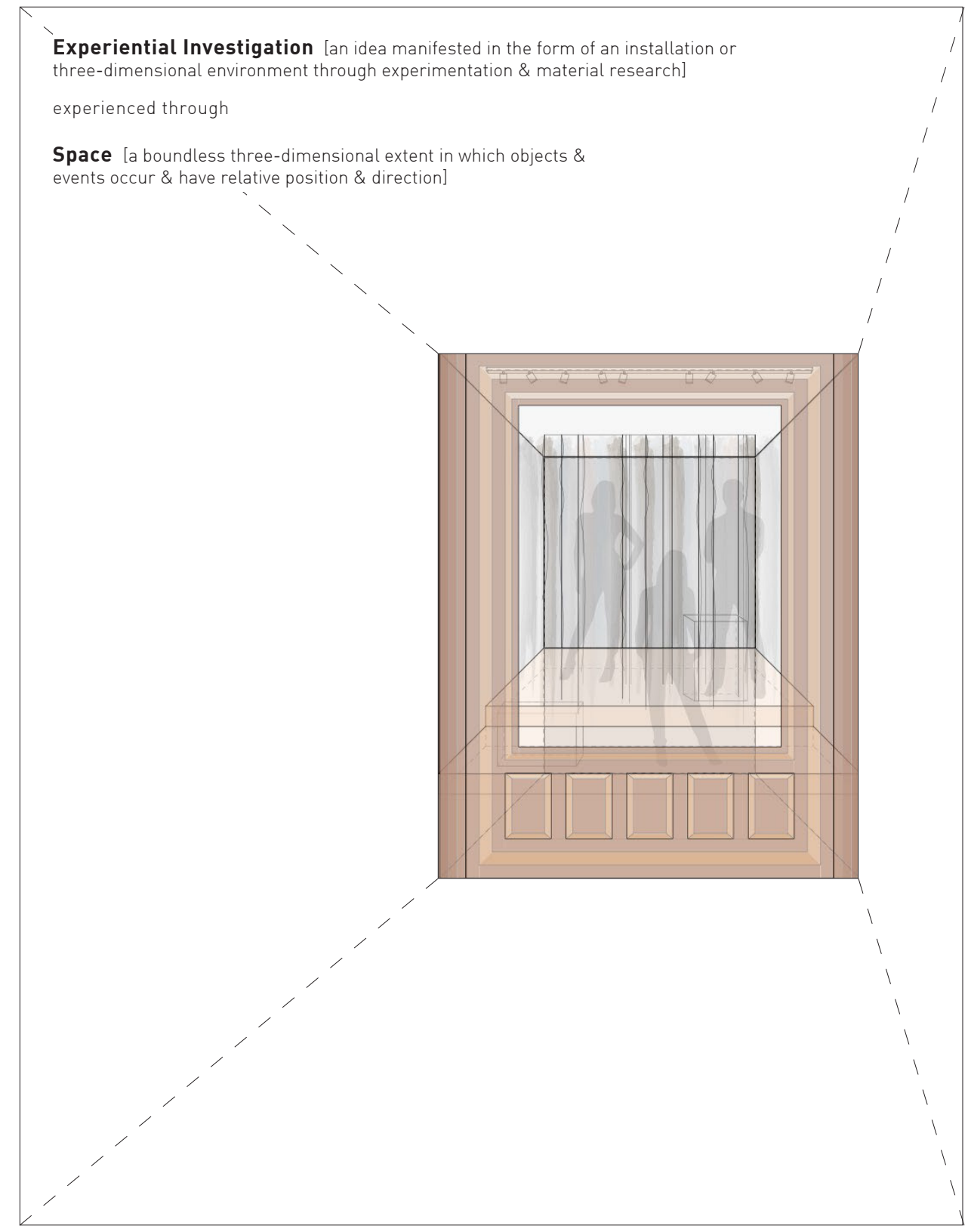

Fig 14 Diorama of the (Un)Ordinary: One of the main components of exhibitionism is scale. As the scale of an object or spatial context is distorted beyond its standard proportions, the more intriguing it becomes. The relationship we share with the things that make up our environment is dependent on its scale and our ability to engage with it. A diorama is an apparatus to explore the quality of scale, and through its process has the ability to rediscover the ordinary. 


\section{Original Site Context}

Architecture can be experienced in its original site context under two conditions: as an exhibition or as an exhibitionist. As an exhibition, the building is within its context, where its program has changed from its original intent and is now preserved for display. This is evident, for example in the Farnsworth House (fig. 15). An architectural landmark in Illinois, it is one of the most well-known modernist, domestic architectures in the International Style and has been designated as a National Historic Landmark since 2006. ${ }^{9}$ Once a weekend retreat home for Edith Farnsworth, it is now a museum hosting tours to the public managed by the Farnsworth House organization as part of the National Trust for Historic Preservation. Though it has been replicated in many forms of representation, its existence is and continues to be an essential part of architectural history. It is one of the rare examples of where an architecture is exhibited in its truest state. Components such as its site, maintained and restored interior and exterior can only be imitated outside of its context. It provides the illusion of an ageless building and has the spatial capacity to transport the viewer back in time.

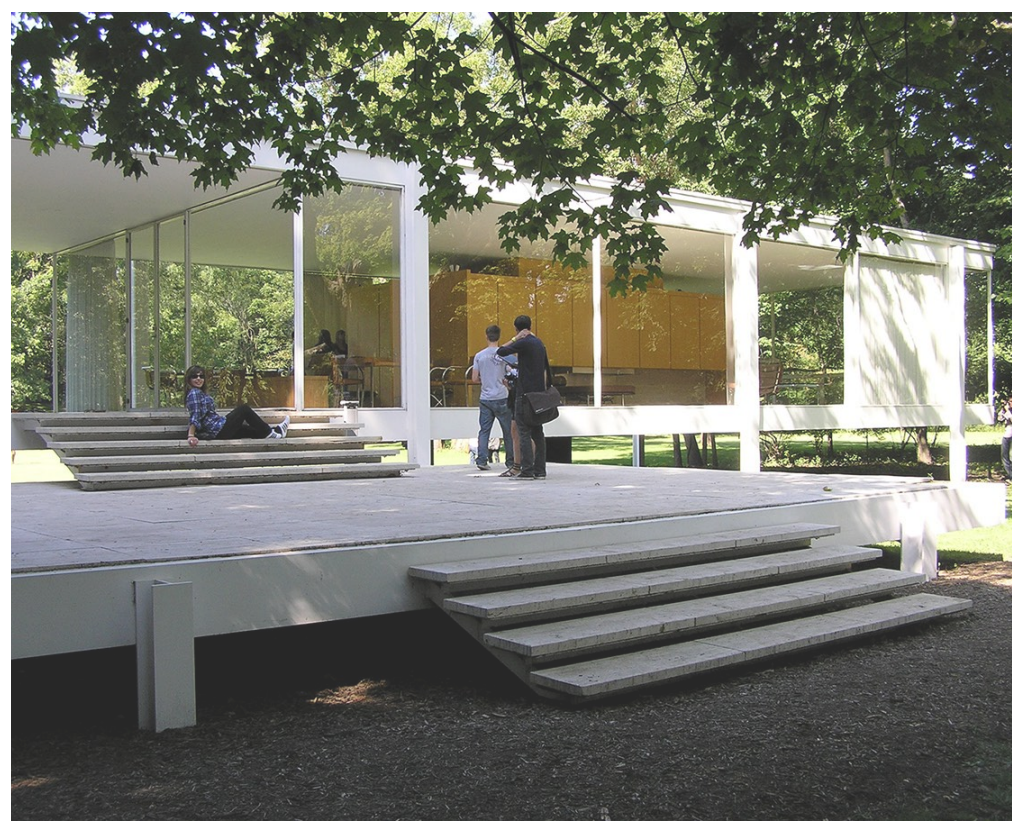

Exhibition

An architecture within its context, where its program has changed from its original intent and is now preserved for display.

Fig 15 Farnsworth House (1951) by Mies van der Rohe, Plano, IL., USA. 


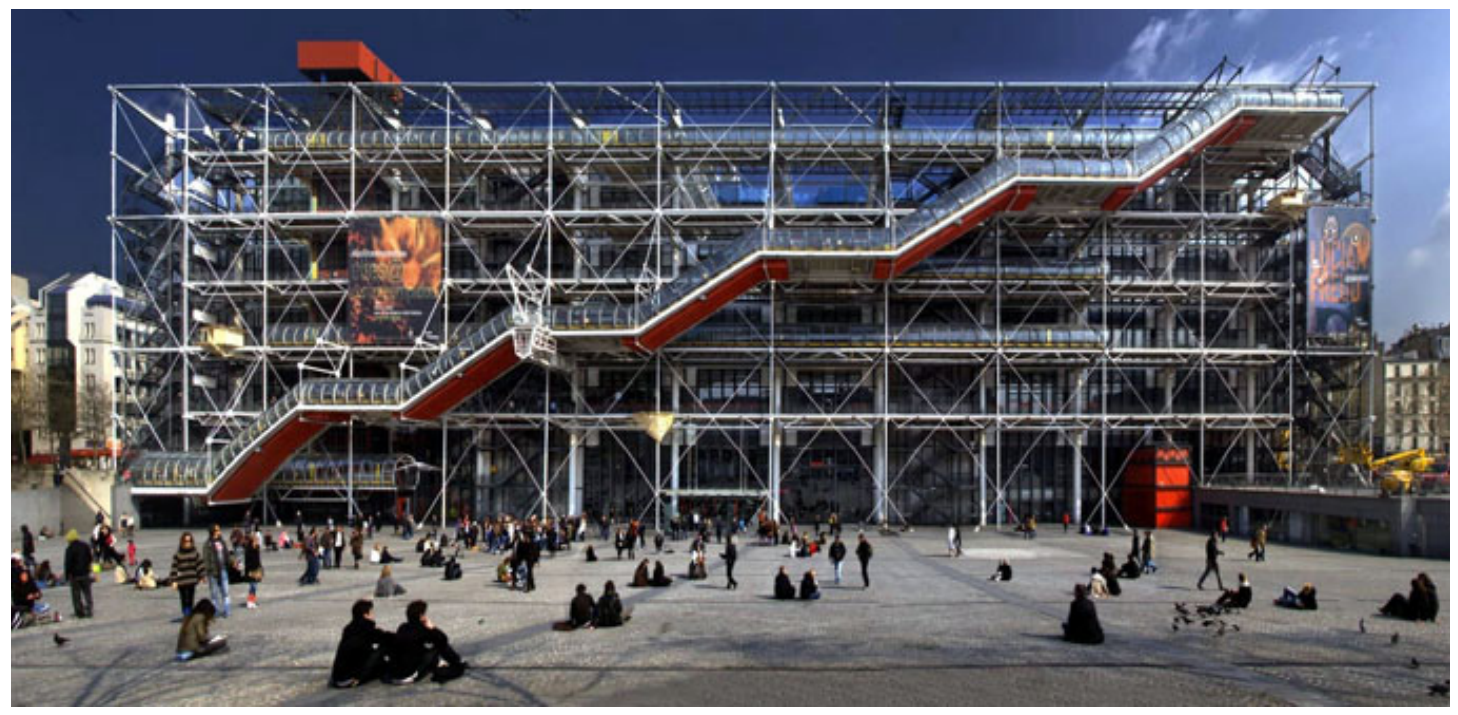

A building that acts as an exhibitionist, functions as per its original intent and finds its program curated through a didactical design of architectural elements that perform as spatial events. This is evident in a building like Centre Pompidou, where the transparent façade reveals a series of internal building systems and constructions (fig. 16). The act of showcasing these often concealed elements provides the viewer with a didactic experience, which in these terms can consider the building as an exhibitionist.

Fig 16 Centre Pompidou (1971-77) by Renzo Piano \& Richard Rogers, Paris, France.

\section{Exhibitionist}

An architecture that functions as per its original intent and finds its program curated through a didactical design of architectural elements that perform as spatial events.

Using the Farnsworth House as a precedent, it can be argued that specific architecture has and continues to be curated in all three ways. Whether the built form is existing or not, an architecture can live on in many forms. Whether or not this is based on nostalgia or a responsibility to the discourse of architectural history, it begs the question - what impact does exhibition architecture have on the evolving discourse of architecture in regards to its spatial and cultural production? ${ }^{10}$ 
Original Site Context [in situ where its function is a state of its existence]

exists through

Content [the events, physical detail \& information in a work or project]

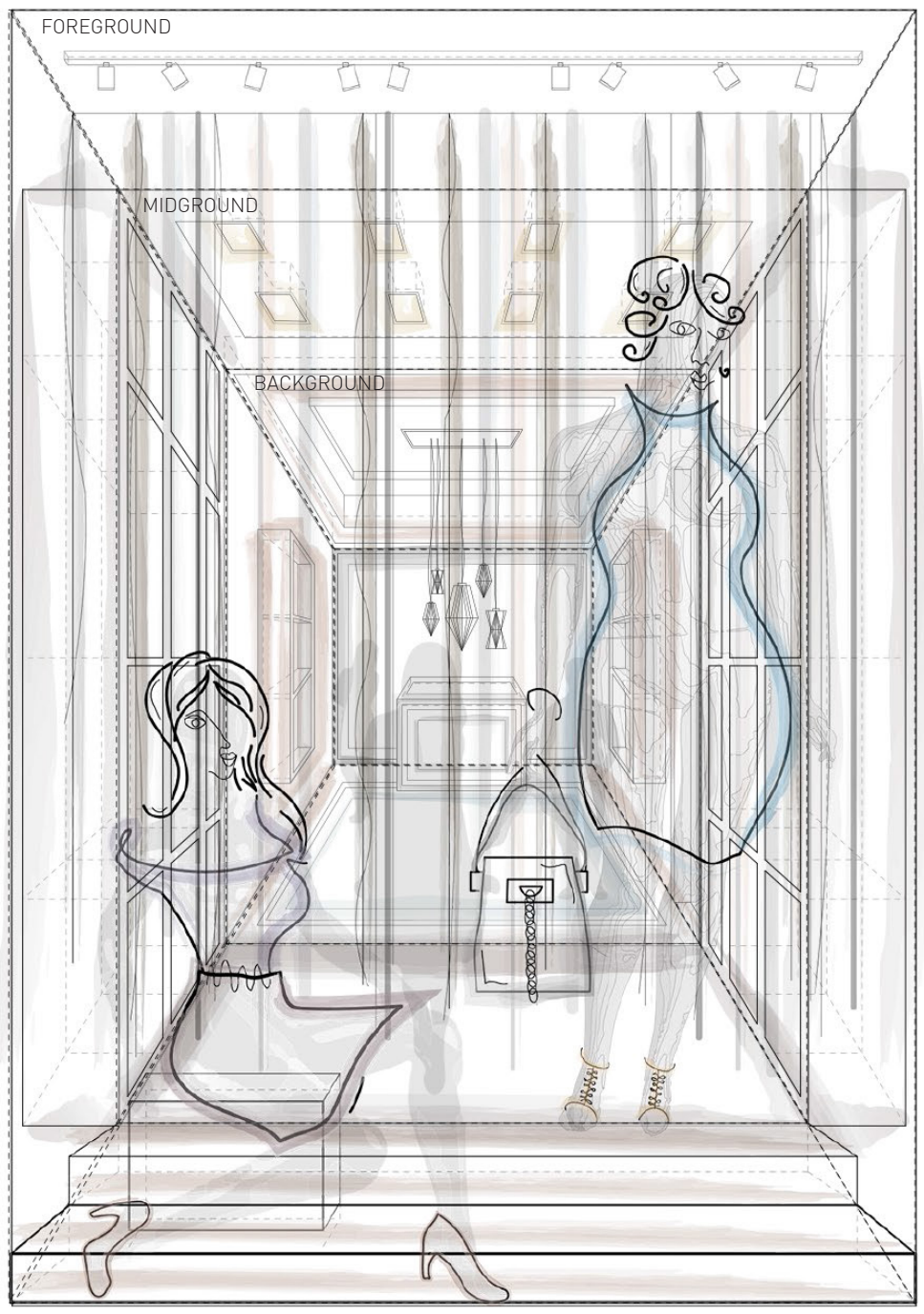

Fig 17 The Authentic Self: The authenticity of architecture lies in one's ability to perceive it. Architectonic components and their relationship to each other are most successfully comprehended when experienced with one's own body through cognitive, emotive and sensorial means.

The vitrine is used as the subject to represent all three curation methods for the reason that it creates a continuous dialogue between the various spatial conditions that are related to the curation of architecture. 

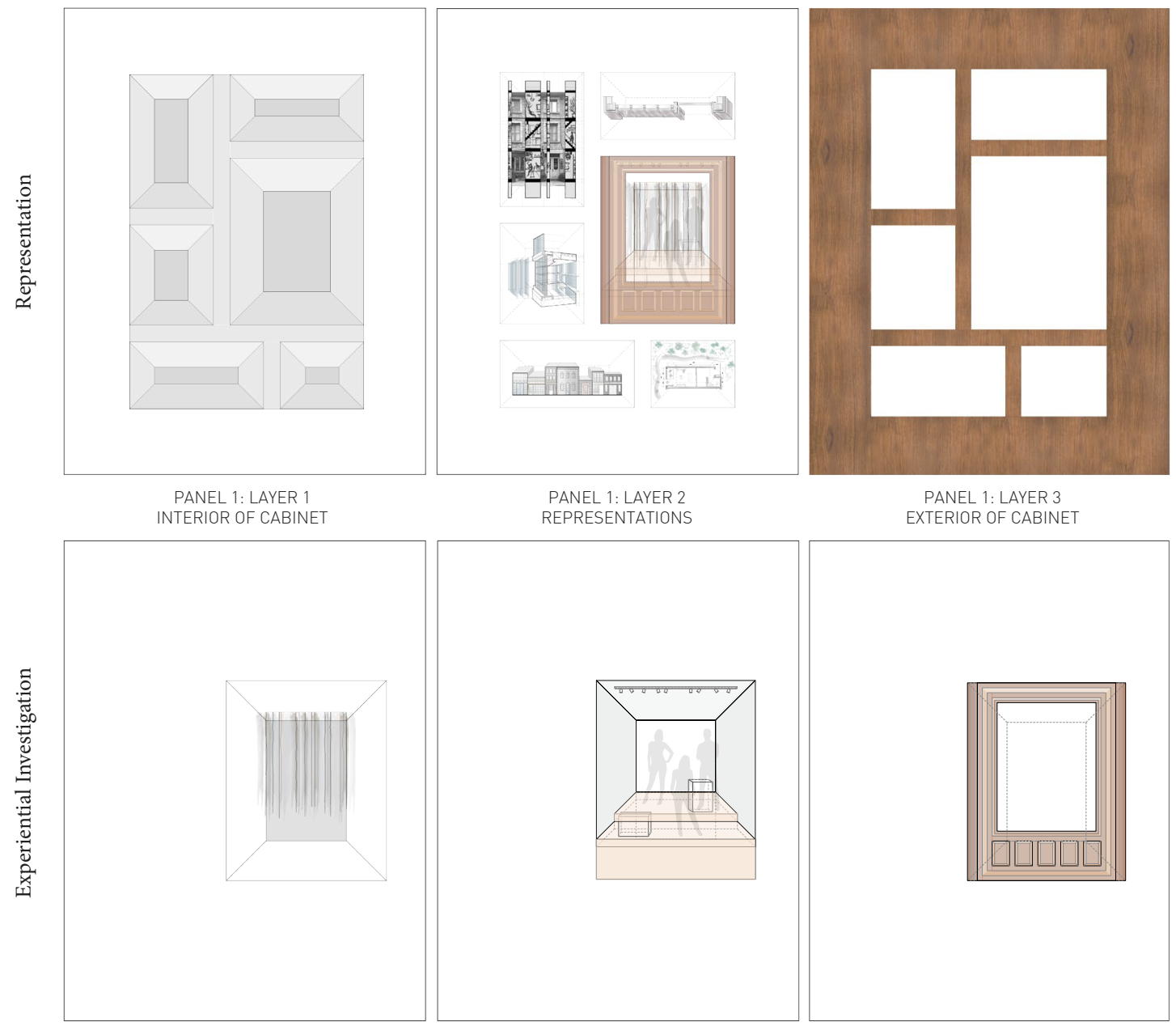

PANEL 2: LAYER 1

PANEL 2: LAYER 2

DIORAMA [MIDGROUND]

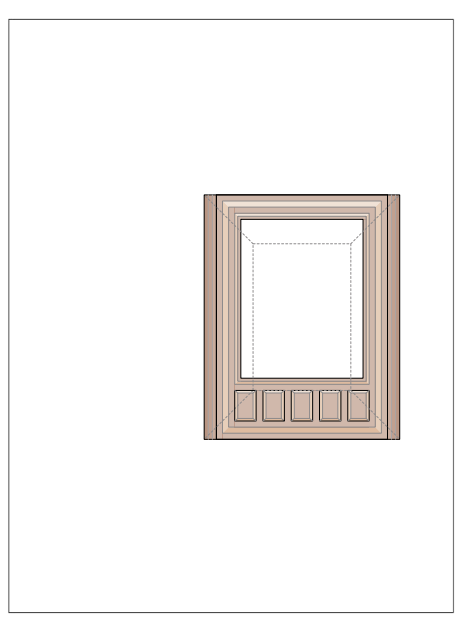

DIORAMA [BACKGROUND

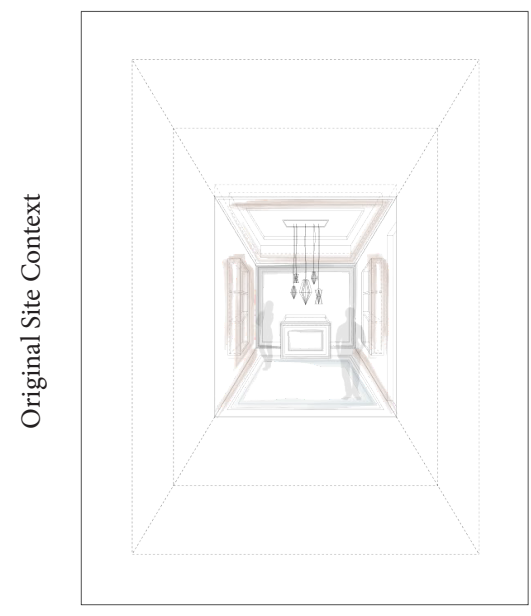

PANEL 3: LAYER 1 VITRINE [BACKGROUND]

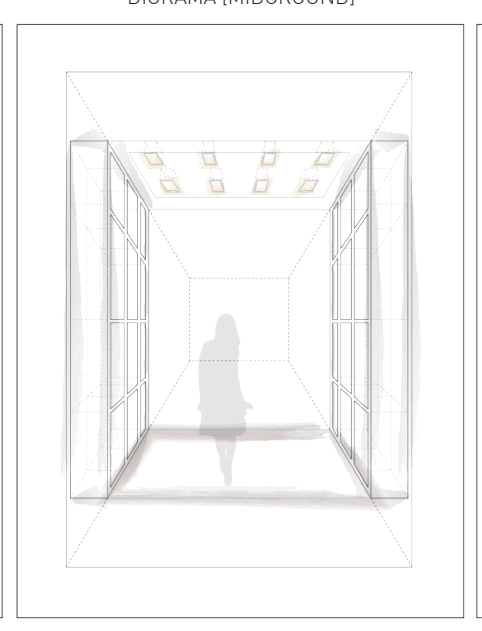

PANEL 3: LAYER 2 VITRINE [MIDGROUND]
PANEL 2: LAYER 3

DIORAMA [FOREGROUND]

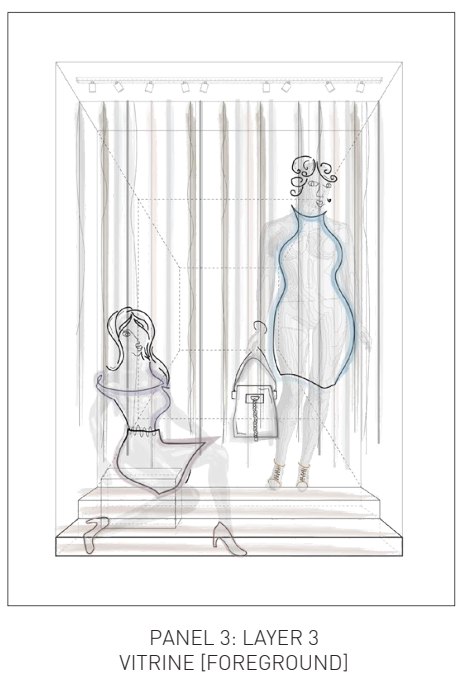

Fig 18 Deconstructed Layers of Each Curation Method 


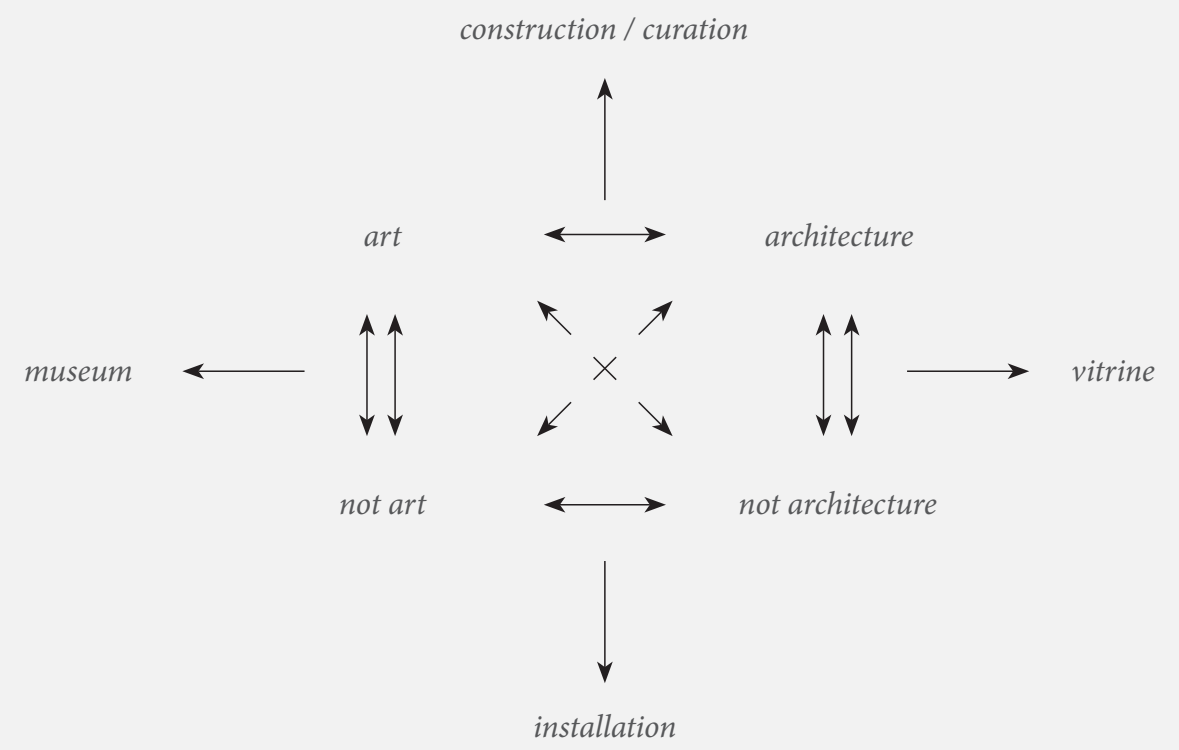

"I see architecture as a spatial practice of many intersecting considerations. It makes social, political, economic, environmental, technical, and informational forces manifest. How these things become singularly manifest does not necessarily take the form of a building. However this takes shape will suggest different modes of presentation.” - Chan, Oncurating

Fig 19 Curating Architecture Diagram

Inspired by Sculpture In The Expanded Field by Rosalind Krauss 

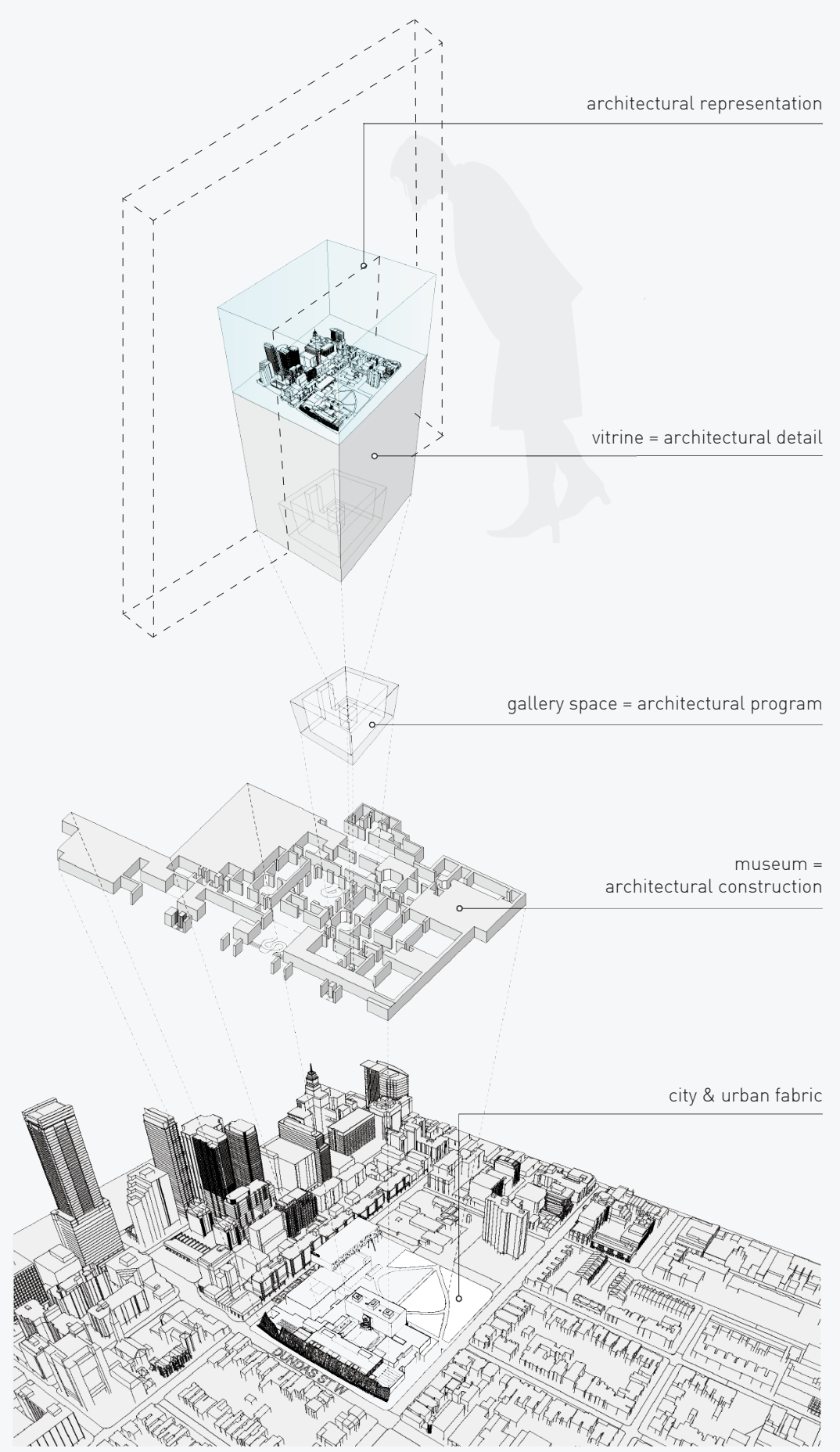

Fig 20 Unfolding Spatial Conditions 


\section{Curating Architecture Through The Vitrine}

The French word vitrine is defined as "a glass showcase." 11 The vitrine can be used to showcase objects/artifacts in a museum as well as represent the storefront on a façade of a building. The vitrine's relationship to the opposing spatial conditions of the museum and the city establishes a narrative evolving the critical inquiry of the role that curatorial practices play on the 'display' of architecture (fig. 20). This leads one to consider if and how the act of exhibition-making is changing the experience of architecture.

In the essay Moving City: Curating Architecture on Site, architecture professors Jonathan Hale and Holger Schnadelbach discuss the concept of a third space composed of "combining the experience of real architectural space with a curatorial overlay of interpretive information... effectively bringing the viewer, the building and the interpretation together." ${ }^{12}$ Taking this further, can we then implement the notion of the third space through explorations of the vitrine as a medium to investigate the curatorial practices of the architecture exhibition (fig. 21)?

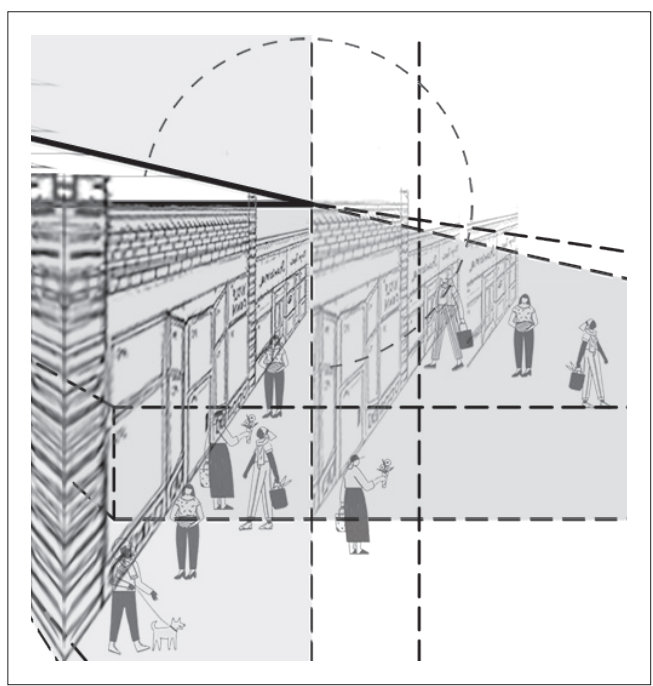

Vitrine

A glass showcase. ${ }^{5}$

The vitrine is used as a subject throughout the thesis as it creates a continuous dialogue between the various spatial conditions that are related to the curation of architecture. 


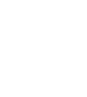

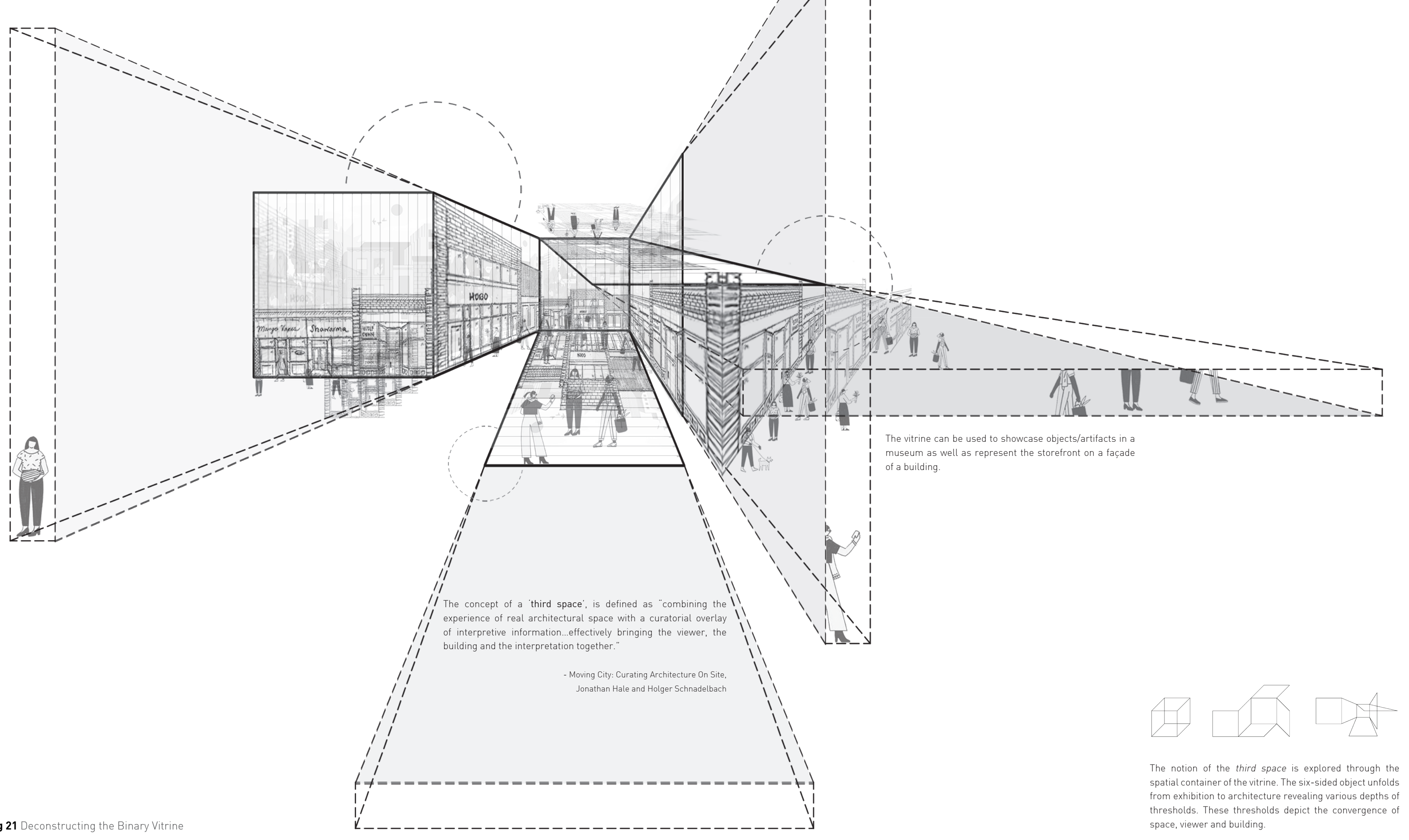


The urban vitrine is an interstice between interior and exterior where the convergence of art and architecture emerges within the urban fabric of a city. Its platform can be interpreted as an exhibition space, creating opportunities for a space in place and/or a place in space. This is the threshold between interior and exterior, simultaneously blurring the duality of private and public spaces. It proposes the function of a space by its prominence within a façade and its connection to the urban fabric. It has the ability to allure and seduce its spectators through its transformative stage. Its temporal state encourages experimentation and is a platform for the confluence of artistic expression and the experience of architecture (fig. 22).

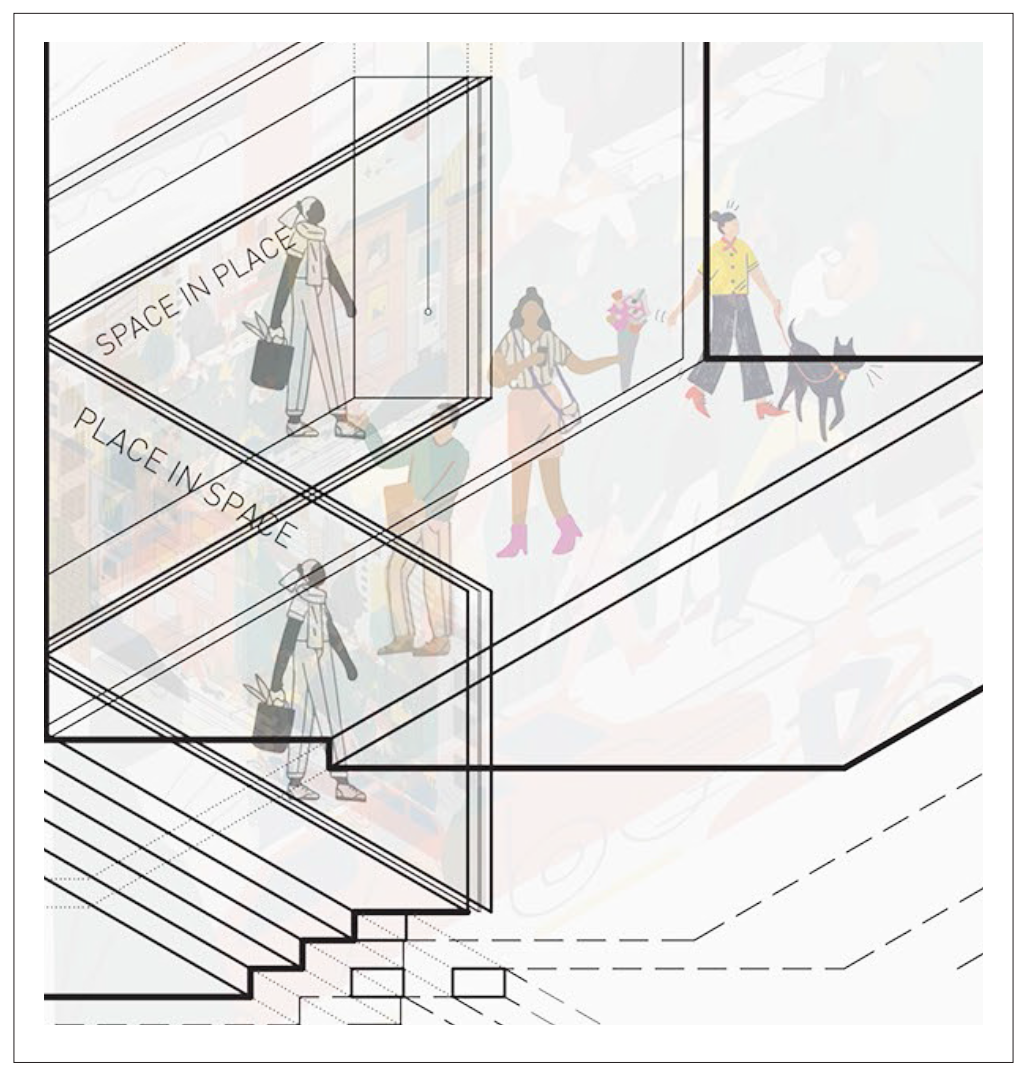

Urban Vitrine

An interstice between interior and exterior where the convergence of art and architecture emerges within the urban fabric of a city.

Urban Fabric

The physical aspects of urbanism emphasizing open spaces and streetscapes but excluding the built environment. 6 


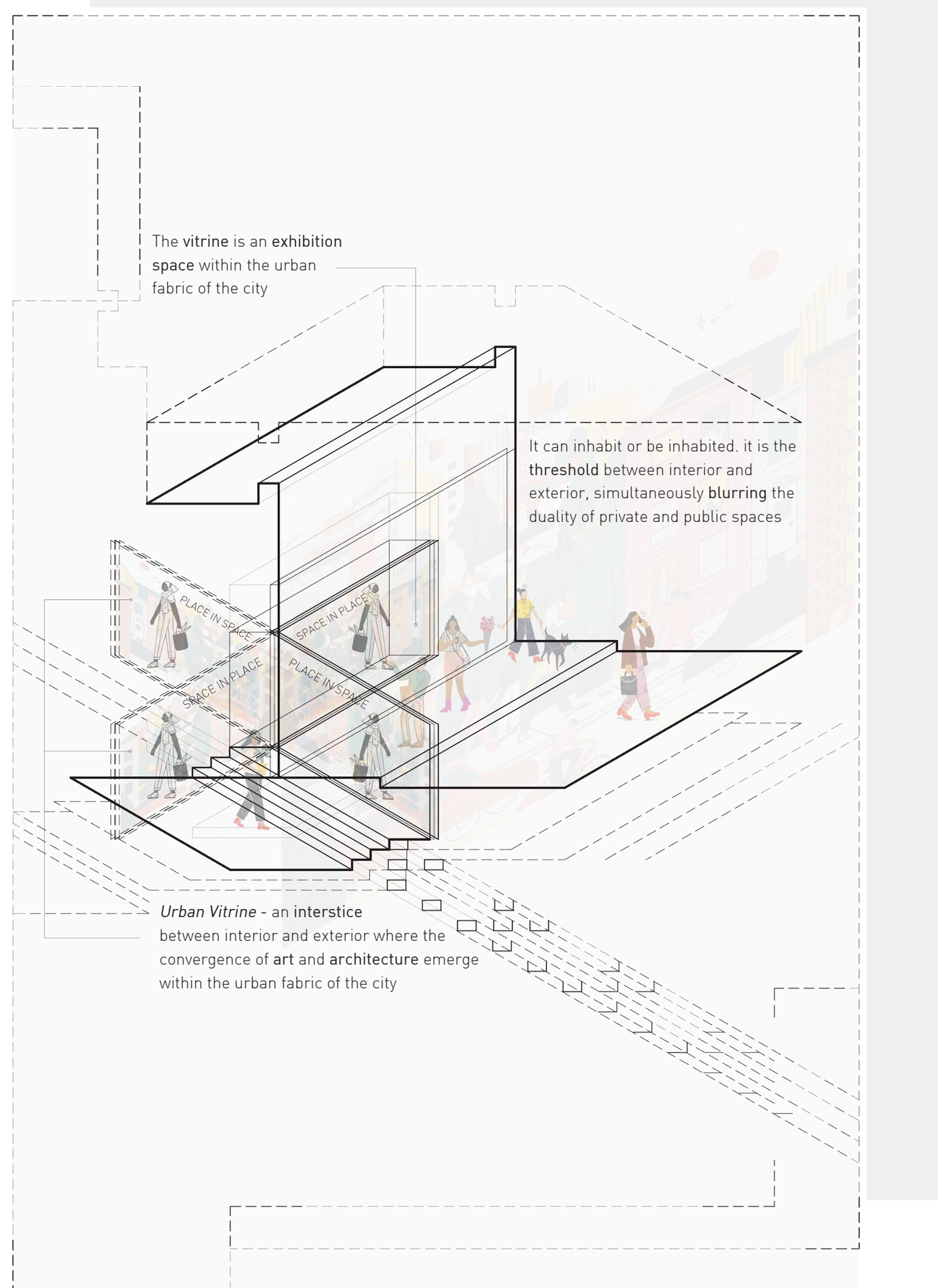

Fig 22 Thresholds 


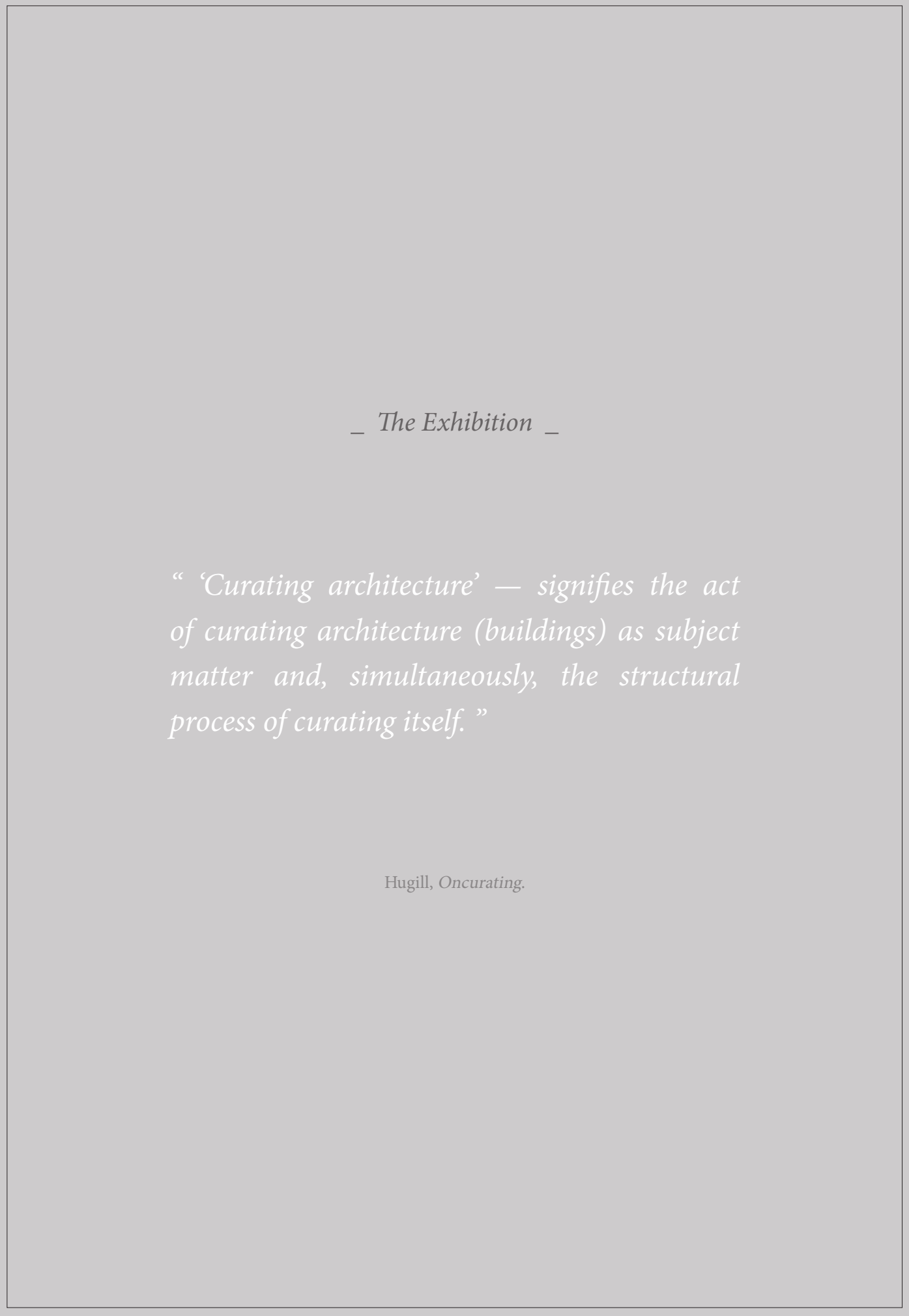

The Eventification of Exhibiting Architecture 


\section{Exhibiting Architecture: Case Studies}

The following case studies are paradigms of organizations and institutions that are founded on the ideals of the confluence of art and architecture. Each precedent represents distinctive methods that contribute to the agency of curating an architecture exhibition.

\section{The Chicago Architecture Biennial, Chicago, IL., USA.}

Architectural Biennials and Triennials are international events that are often based on social and environmental themes that are communicated through a series of architecture exhibitions. The events seek to engage the public, the city and its cultural institutions. Juried architecture exhibitions inhabit the interior, exterior and sometimes the urban fabric of a host city. In doing so, they provide the opportunity to repurpose disused buildings and structures throughout a city as well as become catalysts for adaptive reuse projects. This is evident in the Chicago Cultural Center (CCC) that acts as the main venue for the Chicago Architecture Biennial, where over 70,000 square feet of the centre is repurposed as exhibition space (fig. 23).

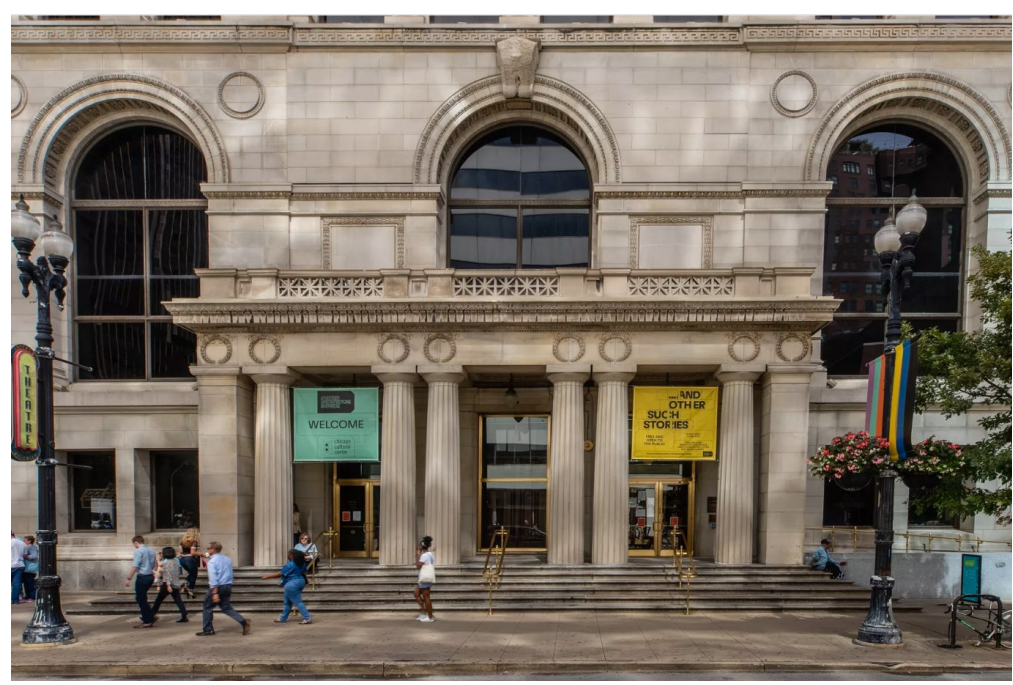

Art

An artistic expression developed through skill, creativity and imagination that produces a product with aesthetic intention.
Fig 23 Chicago Cultural Center (1897), Chicago IL., USA. The main event space for the Chicago Architecture Biennial. 
A landmark within the city, the CCC was originally a central library, built in 1897, and an arts and culture centre since 1977. The original premise of architecture biennials was to communicate and inform people on the latest trends within the field of architecture. With the increase in communication through information technology and media, the biennials/ triennials have now become a vehicle for experimentation, research, criticism and knowledge within a global architectural discourse.
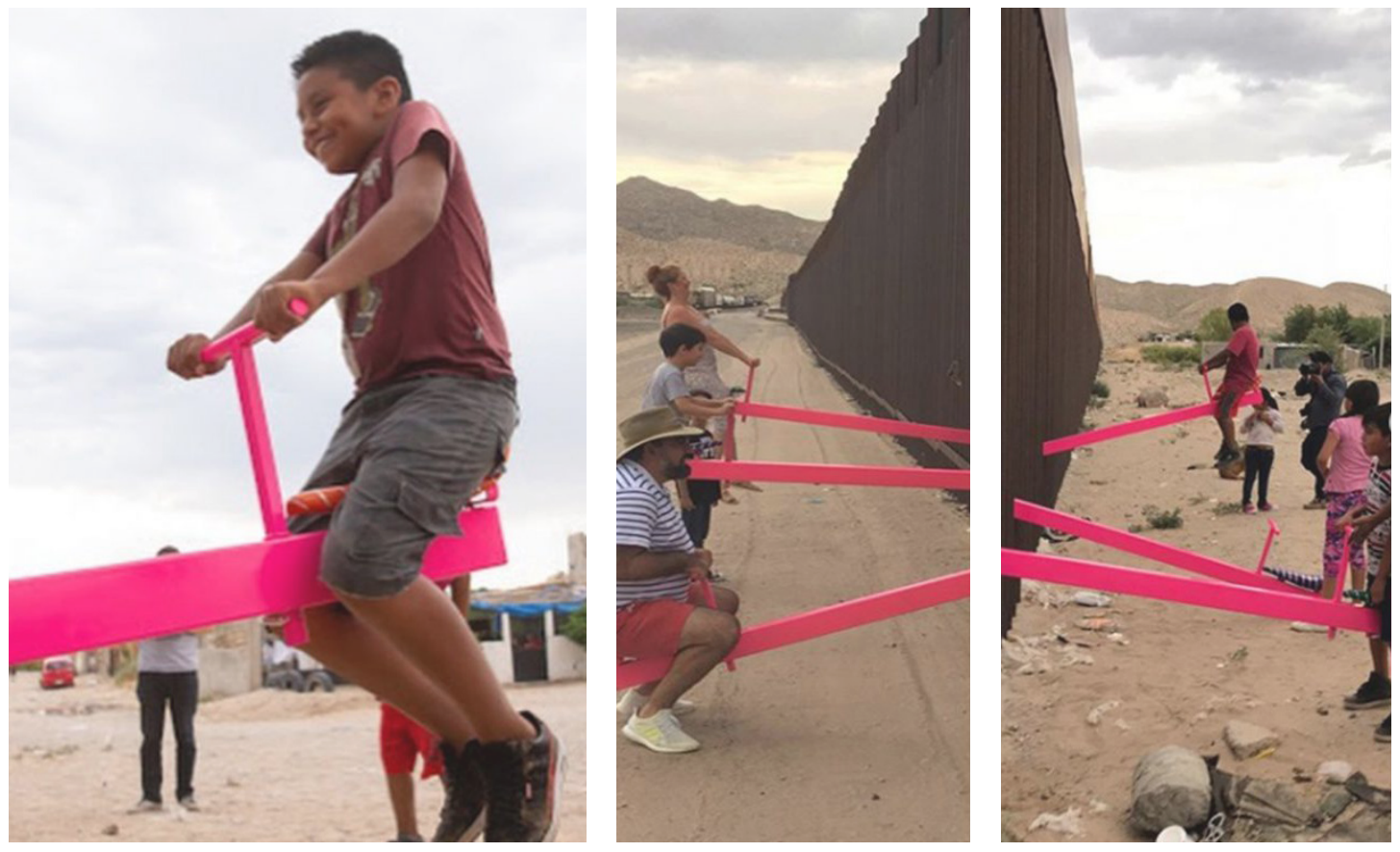

Architecture has the capacity to go beyond its spatial container lof idea and concept generators) and activate the civic and social responsibilities of architects as a sociopolitical instrument. ${ }^{1}$ This is identified in Teeter-Totter Wall by Rael San Fratello - an architectural installation project that reacts to the Secure Fence Act and the border fence constructed to separate the United States from Mexico. This project brings awareness to the political implications that architectural elements (such as walls/fences) can have on societies and cultures. Further, the project breaks down the fundamental properties of a border by disrupting the conventions of architecture and separation by translating the message, "the actions that take place on one side have a direct consequence on the other." ${ }^{2}$ 


\section{Storefront for Art and Architecture, New York, NY., USA.}

Storefront for Art and Architecture is a non-profit organization that houses exhibitions, events, competitions, publications and projects that deal with the intersection of art, architecture and design. In 1993, artist Vito Acconci and architect Steven Holl were commissioned to redesign the existing storefront of the building. The collaboration between artist and architect fully embraced the mission and practice of the organization by blurring the boundaries between art and architecture. The storefront is physically and theoretically a dichotomy of art and architecture; the storefront functions as a vitrine of a building and an exhibition space. Its multifaceted surface is concurrently an architectural element and an architecture exhibition within the same context (fig. 25). Storefront is a paradigm in how architecture can be curated in all three ways (representation, experiential investigation and original site context), allowing architecture to bridge discourse, exhibition, ephemerality and performativeness by exposing the public to ideas and topics related to the urban city and environment. ${ }^{3}$
Fig 25 Gallery façade (1993) by Vito Acconci \& Steven Holl for Storefront for Art and Architecture, New York, NY., USA.

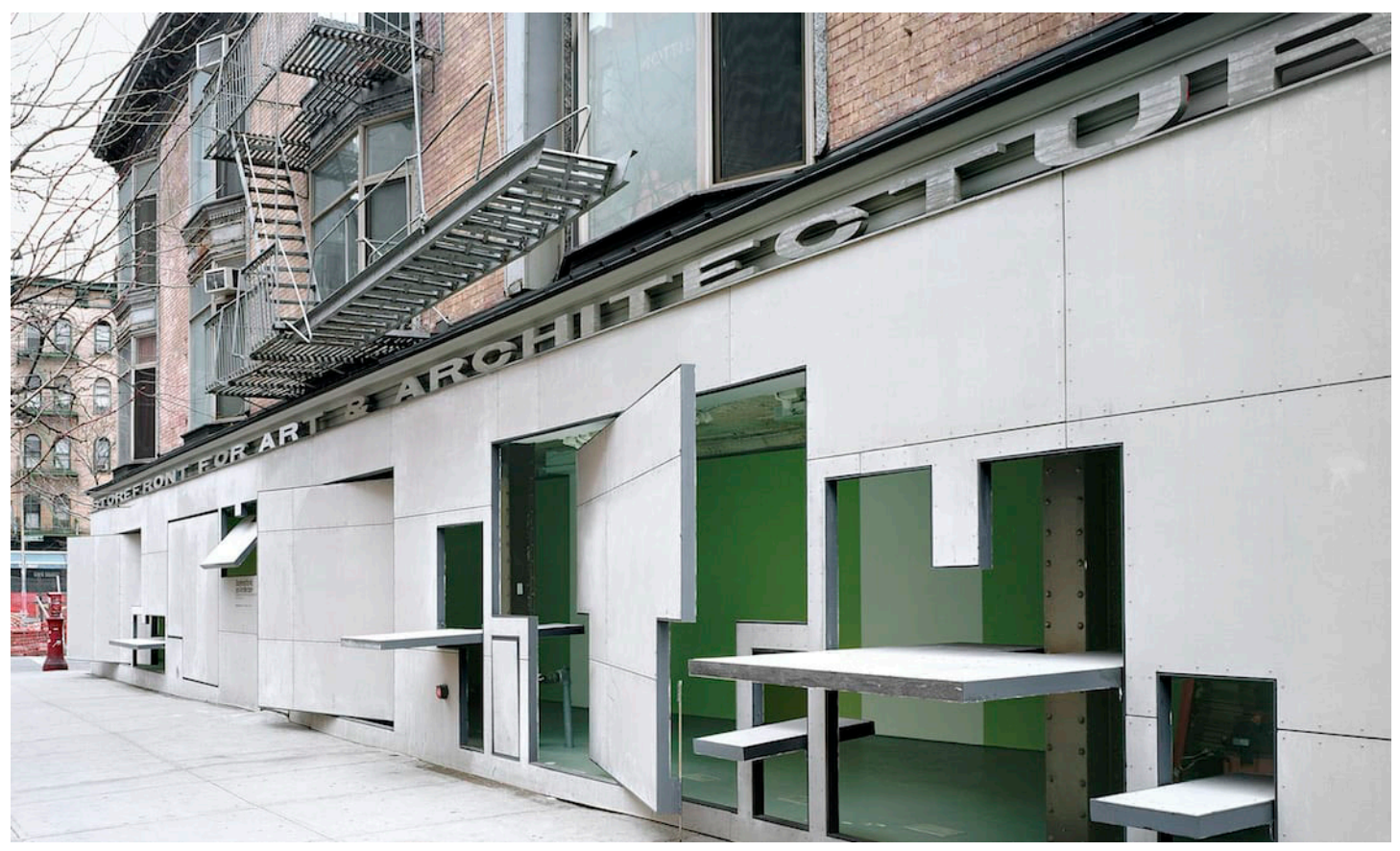


Wrightwood 659, Chicago, IL., USA.

Wrightwood 659 is an adaptive reuse project transforming a 1920s brick apartment building into an exhibition and gallery space dedicated to architecture and socially engaging art (fig. 26). The cohesion between architectural elements go beyond their functional obligation. As visitors move through different spatial conditions, they are presented with curated architectural experiences achieved through didactic design strategies. These moments transform the building into an exhibitionist experience.

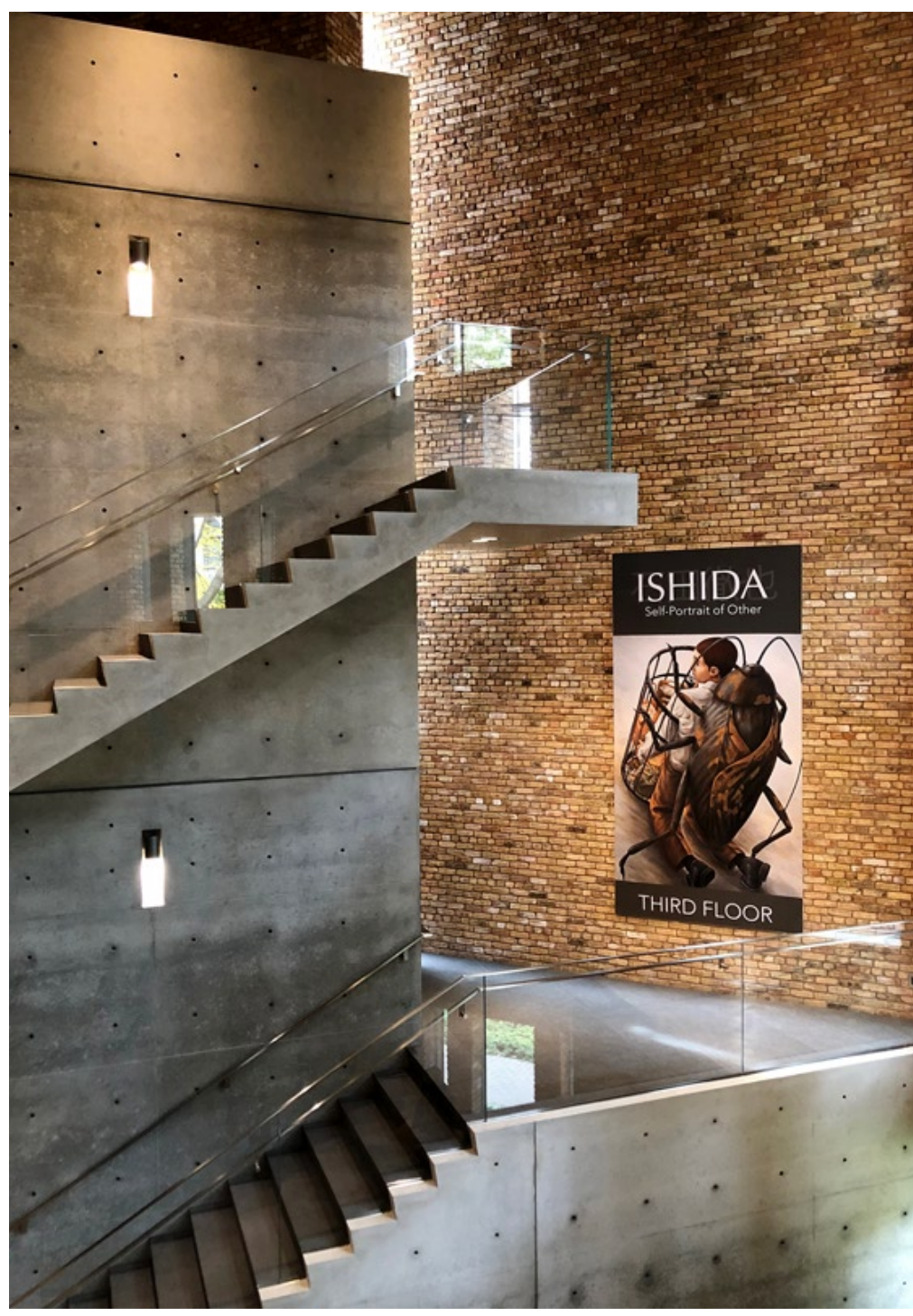

Fig 26 Wrightwood 659 (2018) by Tadao Ando Architect and Associates, Chicago, IL., USA. 
Whether occupied by artistic collections or in an empty state of transiency between expositions, the architecture always remains exhibited. An instance where this occurs is on the exterior second level where a cantilevered polished stone surface extends from the glazing, towards a perimeter of trees (fig. 27). The trees are echoed by their imprint of the form onto the solid surface which becomes animated by their movement. The architectural elements elevate the viewer's experience with the curated works by creating a framework for the works to inhabit while subserviently exhibiting the architectural elements themselves. This demonstrates the overlap of the practice of curation as a new disciplinary agent within the architectural design strategy.

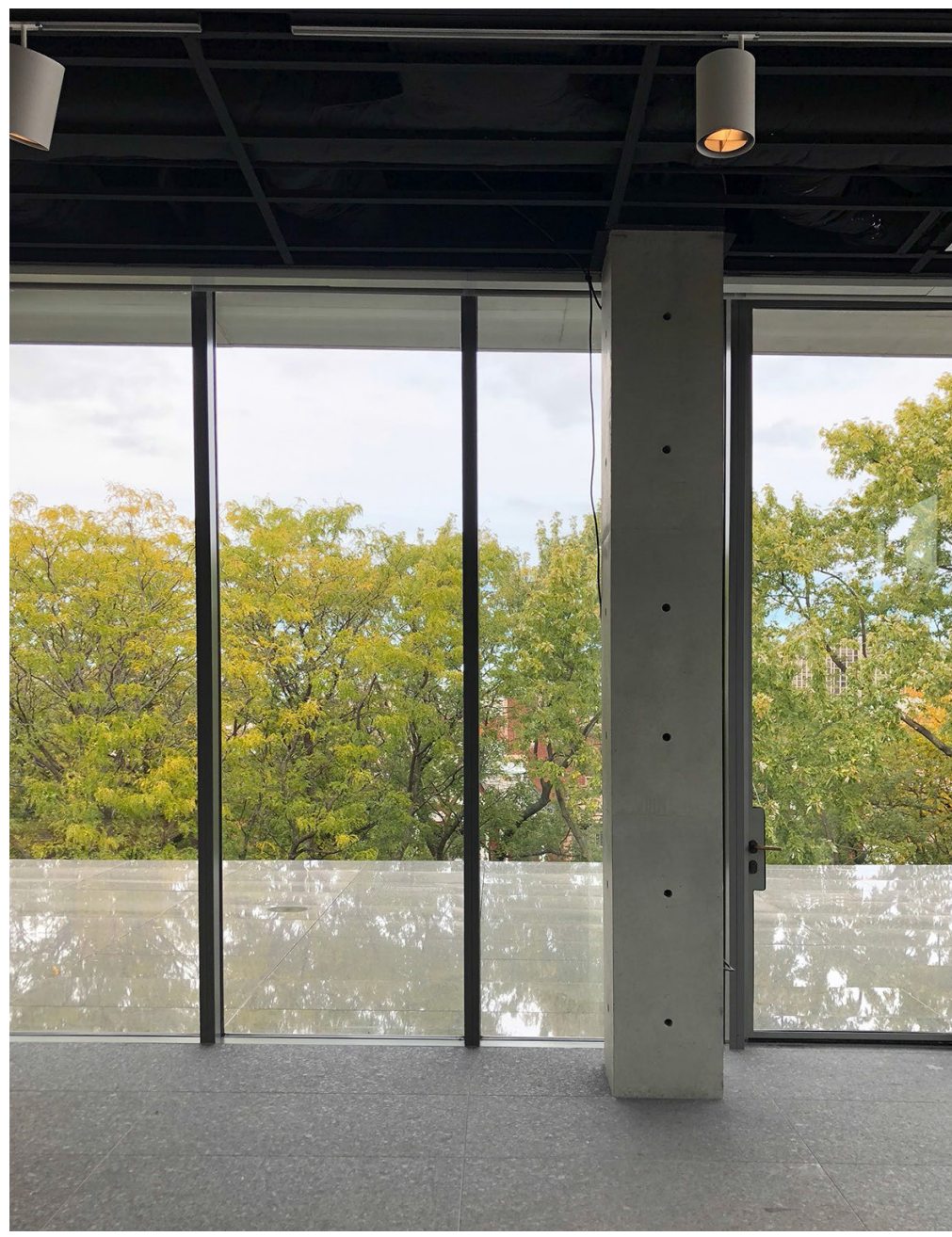

Fig 27 Wrightwood 659 (2018) by Tadao Ando Architect and Associates, Chicago, IL., USA. 


\section{Curating Spaces For Events}

An architecture exhibition can be described as a space for events. Architect Bernard Tschumi identifies architecture as a series of events that is activated through the movement of bodies. ${ }^{4}$ Has the integration of curatorial practices become a device used to activate these events in order to reinterpret the conventional components of architecture? Tschumi believes that the organization of events are associated with the notion of use, function, activities and program. ${ }^{5}$ Exhibiting architecture through curatorial practices then has the ability to offer a different interpretation of architecture to the public which the standardized built environment fails to do. In the built environment, conventional and unconventional architectonic components are systematically integrated with one another, for example a staircase connecting two floors. In the exhibition space, these components can be portrayed independent of one another, deconstructed and reconstructed in different configurations and forms. Is it possible for architectural elements to exist beyond their functional logic, which could then further inform their identity (fig. 28)? If so, perhaps introducing curatorial practices as part of the design process could expand architecture beyond its purely functional objectives.
Event

In relation to Bernard Tschumi's theory of "there is no space without event". An event is a spatial condition consisting of time, action and movement that is activated by the human body. ${ }^{7}$ 


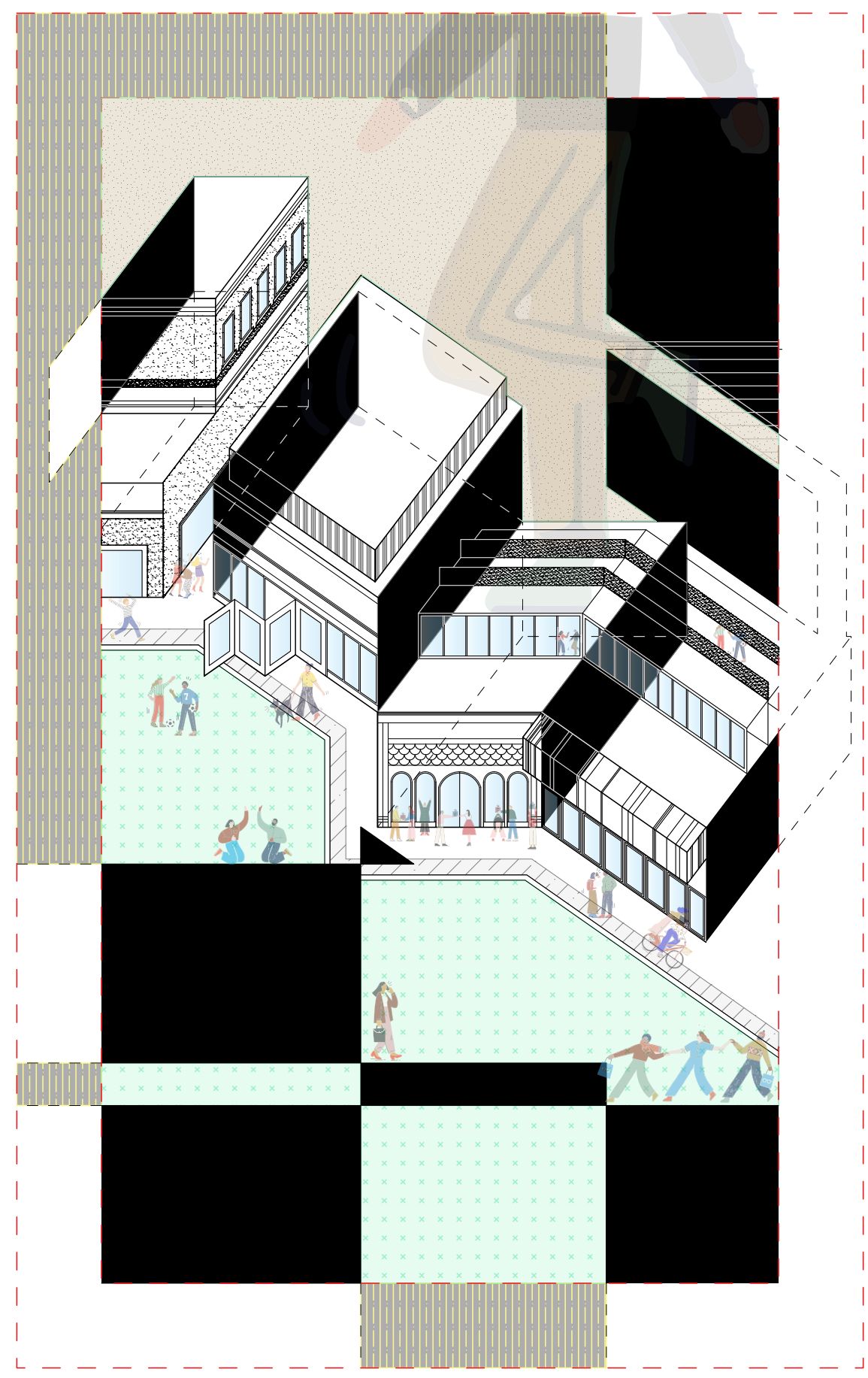

Fig 28 Architectural Didactics - Stairs At Play: The illustration is an abstraction of an image taken in the interior space of the Azrieli School of Architecture \& Urbanism building. An architectural element such as stairs, is used to explore the nature of didactics within architecture through a play on scale and perception. 


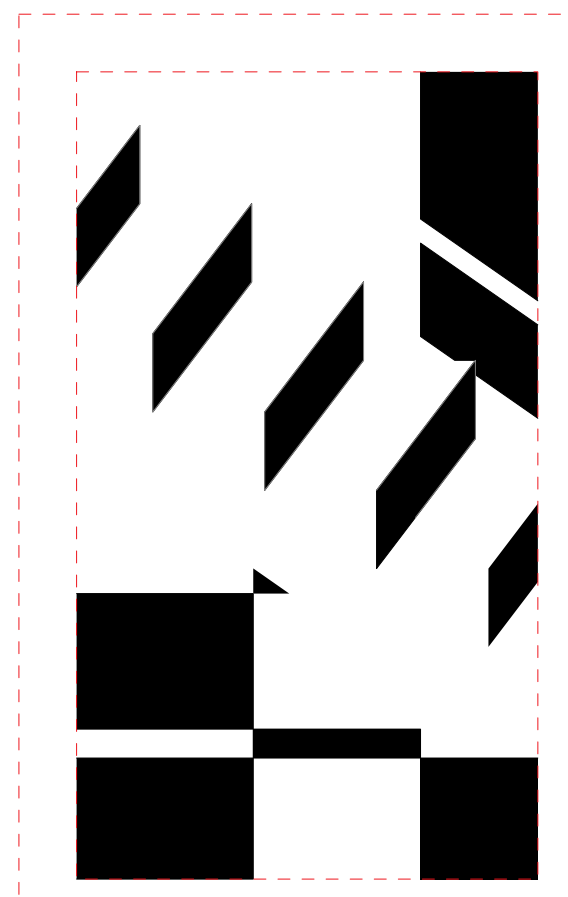

solid and void forms

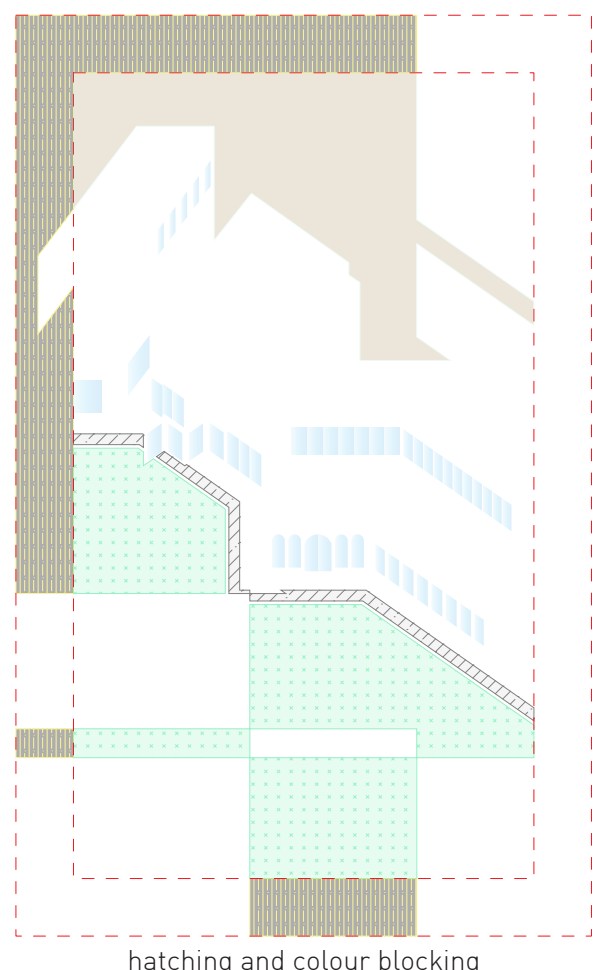

hatching and colour blocking

Fig 29 Architectural Didactics - Stairs At Play Deconstructed Layers of the Drawing

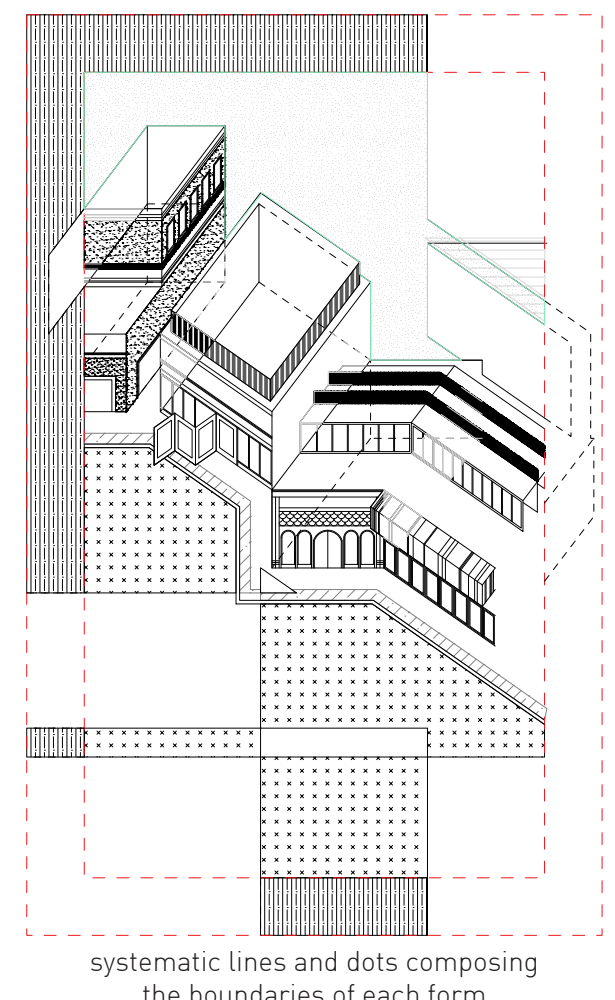

the boundaries of each form

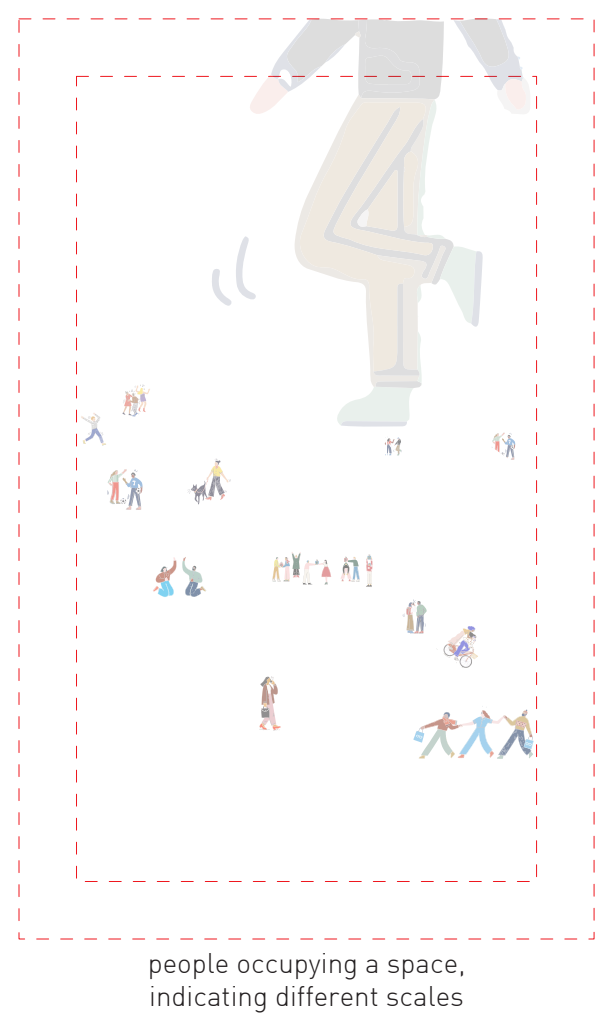

The Eventification of Exhibiting Architecture 


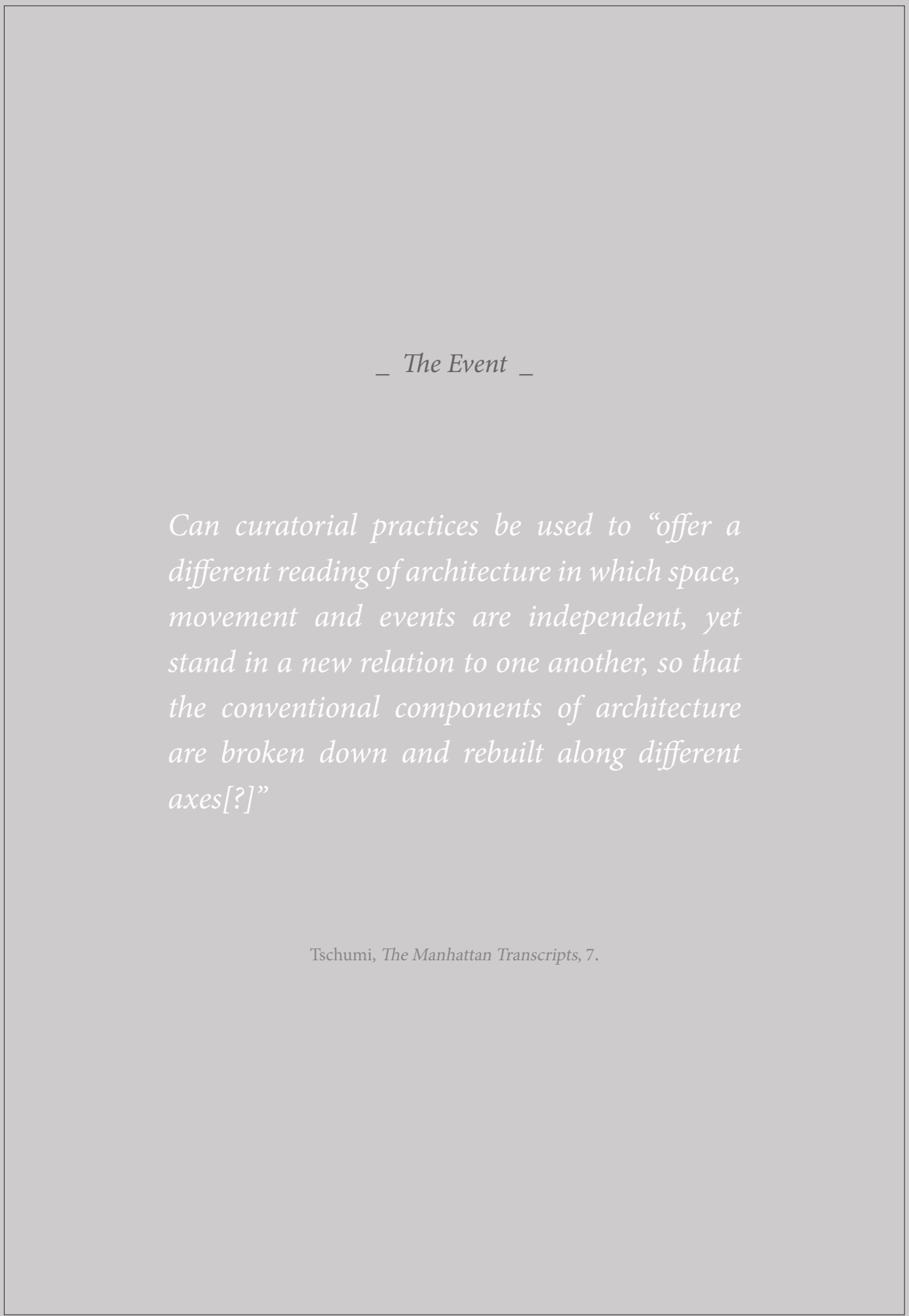

The Eventification of Exhibiting Architecture 


\section{Index Of Architectural Didactics}

The emerging thesis project offers an opportunity to explore the role of architectural elements and compare how they are proposed in exhibition environments versus how they are implemented in conventionally built environments. This devises the potential for the investigation of architectural elements that participate in a duality of programs beyond their practicality and conventions. If we reference Rem Koolhaas' “Elements of Architecture" from the 2014 Venice Architecture Biennale: Fundamentals, we can analyze the index of architectural elements that exist dualistically as an object on display or act as an architectural backdrop within the spatial condition of the exhibition such as The Ceiling display (fig. 30).

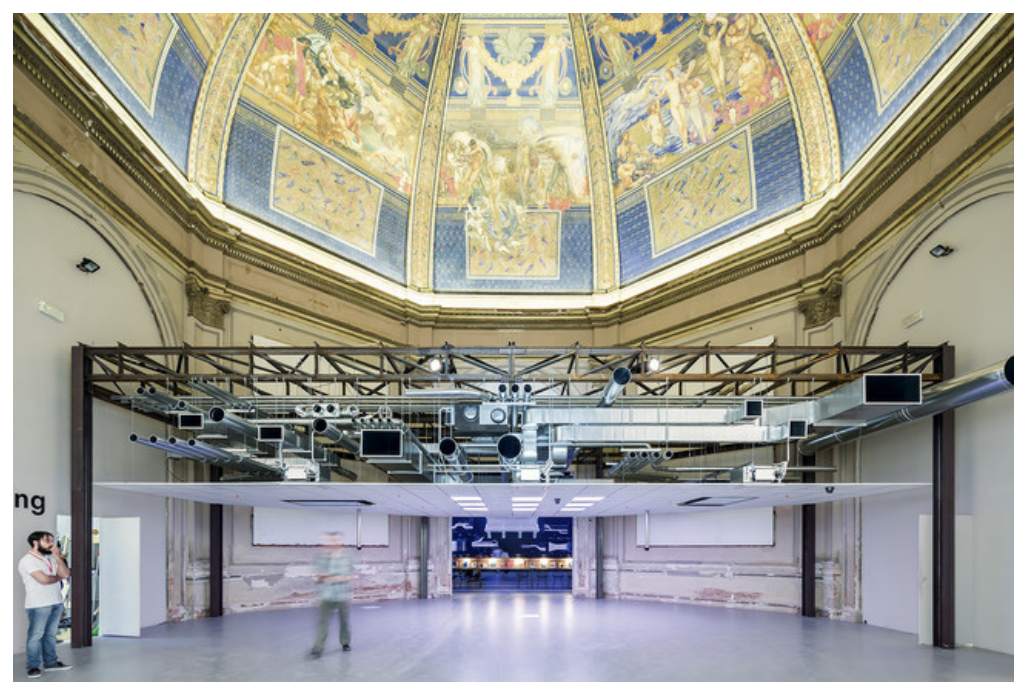

Fig 30 The Ceiling display from the 2014 Venice Architecture Biennale: Fundamentals in Venice, Italy. Located in the Central Pavilion in Venice's Giardini, the drop ceiling installation is offset by the dome within the pavilion Ipainted in 1909 by Galileo Chini. 


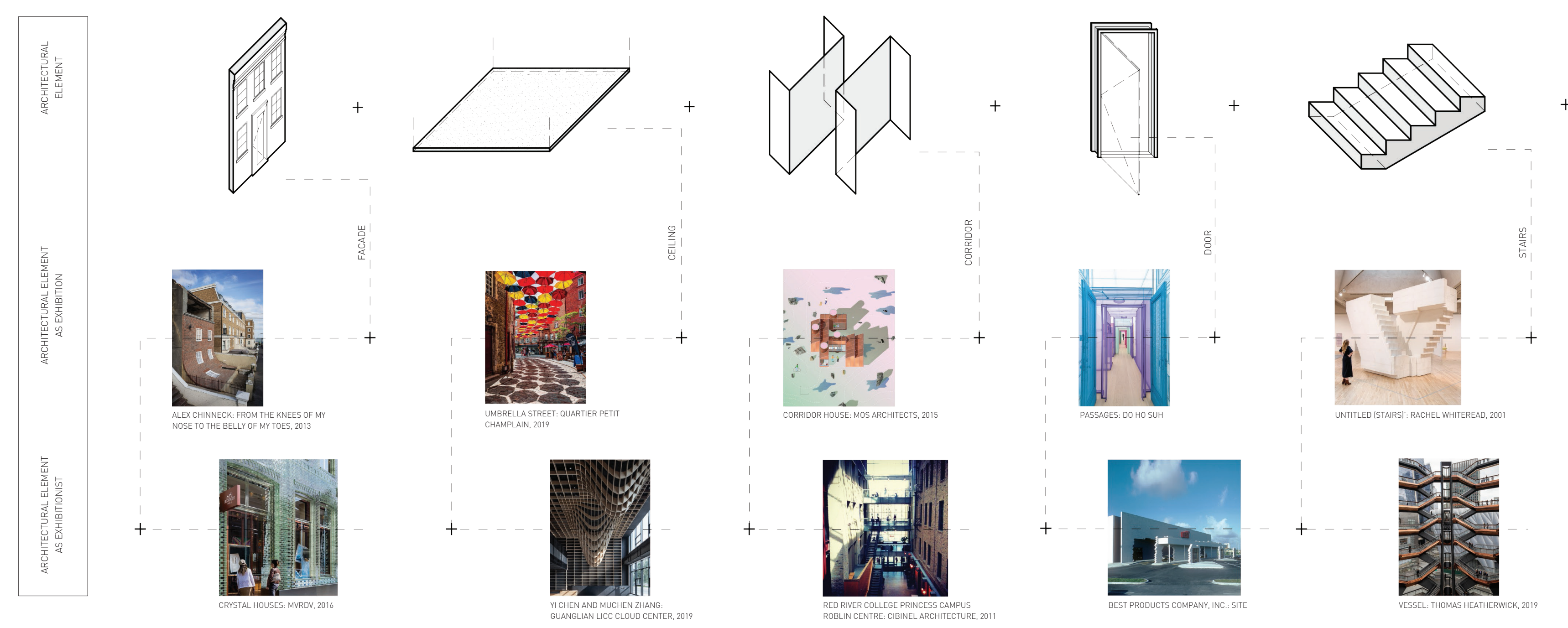



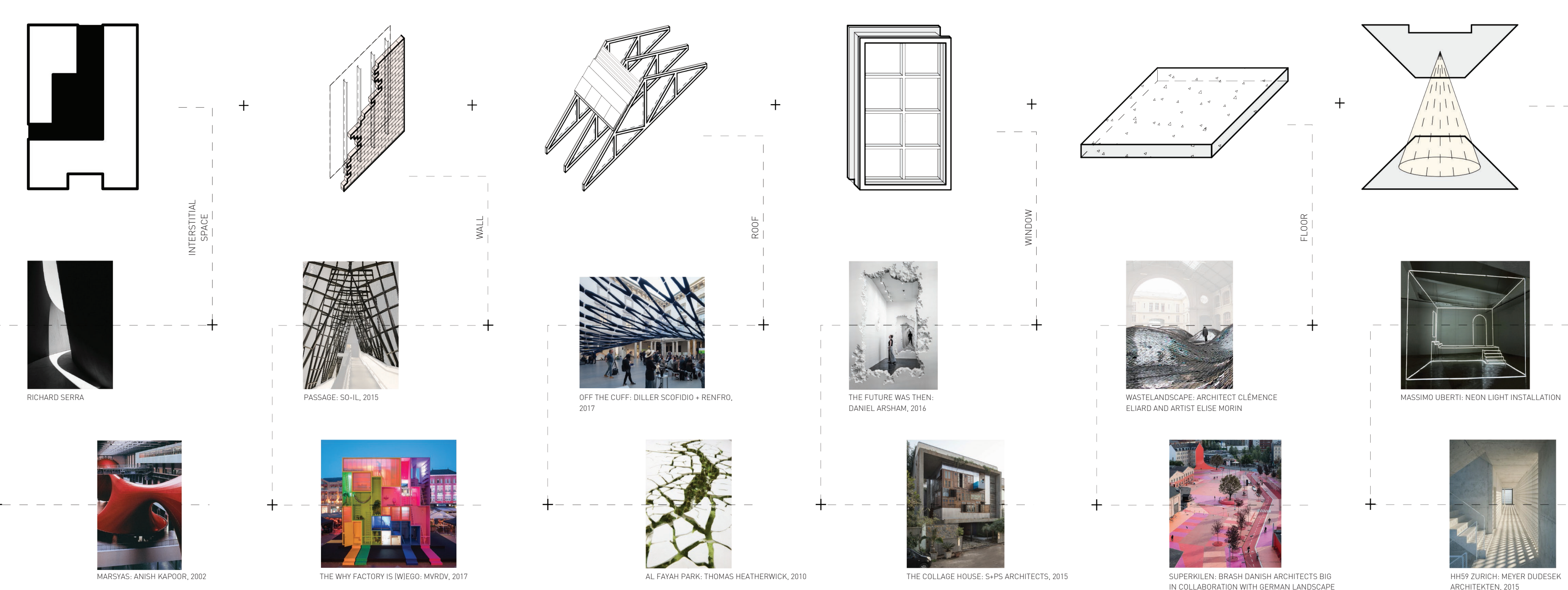


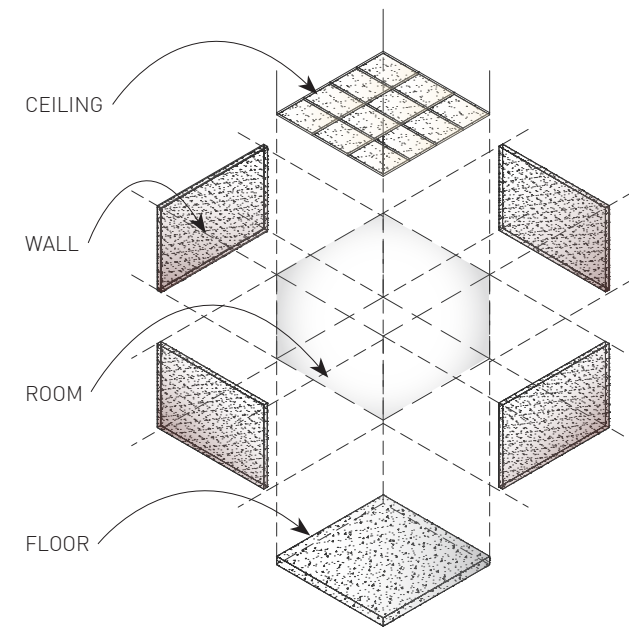

Index of Architectural Elements is an analysis comparing exhibition and exhibitionist architectures within the context of the urban and city fabric (fig. 31). Architectural elements are versatile and can work in two basic ways. First, as a cohesive unit, multiple architectural components can come together to create a spatial condition through the connection of walls, floors and ceilings (fig. 32). Second, distinct elements can become their own independent entities performing functional and programmatic roles within a space. An example of this is the repetition of stairs to form a continuous spatial condition such as Vessel in New York, NY., USA (fig. 33).

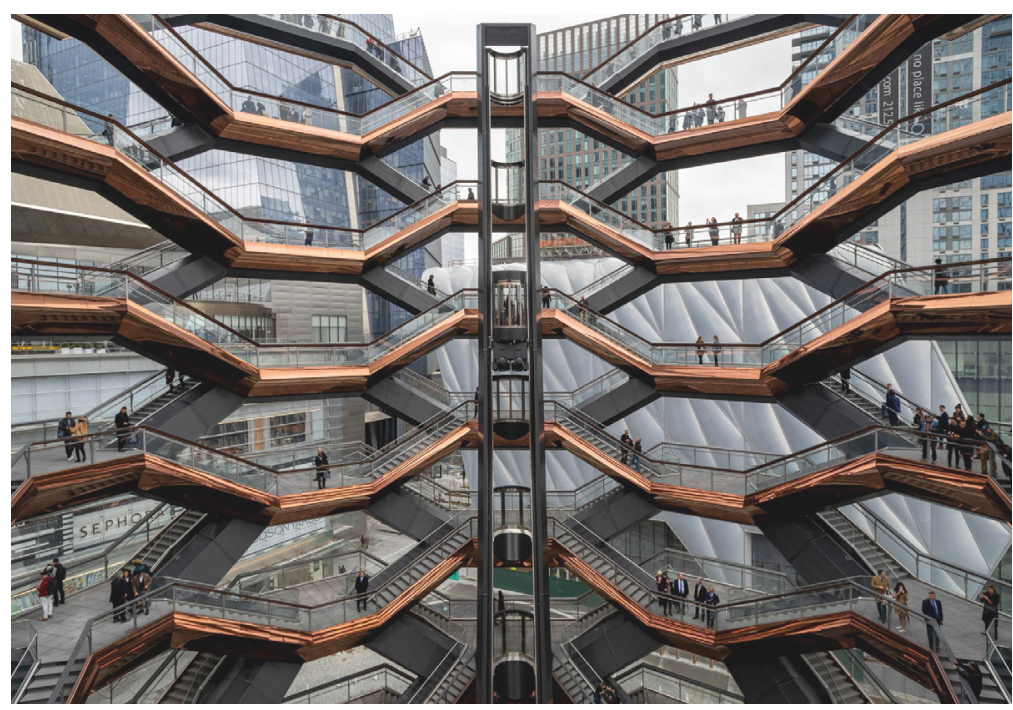

Fig 32 Cohesion Element Diagram.
Fig 33 Vessel (2019) by

Thomas Heatherwick in New York, NY., USA, is a social landmark inspired by the Indian stepwells of Rajasthan. 


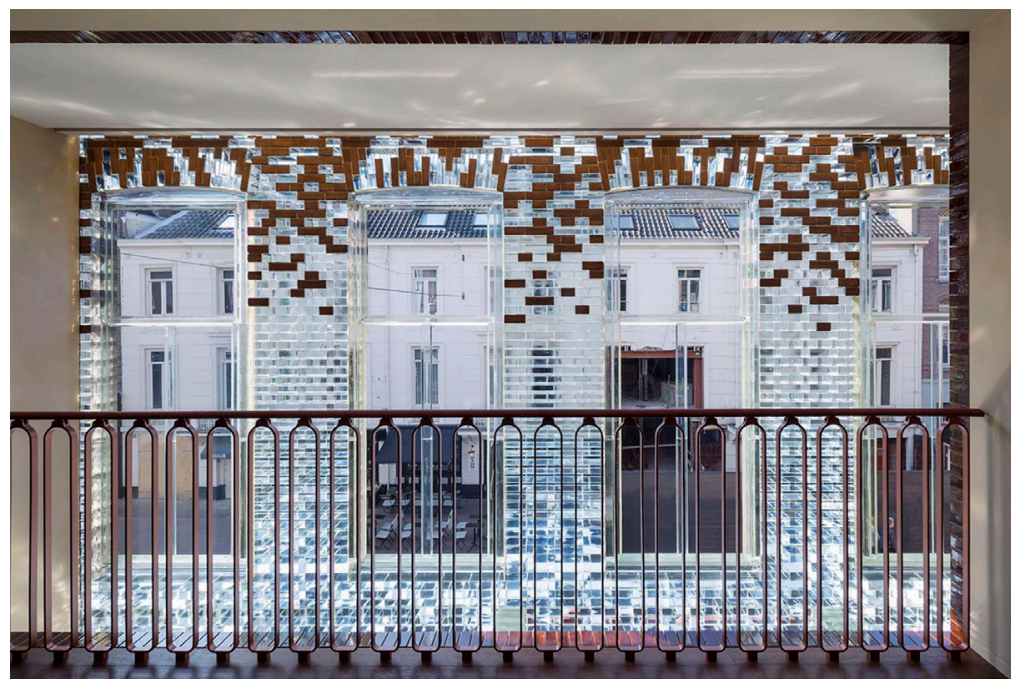

When architecture is curated - in other words, put on display within its context - it transgresses conventional notions by opening us to improvisational ones, transforming the performance of a building into an architecture. Analyzing Alex Chinneck's work, From the Knees of my Nose to the Belly of my Toes, transforms our perception of the architectural façade by peeling back the façade from the rest of the building (fig. 34). This simple action alters our perception of the rigid brick façade into a malleable surface. This can be compared to Crystal Houses by MVRDV in how they achieve a transparent façade fabricated out of glass, through material research and experimental design (fig. 35). The design process and architectural outcome of the façade personifies the building as an exhibitionist. Hence, within the urban context, the role of the façade establishes an architectural exhibitionism meant to be "not of architecture, but about architecture?"1

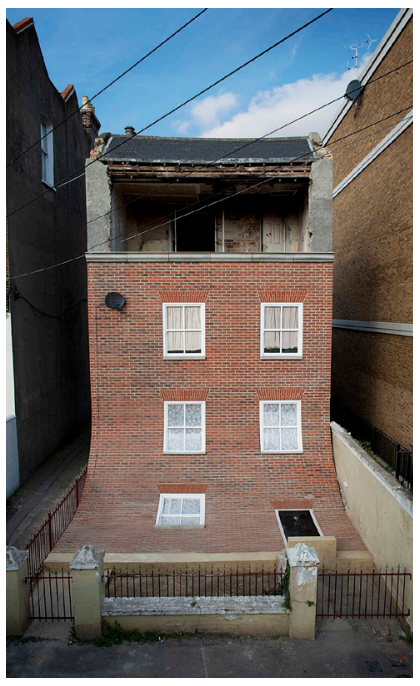

Fig 34 Crystal Houses (2016) by MVRDV, Amsterdam, Netherlands. (left)

Fig 35 From the Knees of my Nose to the Belly of my Toes (2013) by Alex Chinneck, Kent, UK. (right) 


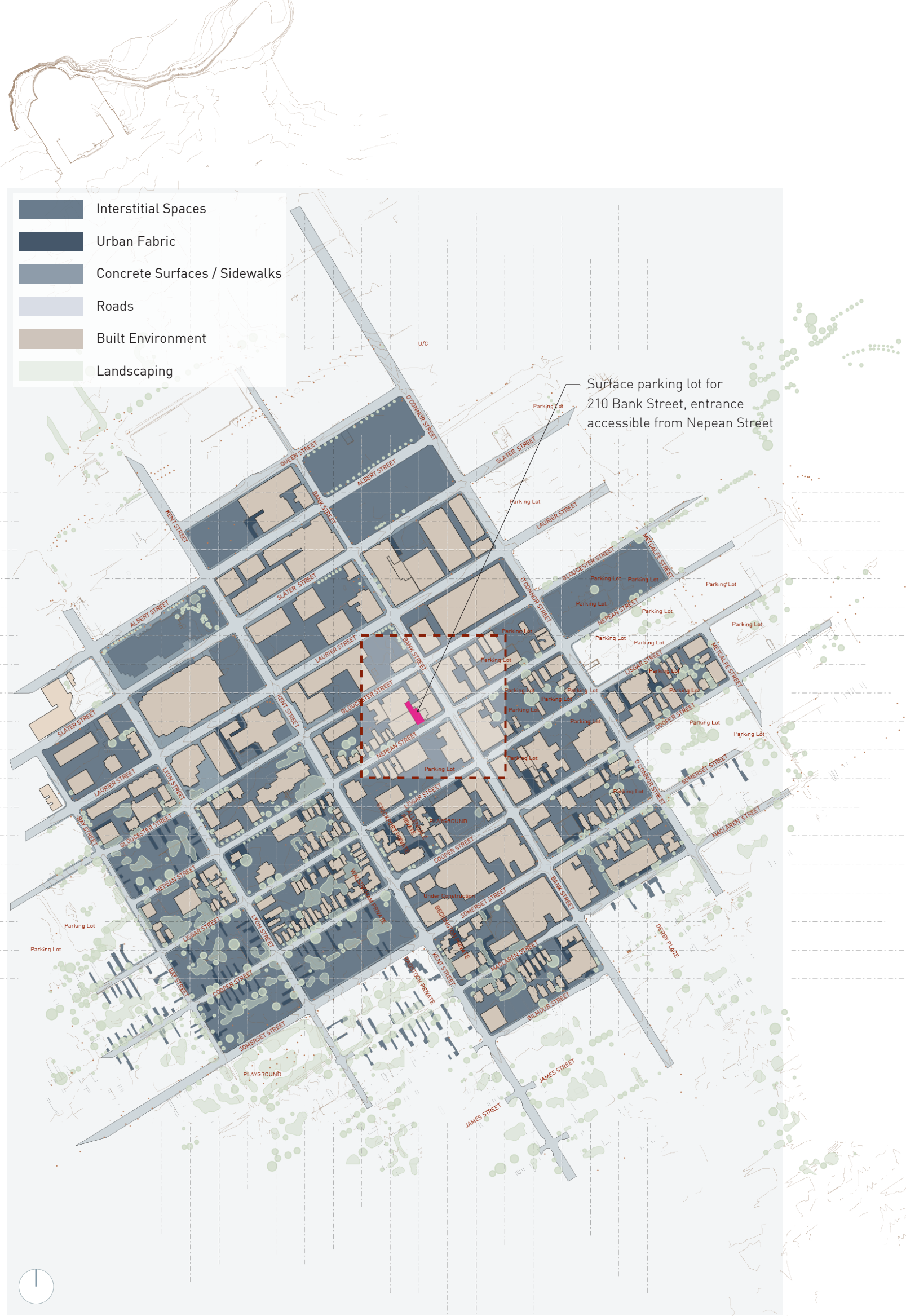

Fig 36 Site Plan - Centretown, Ottawa, ON. 


\section{Site(s) For Events}

The downtown core of Ottawa longs for a resurgence within the rigid city fabric of regimented activity. The lack of presence and density after business hours creates the opportunity for bleak, isolated conditions within the interstitial spaces of the urban fabric. The surrounding buildings may not be occupiable past business hours but the interstitial spaces among them have the potential to initiate events and activities for an extended period of time (fig. 36 ).

The existing context for the proposed architecture is an underutilized surface parking lot accessible from Nepean Street, situated between a high-rise residential complex and a commercial retail unit. The parking lot services the retail unit whose entrance is located on 210 Bank Street (fig. 37). The site is located in an area known as Centretown, densified by commercial, residential, educational, and institutional programs (fig. 38). There is an evident juxtaposition between the two existing buildings that inform the perimeter of the parking lot. The residential complex follows a conventional design based on efficiency and logic, whereas the retail unit and surrounding commercial buildings are improvisational in design. They show a palimpsest of conventions, resulting from a series of exterior alterations. The combination of the existing conventional and improvisational site lines imprinted onto the site is used to inform the circulatory rhythm throughout the architecture. The built form is elevated above the parked vehicles with minimal disruption to the existing use. The convergence of the existing use and the proposed curated spatial events create dualistic instances comprised of informal and formal spatial conditions. 
The architecture is comprised of various functions in order to initiate the occurrence of events for intermediary activities such as public work areas, a pop-up venue for local businesses, a gallery space and a remote studio for the Azrieli School of Architecture and Urbanism at Carleton University. The curated events are designed to engage interactions and exchanges amongst the public as well as the public and architectonic components. Curiosity is the catalyst for curation, initiated by a series of events, that are experienced through the act of viewing when architectonic conventions are at play.

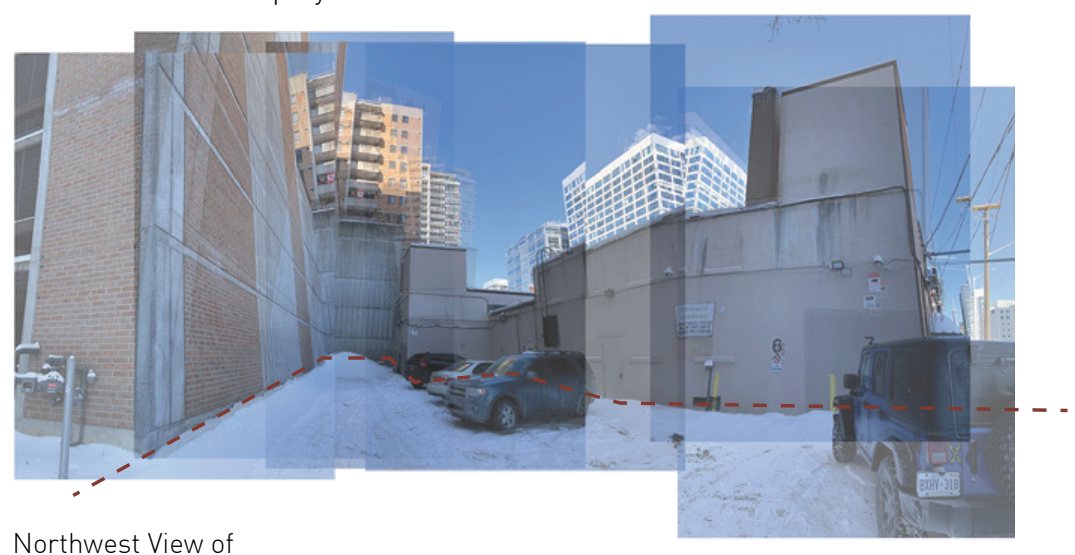

Existing Surface Parking

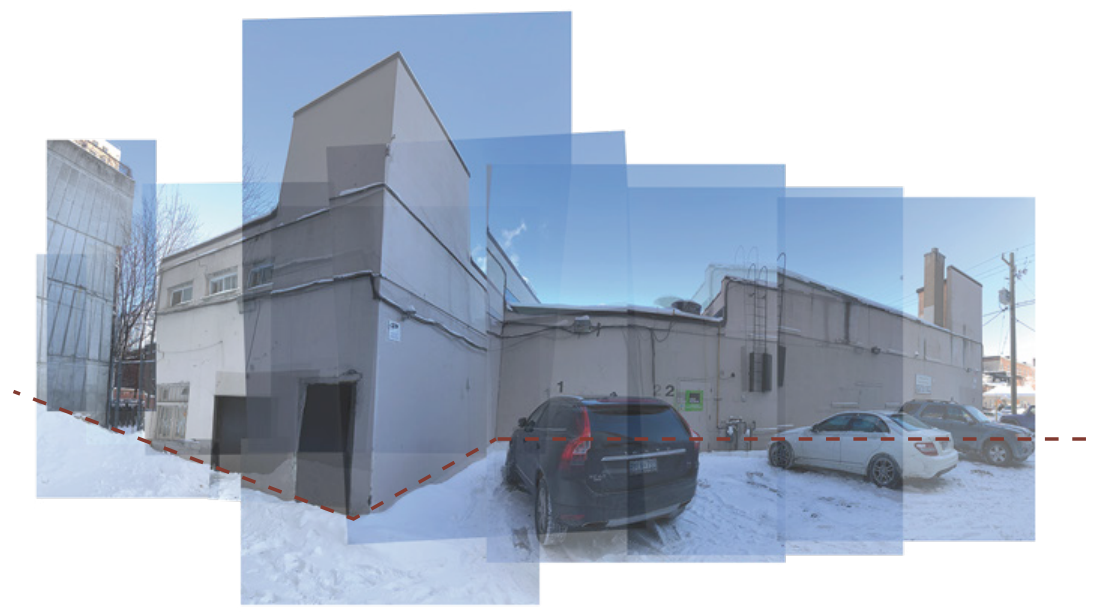

Northeast View of

Existing Surface Parking

Fig 37 Existing Site Conditions 


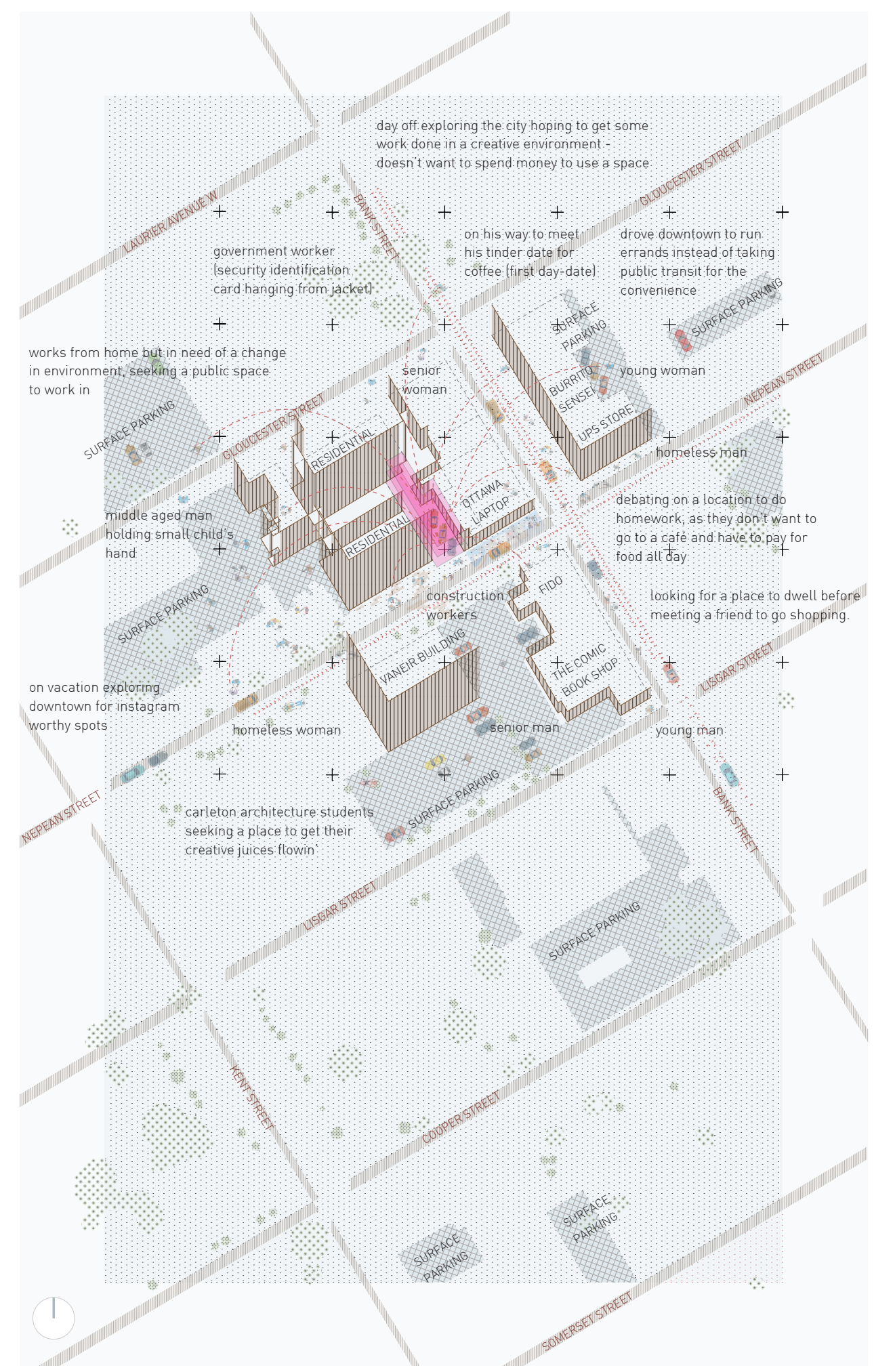

Fig 38 Exploration of Site Activity 


\section{The (Un)Curated Event}

The architecture is an extension to the urban fabric of the city. It is a space where curated exhibitionism is discussed, created and experienced through the built environment. A combination of spatial conditions are designed to encapsulate the notion of curation, the role of the event and the activity of people. The built environment is transformed and activated by an architecture of curated exhibitions. This is achieved through the introduction of the urban vitrine during instances where architectural elements push the boundaries and functionality of a space, consequently creating a reinterpreted spatial experience. The urban vitrine establishes a frame that promotes the act of viewing. By its physical presence, the urban vitrine relies on the participation of the viewer to seek out and engage with the subject. Depending on their location, people can take on the role of either the viewer or subject. This is attained by providing an opportunity to engage with what is being exhibited through multiple points of view. The characteristics of the urban vitrine las described in the previous section, Curating Architecture Through the Vitrine), are realized through a series of informal and formal spatial conditions linked together by a circulatory journey of spontaneous spatial events.

The space is conceived through the action of an event rather than a program. It is a public interface for architectural production where strategic acts of display demand engagement by the viewer; the basis for an architectural narrative. The building is a framework for the architectural design to activate the precarious relationship between the viewer and architectonic components. This is achieved through a narrative of subtle actions involved in constructing the architectural components that make up the spatial context. The architecture is a physical manifestation of curation and architecture as an event. It becomes a manifestation of the ideas, theories, topics and questions discussed throughout this thesis project.
Viewer

One who participates in viewing events that take place.

The viewer can also become the subject of viewing.

Subject

A person, spatial condition or object involved in the experience of an event. 
The design is communicated through a series of sectional narratives which capture moments of exhibitionism that exist through simultaneous juxtaposed events (fig. 39, $42 \& 49$ ). The body's relationship to space is distinctively experienced in section, as one occupies space they are consistently moving through a range of sectional spatial conditions. The sectional conditions illustrated through carefully and conceptually selected vignettes richly depict scale, materiality, movement, time and the eventification of architecture. The unconventional display of these architectonic conditions distort the conventions that constitutes the theory of a wall, floor and ceiling, by a dematerialization of a plane and surface. The juxtaposition created from the limitations and possibilities of architectonic components generate didactic spatial conditions. By disrupting the function of these components, the viewer is compelled to reinterpret their presence in space. 


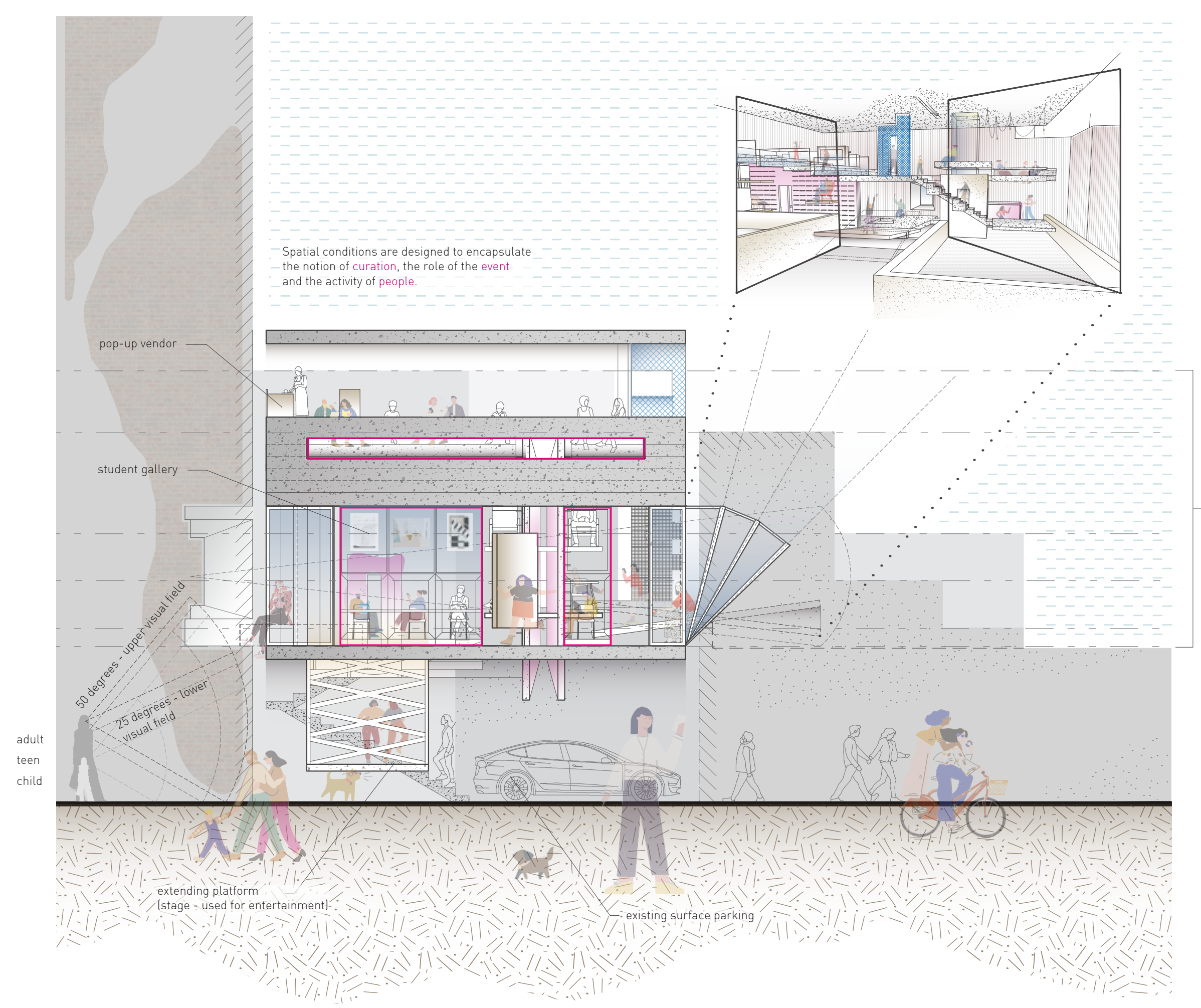




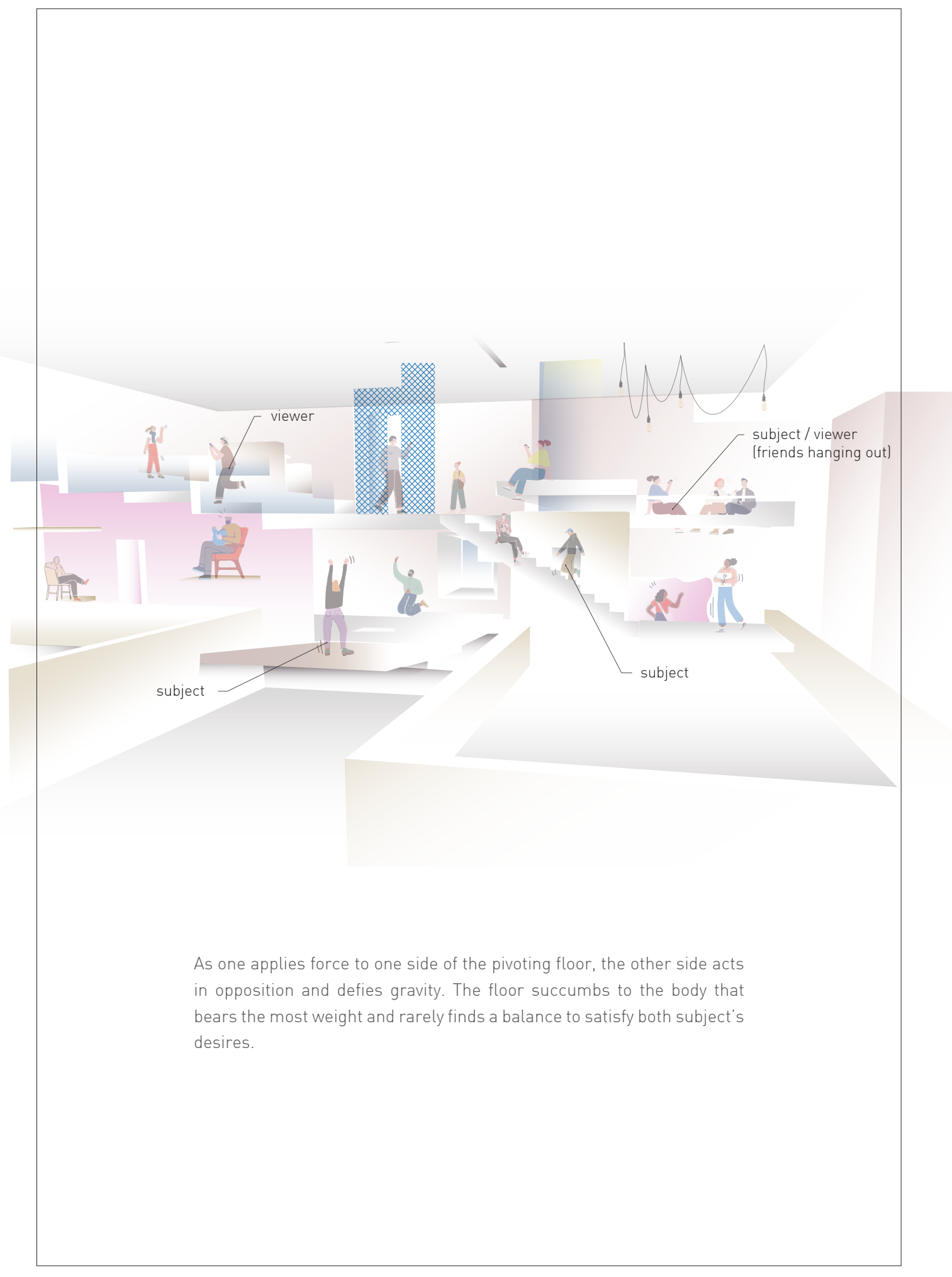

Fig $\mathbf{4 0}$ Teeter-Totter Floor 


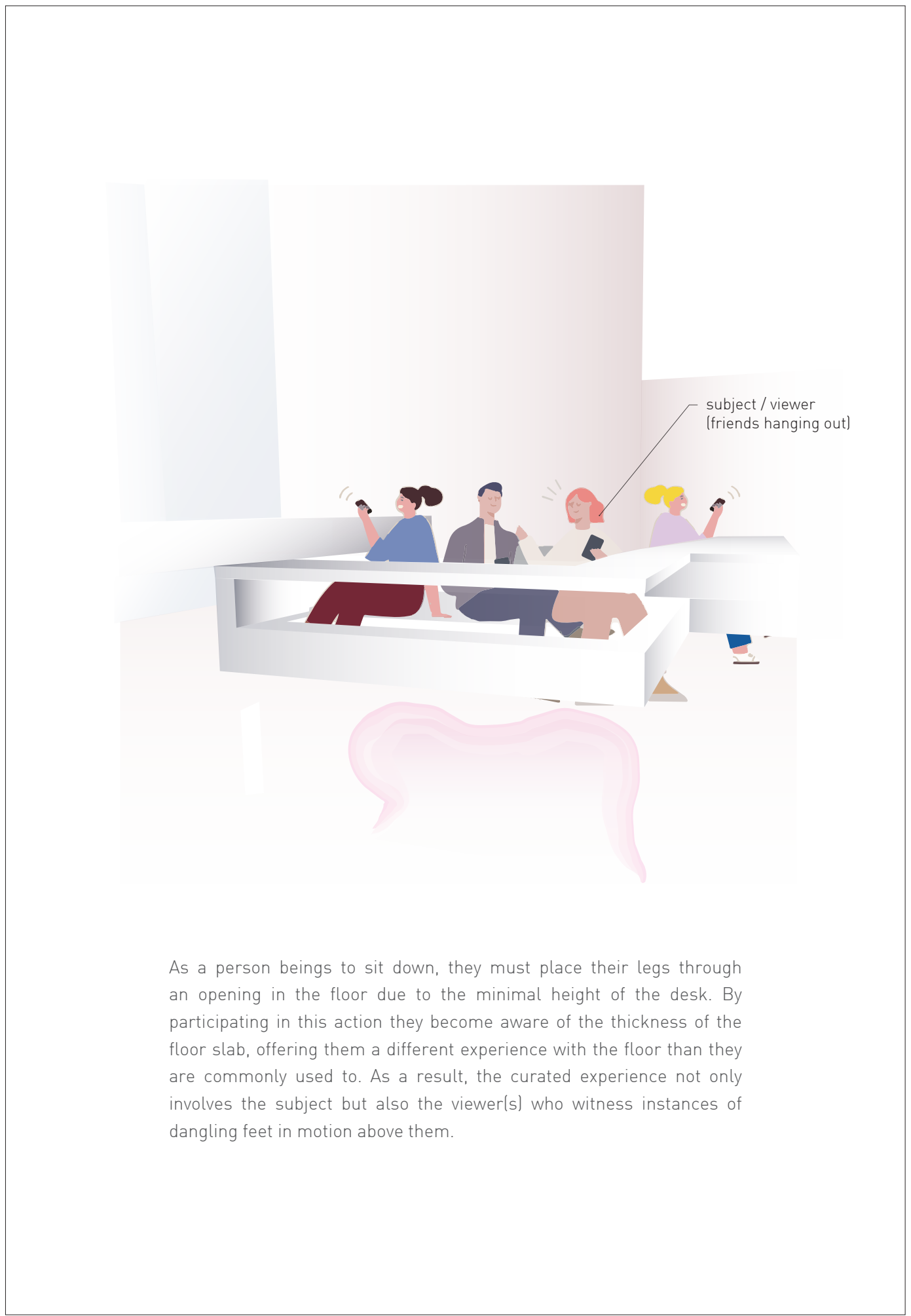

Fig 41 Threshold of a Floor 


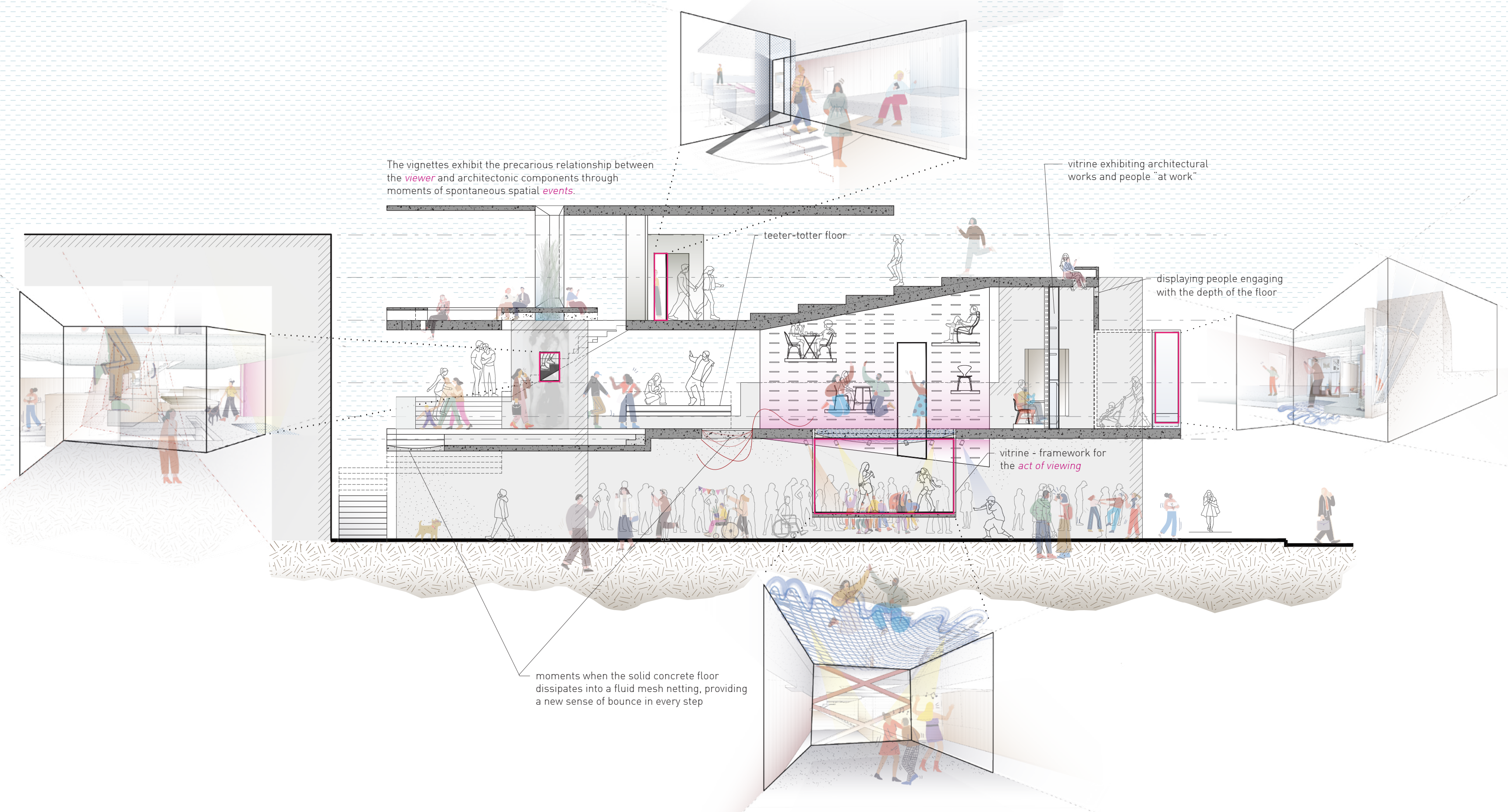




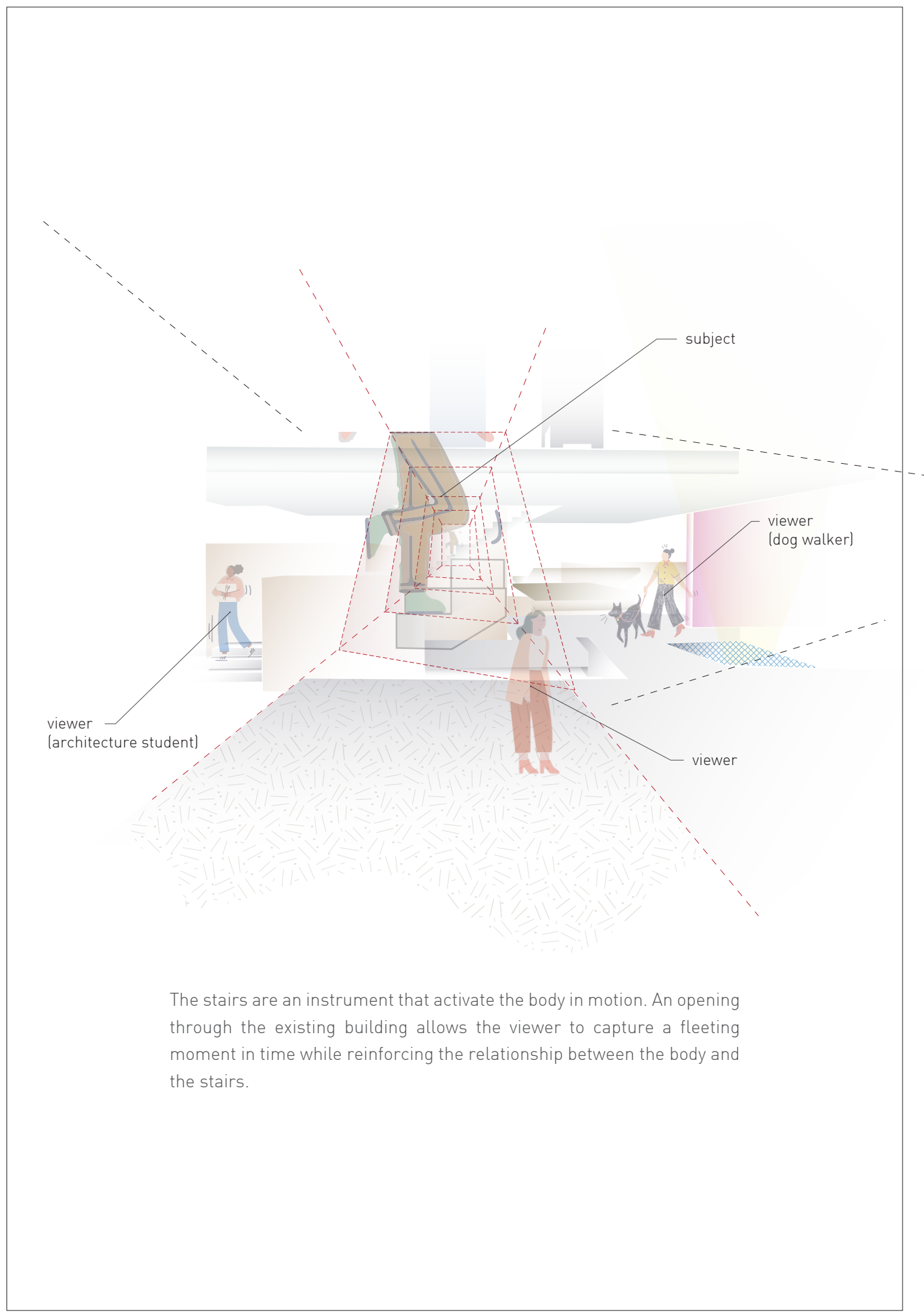

Fig 43 Stairs In Action 


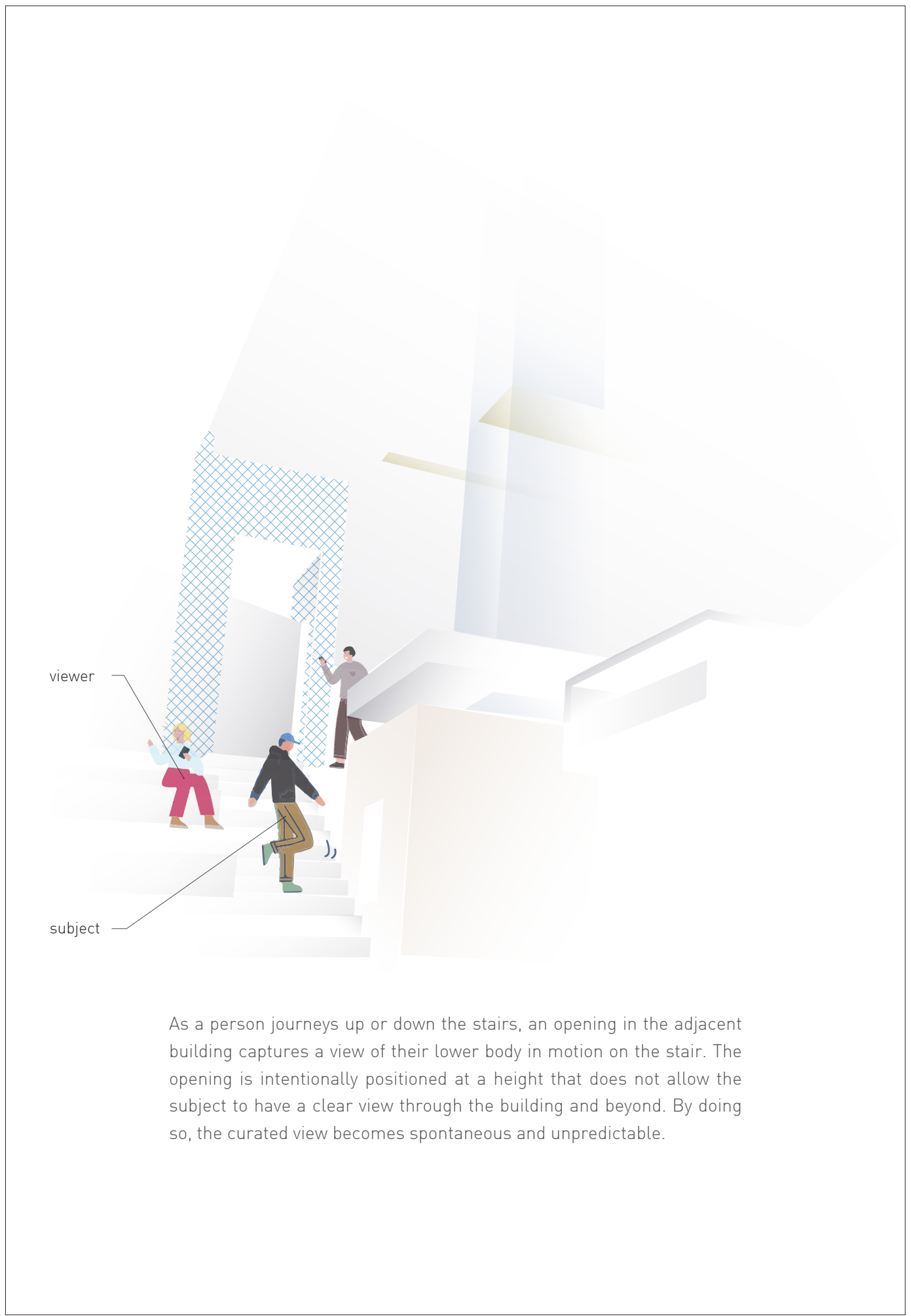

Fig 44 Peek-A-Boo on the Stairs 


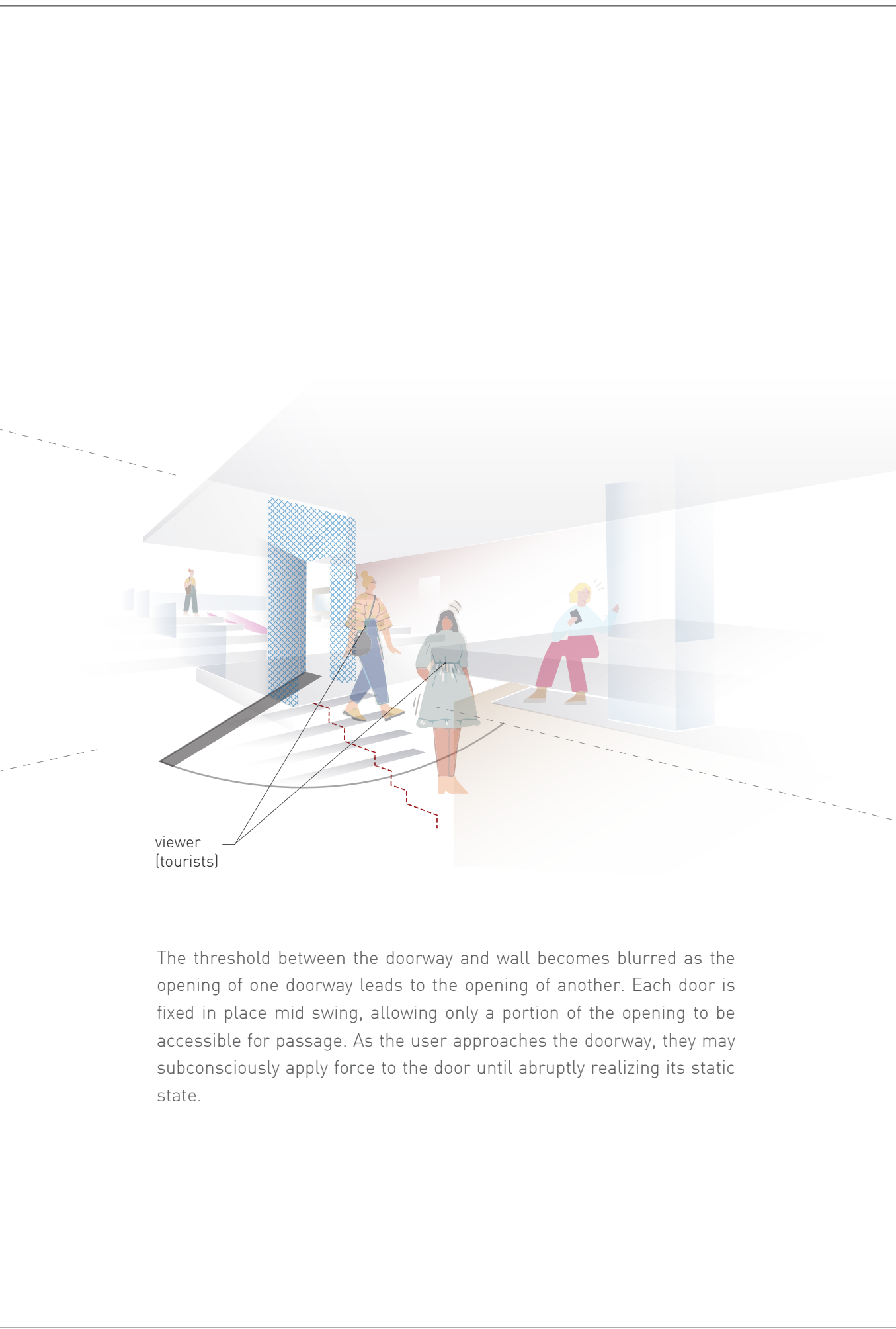

Fig $\mathbf{4 5}$ Thresholds of a Door 


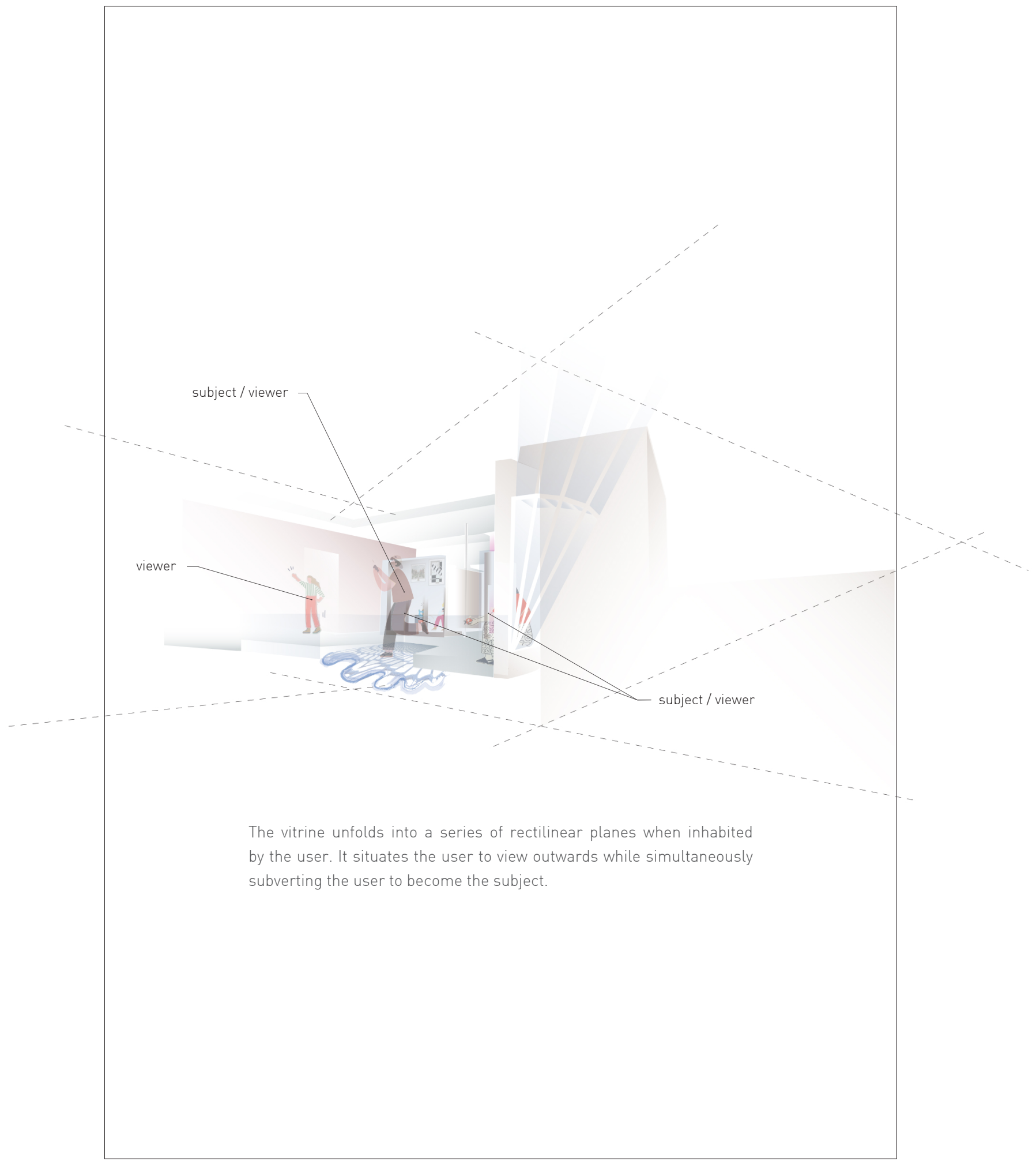

Fig 46 The Extending Window 


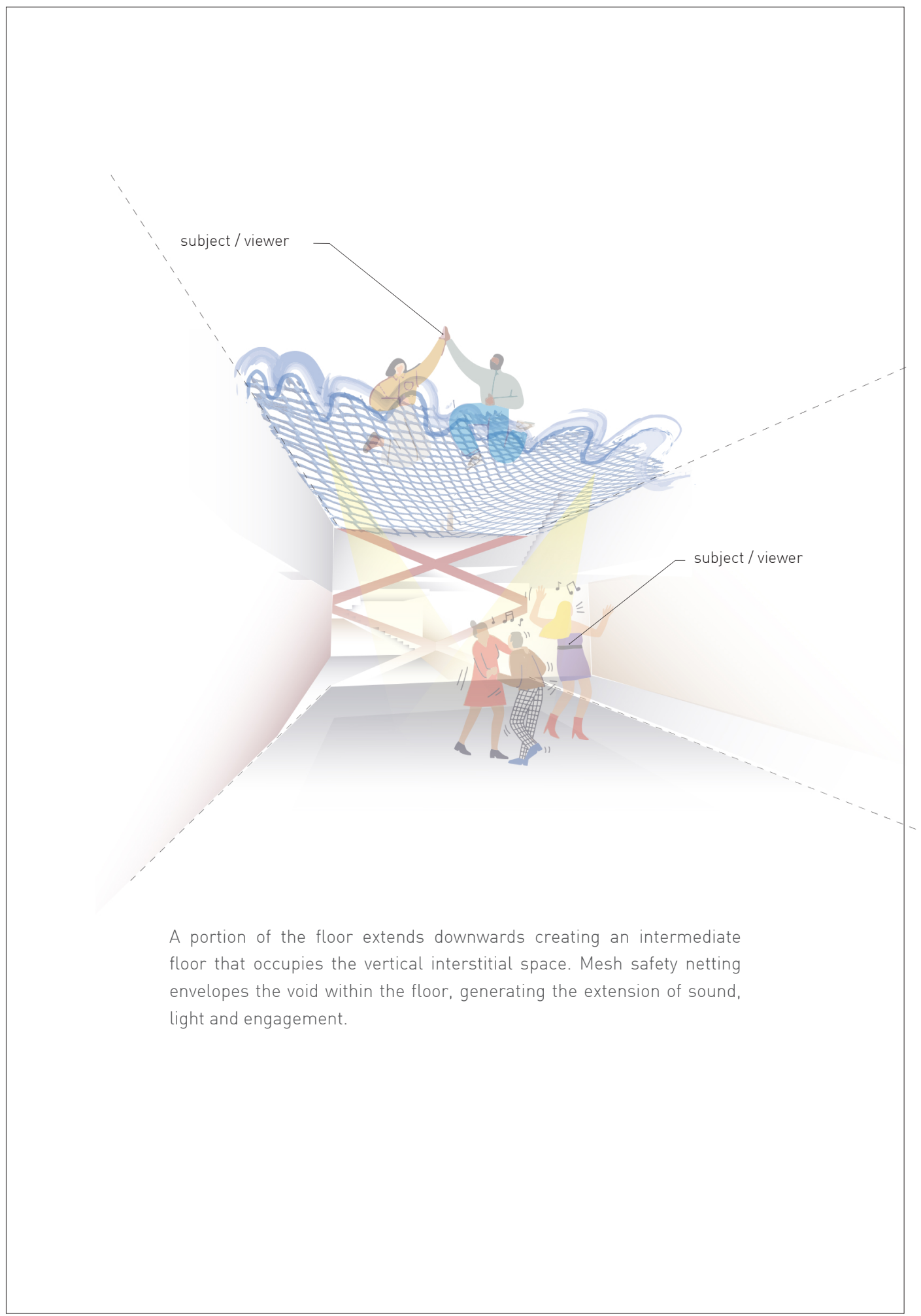

Fig $\mathbf{4 7}$ Interstice of Floors 


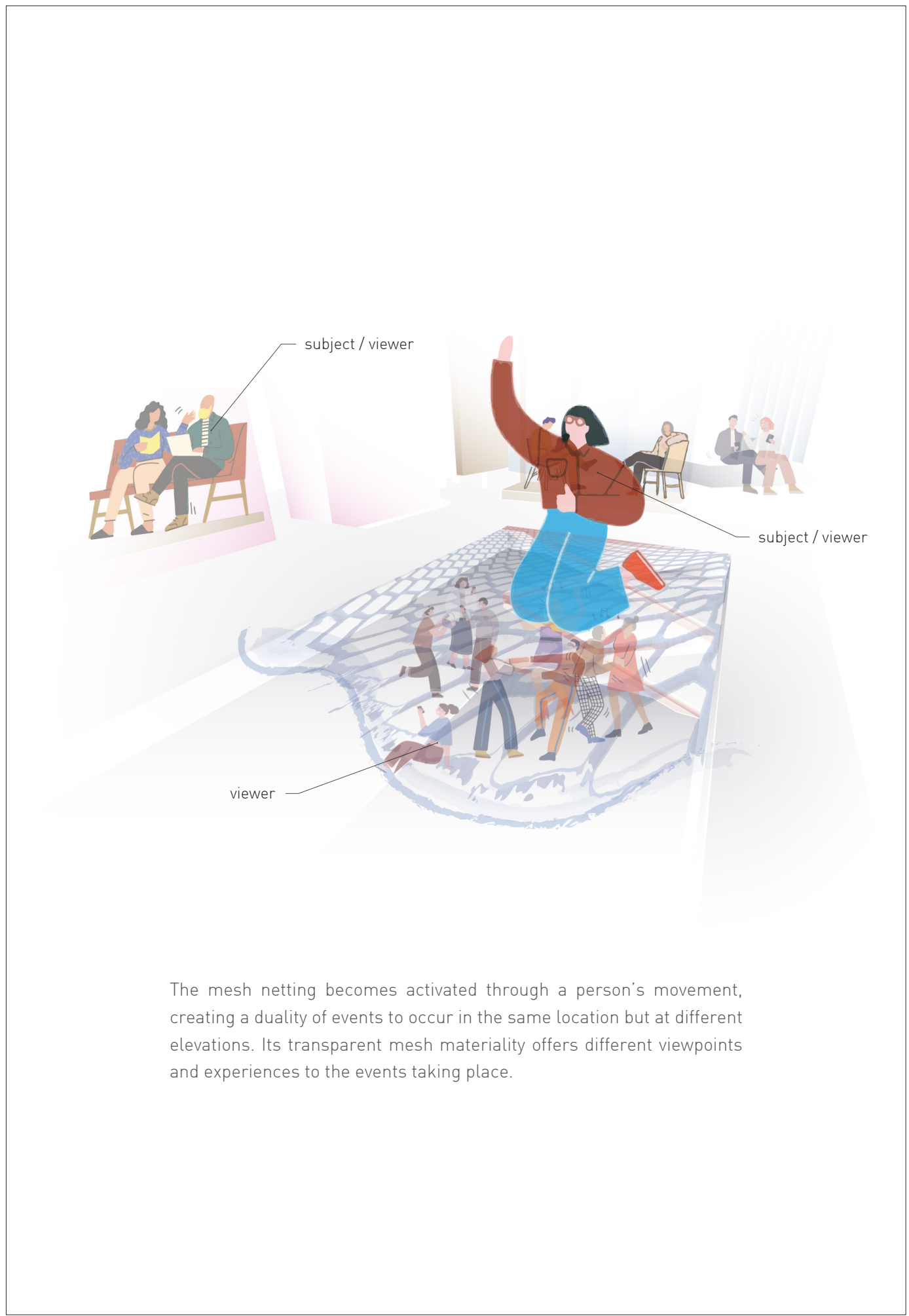

Fig 48 Bounce in Every Step 



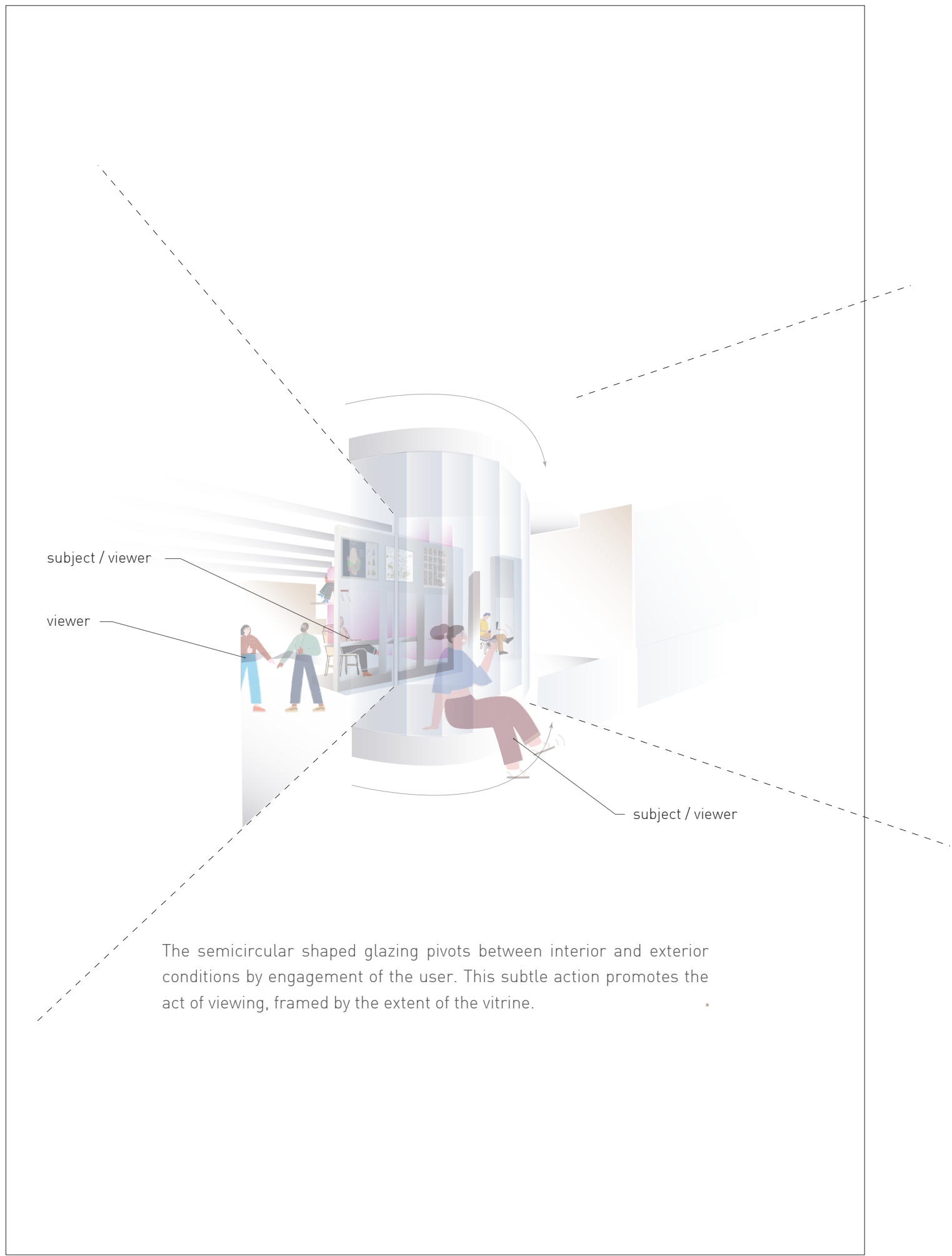

Fig $\mathbf{5 0}$ Swiveling from Interior to Exterior Conditions 


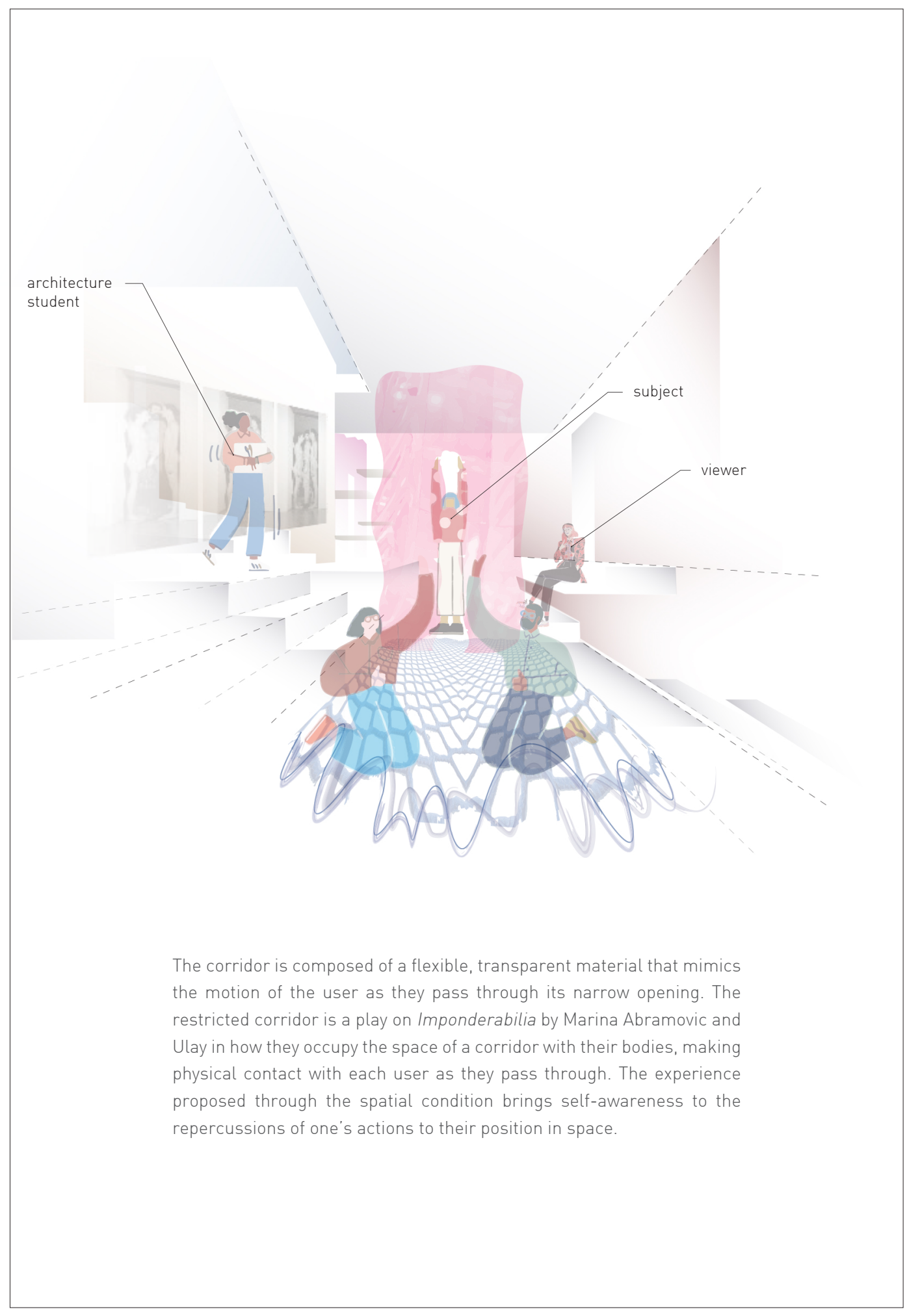

Fig 51 The Buffer-less Corridor 


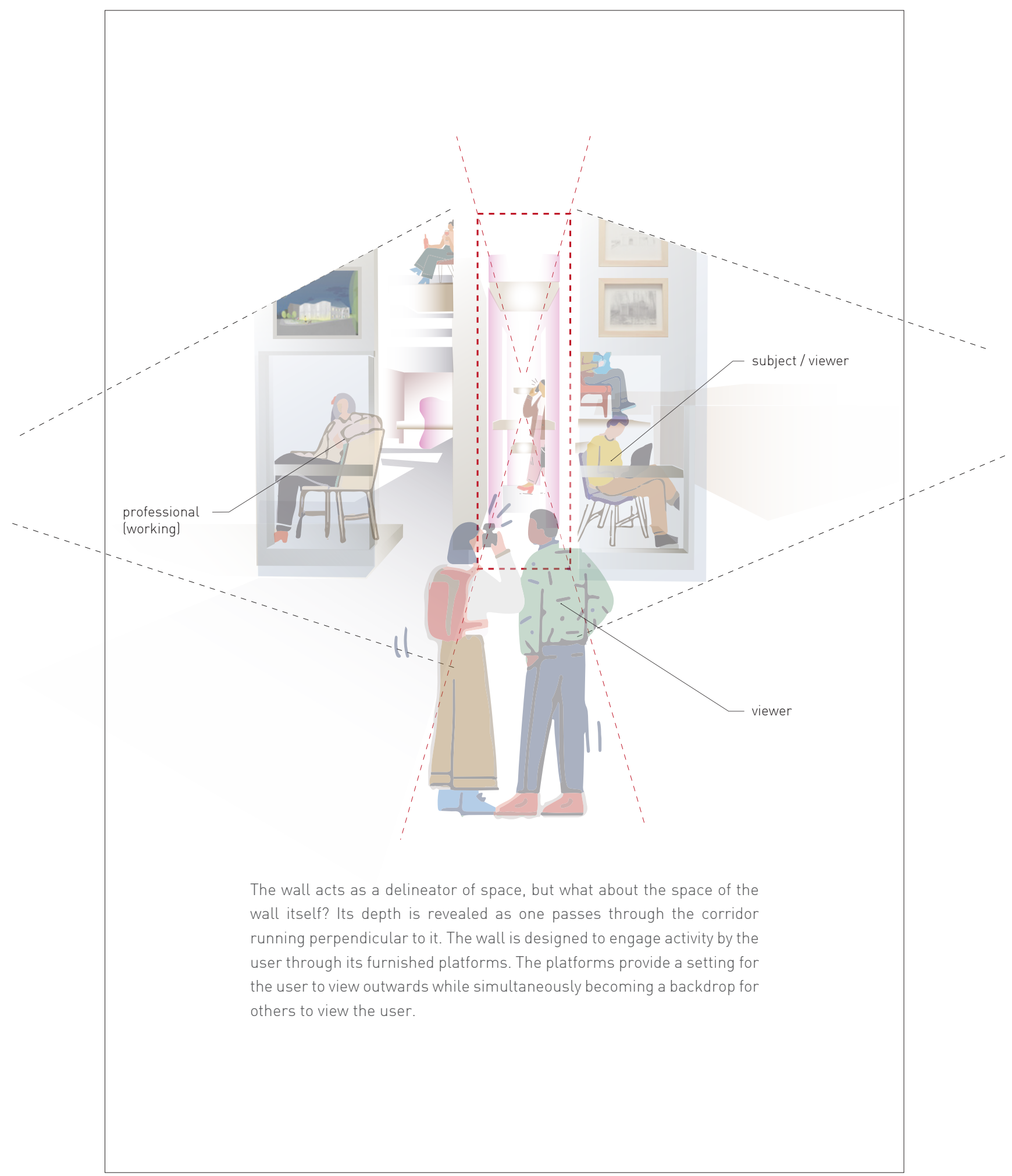

Fig 52 Depths of a Wall 


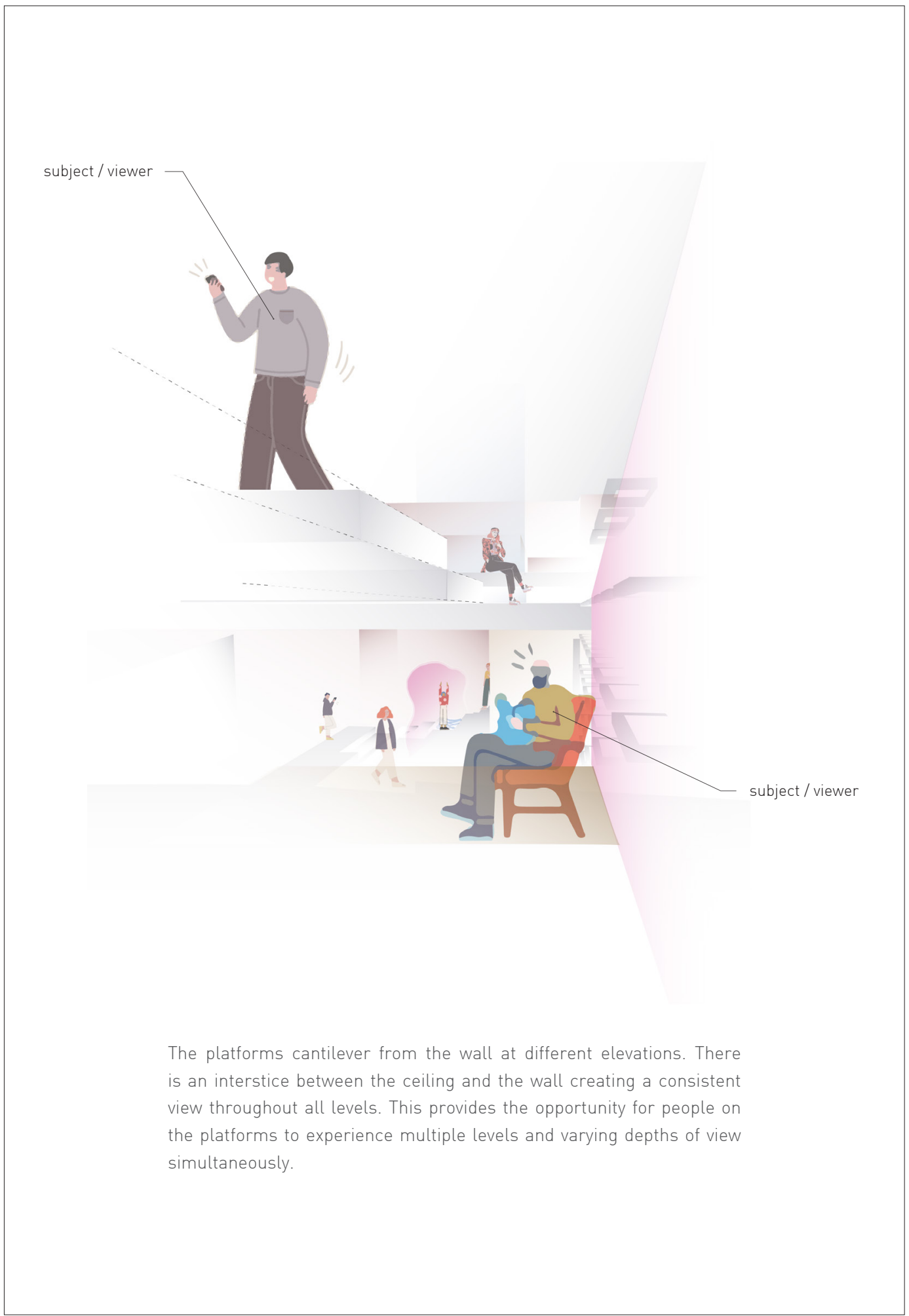

Fig $\mathbf{5 3}$ Sitting on a Wall 


\section{Postscript}

Curating architecture provided a context in this thesis to discover and rediscover the notions of convention versus invention through creativity, investigation and experimentation. Could this, then, present an opportunity for practitioners to expand their architectural horizons and delve into a multiplicity of subjects at their discretion? It offers a chance for those within the discipline to invite the public to perceive and understand architecture through a different lens beyond their everyday environment.

The thesis has opened a dialogue to reinterpret how the form and function of architectural elements perform within and outside of the built environment. We can understand how the agency of curatorial practises challenges the design process in how architecture is developed, produced and communicated. In the context of this thesis, curating architecture was a way to educate the public about architecture by making them cognizant of the architectural elements that surround them. Exhibitionism was identified as a platform to design spatial outcomes as a series of events (activated by people) through the narrative of the urban vitrine. Consequently, the architecture became a backdrop to the spatial events as a way to investigate and challenge the function of architectural elements.

Throughout the unfolding of this thesis, it is important to question how the role of curation can be utilized to create didactic tendencies in different forms of architecture. Future curated events could be an extension of an existing or new building within the urban fabric, occupying multiple locations at varying scales and durations. The outcome being a multifaceted architecture activated by people through their interpretations and experiences with (un)conventional architectural elements.

The Eventification of Exhibiting Architecture 
As the notion of exhibiting architecture and its effects on architectural production continue to be questioned and discussed, this thesis suggests the criticality of architecture can be constructively challenged to reflect on its influence on professional practices and the built environment. We should then ask the pertinent question, what is the exhibition/exhibitionist content teaching us and how do we situate ourselves within the work? Lastly, this thesis hopes to encourage us to identify, investigate and discover our own interpretations of architecture; for they too may - one day - be exhibited. 


\section{Endnotes}

\section{Introduction}

1. Carson Chan, Alison Hugill, "Curating Architecture: The Architecture of Estrangement," On Curating 31 (n.d.) http://www.on-curating.org/issue-

31-reader/curating-architecture-the-architecture-of-estrangement.html\#. XZ5bxudKgnX

2. Merriam-Webster Dictionary, (2019). https://www.merriam-webster.com/ dictionary/architecture

3. Mark Lamster, Architecture and Film, (New York: Princeton Architectural Press, 2000), 2.

4. Ibid, 12.

5. Eeva-Liisa Pelkonen, Exhibiting Architecture: A Paradox?, (New York: Yale School of Architecture, 2015), 10.

\section{The Brief}

1. Adrian George, The Curator's Handbook, (United Kingdom: Thames and Hudson, 2015), 2.

2. Ibid, 2.

3. Ibid, 2.

4. Lea-Catherine Szacka, Biennials/Triennials: Conversations on the Geography of Itinerant Display, (New York: Columbia Books on Architecture and the City, 2019), 121.

5. Ibid, 8 .

6. Vito Acconci and Steven Holl, Storefront for Art and Architecture, (Austria: Herausgeber, 2000), 8. 
7. Chicago Art Institute, "Anticipating The Architectural Outcome," featuring Kisho Kurokawa's drawings on Illinois Center Sporting Club, Chicago, Illinois, (1988/90).

8. SPMB, “Softscape," (2011). https://www.spmb.ca/SOFTSCAPE-1

9. "Farnsworth House," National Historic Landmarks Program, (n.d.) https:// web.archive.org/web/20071020134659/http:/tps.cr.nps.gov/nhl/detail.

cfm?Resourceld=1144699865\&ResourceType=Building

10. Szacka, Biennials/Triennials: Conversations on the Geography of Itinerant Display, 27

11. Merriam-Webster Dictionary, (2019). https://www.merriam-webster.com/ dictionary/vitrine

12. Jonathan Hale and Holger Schnadelbach, Curating Architecture and the City: Moving city: Curating architecture on site, (New York: Routledge, 2009), 51.

\section{The Exhibition}

1. Szacka, Biennials/Triennials: Conversations on the Geography of Itinerant Display, 31.

2. Sakshi, Lakhotia. "Mexico Wall: Forget what Trump says, these architects found the perfect way to put the wall to good use." Architecture \& Design (2019).

3. Szacka, Biennials/Triennials: Conversations on the Geography of Itinerant Display, 26.

4. Omar Khan, Hannah Dorita, and Bernard Tschumi. "Performance/ Architecture: An Interview with Bernard Tschumi." Journal of Architectural Education (1984-) 61, no. 4 (2008): 53.

5. Bernard, Tschumi, Architecture and Disjunction, (MIT Press, 1996), 146.

\section{The Event}

1. Mirko Zardini, “Exhibiting and Collecting Ideas: A Montreal Perspective." Log, no. 20 (2010): 81. 


\section{Glossary (Sources)}

1. Agency

Doucet, Isabelle; Cupers, Kenny. "Agency in Architecture: Reframing

Criticality in Theory and Practice" Footprint (Online), 1, January 2009).

2. Curation

George, Adrian. The Curator's Handbook. United Kingdom: Thames and

Hudson, 2015, 2.

3. Content

Szacka, Lea-Catherine. Biennials/Triennials: Conversations on the

Geography of Itinerant Display. New York, NY: Columbia Books on

Architecture and the City, 2019, 25.

4. Space

"Space," Merriam-Webster Dictionary, Accessed November 3, 2019,

https://www.merriam-webster.com/dictionary/space

5. Vitrine

"Vitrine," Merriam-Webster Dictionary, Accessed September 24, 2019,

https://www.merriam-webster.com/dictionary/vitrine

6. Urban Fabric

"Urban Fabric," Your Dictionary, Accessed October 11, 2019,

https://www.yourdictionary.com/urban-fabric

7. Event

Tschumi, Bernard. Architecture and Disjunction. MIT Press, 1996, 146.

Note: All other terms listed in the Glossary of this document are of my own interpretation. 


\section{Bibliography}

Acconci, Vito; Holl, Steven. Storefront for Art and Architecture. Austria:

Herausgeber, 2000.

Chan, Carson; Hugill, Alison. "Curating Architecture: The architecture of Estrangement," Oncurating 31 (n.d.) Accessed October 3, 2019. http://www. on-curating.org/issue-31-reader/curating-architecture-the-architecture-ofestrangement.html\#.XZ5bxudKgnX

Di Carlo, Tina. "Exhibitionism." Log, no. 20 (2010): 151-58. Accessed April 13, 2020. www.jstor.org/stable/41765385.

Doucet, Isabelle; Cupers, Kenny. “Agency in Architecture: Reframing Criticality in Theory and Practice" Footprint (Online), 1, January 2009).

“Farnsworth House," National Historic Landmarks Program, (n.d.) https:// web.archive.org/web/20071020134659/http:/tps.cr.nps.gov/nhl/detail. cfm?Resourceld=1144699865\&ResourceType=Building

Foster, Hal. The Art-Architecture Complex. London: Verso, 2011.

George, Adrian. The Curator's Handbook. United Kingdom: Thames and Hudson, 2015.

Hale, Jonathan; Schnadelbach, Holger. Curating Architecture and the City: Moving city: Curating architecture on site. New York: Routledge, 2009.

Khan, Omar; Dorita, Hannah; Tschumi, Bernard. "Performance/Architecture: An Interview with Bernard Tschumi." Journal of Architectural Education (1984-) 61, no. 4 (2008): 52-58. www.jstor.org/stable/40480866.

Koolhaus, Rem. Fundamentals: 14th International Architecture Exhibition La Biennale Di Venezia. Marsilio Editori, 2014.

Kurokawa, Kisho. Anticipating The Architectural Outcome. Drawings on Illinois Center Sporting Club. Chicago Art Institute, Chicago, IL., 1988/90. 
Lakhotia, Sakshi. "Mexico Wall: Forget What Trump Says, These Architects Found the Perfect Way to Put the Wall to Good Use." Architecture \& Design, August 10, 2019. https://www.architecturaldigest.in/content/trump-usmexico-border-wall-architects-seesaw/.

Lamster, Mark. Architecture and Film. New York, NY: Princeton Architecture Press, 2000.

Merriam-Webster Dictionary, s.v. "architecture," Accessed September 9 , 2019. https://www.merriam-webster.com/dictionary/architecture

Merriam-Webster Dictionary, s.v. "vitrine," Accessed September 24, 2019. https://www.merriam-webster.com/dictionary/vitrine

Pelkonen, Eeva-Liisa. Exhibiting Architecture: A Paradox?. New York: Yale School of Architecture, 2015.

Shklovsky, Viktor. "Art, As Device." Poetics Today 36, no. 3 (September 2019): 157. Accessed September 9, 2019. https://warwick.ac.uk/fac/arts/ english/currentstudents/undergraduate/modules/fulllist/first/en122/ lecturelist2017-18/art_as_device_2015.pdf.

"Softscape." spmb. Accessed November 26, 2019. https://www.spmb.ca/ Softscape-1.

Szacka, Lea-Catherine. Biennials/Triennials: Conversations on the Geography of Itinerant Display. New York, NY: Columbia Books on Architecture and the City, 2019.

Tschumi, Bernard. Architecture and Disjunction. MIT Press, 1996.

Tschumi, Bernard. The Manhattan Transcripts. London: Academy Editions, 1994.

Umolu, Yesomi; Angiama, Sepake; Tavares, Paulo. ...And Other Such Stories: 2019 Chicago Architecture Biennial. Columbia Books on Architecture and the City, 2019.

Zardini, Mirko. "Exhibiting and Collecting Ideas: A Montreal Perspective." Log, no. 20 (2010): 77-84. Accessed February 9, 2020. www.jstor.org/ stable/41765375. 


\section{Figures (Sources)}

Figure 01: Architecture Within Its Context

“The Winnipeg Art Gallery." Winnipeg Architecture Foundation. Accessed October 2, 2019. https://www. winnipegarchitecture.ca/the-winnipeg-art-gallery/.

Figure 02: Architecture Removed From its Context

“The Winnipeg Art Gallery." Winnipeg Architecture Foundation. Accessed October 2, 2019. https://www. winnipegarchitecture.ca/the-winnipeg-art-gallery/.

Figure 03: Architecture Relocated in the Museum

“The Winnipeg Art Gallery." Winnipeg Architecture Foundation. Accessed October 2, 2019. https://www. winnipegarchitecture.ca/the-winnipeg-art-gallery/.

Figure 04: White Box Diagram

“Untitled." Accessed October 2, 2019. https://i.pinimg.com/originals/b8/c9/c2/

b8c9c289ee7b50c5aca7da57b1cb55d0.jpg

Figure 05: Matrix

Don't Miss a Sec', Monica Bonvicini, 2004

Monica Bonvicini. Accessed September 8, 2019. http://monicabonvicini.net/dont-miss-a-sec/.

Snake, Richard Serra, 2005

“Snake." Guggenheim. Accessed September 8, 2019. https://www.guggenheim.org/artwork/3.

Realizing An Anthropometry, Yves Klein, 1960

Klein, Yves. "Yves Klein Realizing an Anthropometry with Elena in His Studio (ANT 133), 1960."

Photographs - Yves Klein realizing an Anthropometry with Elena in his studio (ANT 133) - Yves Klein.

Accessed September 8, 2019. http://www.yvesklein.com/en/photographies/view/580/yves-klein-realizingan-anthropometry-with-elena-in-his-studio-ant-133/.

Splitting, Gordon Matta-Clark, 1974

Folland, Tom, "Gordon Matta-Clark, Splitting." Smarthistory. Accessed September 8, 2019. https:// smarthistory.org/gordon-matta-clark-splitting/.

Falling Clock, Daniel Arsham, 2011

Martell, Hayley. "Falling Clock." Daniel Arsham. Accessed September 8, 2019. https://www. danielarsham.com/collection/falling-clock. 
Withdrawing Room, Elizabeth Diller, 1987

Diller Scofidio + Renfro. "Withdrawing Room." Elizabeth Diller. Accessed February 22, 2020. https:// dsrny.com/project/withdrawing-room

Imponderabilia, Marina Abramovic \& Ulay, 1977-2017

Abramovic, Marina; Ulay. “Imponderabilia.” Lisson Gallery. Accessed February 3, 2020.

Marsyas: Anish Kapoor, 2002

“Marsyas, Anish Kapoor, 2002." Columbia College. Accessed September 8, 2019. https://www.college. columbia.edu/core/content/marsyas-anish-kapoor-2002.

Figure 06: Kunstkammer

“Cabinets of Curiosities in the Seventeenth Century." Res Obscura. Accessed October 2, 2019. https://resobscura.blogspot.com/2011/01/cabinets-of-curiosities-in-seventeenth.html?utm_ source=twitterfeed\&utm_medium=twitter.

Figure 08: The Evolution of Exhibiting Architecture

1932: Display at Bullocks-Wilshire Department Store, Los Angeles, CA., USA.: Modern Architecture International Exhibition - Philip Johnson and Henry-Russell Hitchcock

"Gallery of AD Classics: Modern Architecture International Exhibition / Philip Johnson and Henry-Russell Hitchcock - 1." ArchDaily. Accessed October 3, 2019. https://www.archdaily.com/409918/ad-classicsmodern-architecture-international-exhibition-philip-johnson-and-henry-russell-hitchcock/51f82342e8 e44e625700015c-ad-classics-modern-architecture-international-exhibition-philip-johnson-and-henryrussell-hitchcock-image.

1938: December 7, 1938-January 30, 1939. Photographic Archive. The Museum of Modern Art Archives, New York, NY., USA. Photographs by Soichi Sunami

“Bauhaus: 1919-1928." The Museum of Modern Art. Accessed October 3, 2019. https://www.moma.org/ calendar/exhibitions/2735?installation_image_index=0.

1941: The Ecole Des Beaux-Arts And Architectural Education by Paul P. Cret

Cret, Paul P. “The Ecole Des Beaux-Arts and Architectural Education." Journal of the Society of Architectural Historians. University of California Press, April 1, 1941. https://jsah.ucpress.edu/ content/1/2/3.

1957: Berlin Interbau (1957) Postcard

Berlin Inter - Aerial photo of the Hansaviertel District, 1962, Berlin Inter - Orientation sign for the new buildings in the Hansaviertel

“Berlin Interbau (1957)." Architectuul. Accessed October 3, 2019. http://architectuul.com/architecture/ berlin-interbau-1957. 
1980: Façades of the Strada Novissima at the 1980 Biennale Architettura

“Exhibiting the Postmodern.” James Taylor-Foster, June 22, 2019. Accessed October 3, 2019. https:// james.tf/exhibiting-postmodern.

1982: Opening night of Performance A to Z, first event hosted at Storefront

"Newsletter." Storefront for Art and Architecture I Programming: Exhibitions: Performance A-Z.

Accessed October 3, 2019. http://storefrontnews.org/programming/performance-a-z/.

2005: Bi-City Shenzhen Biennale of Urbanism / Architecture 8th edition to run 2019, titled Urban Space and Technological Innovation.

"Gallery of 11 Architecture Biennials to Pay Attention to in 2019 - 2." ArchDaily. Accessed October 3, 2019. https://www.archdaily.com/908891/11-architecture-biennials-to-pay-attention-to-in2019/5c34e8d908a5e5968e000018-11-architecture-biennials-to-pay-attention-to-in-2019-image.

2007: Trienal de Arquitectura de Lisboa 5th edition to run 2019, titled The Poetics of Reason.

Vada, Pedro. “Details about Lisbon Triennale 2019." ArchDaily. ArchDaily, July 24, 2019. Accessed

October 3, 2019. https://www.archdaily.com/921450/details-about-lisbon-triennale-2019.

2015: Chicago Architecture Biennial. First biennial to be established in North America 3rd edition to run 2019, titled ...And Other Such Stories.

"Architecture Critics Take on the Chicago Architecture Biennial land Each Other)." Archinect News. Accessed November 16, 2019. https://archinect.com/news/tag/465082/chicago-architecture-biennial.

2019: Bauhaus in Greece International conference to take place in Athens for the 100th anniversary of the foundation of Bauhaus at The Athens School of Fine Arts.

“Bauhaus and Greece." Bauhaus 2019. Accessed November 16, 2019. http://bauhaus2019.asfa.gr/index. php/en/.

2019: Bienal de Arquitectura Latinoamericana

“BAL Bienal De Arquitectura Latinoamericana." balpamplona. Accessed November 16, 2019. https:// www.balpamplona.org/.

Figure 09: John A. Russell Architecture Building (1959), University of Manitoba, Winnipeg, MB. Kressock, David. “University of Manitoba J.A. Russell Building." LM Architectural Group. Accessed March 11, 2020. http://www.lm-architects.com/portfolio/university-of-manitoba-j-a-russell-building/

Figure 16: Centre Pompidou (1971-77) by Renzo Piano \& Richard Rogers, Paris, France. “Centre Pompidou." Paris Digest. Accessed March 11, 2020. https://www.parisdigest.com/monument/ centre-pompidou.htm 
Figure 23: Chicago Cultural Center (1897), Chicago IL., USA.

Freund, Sara. "11 Exhibits We Loved at the Chicago Architecture Biennial 2019." Curbed Chicago. Curbed Chicago, October 18, 2019. https://chicago.curbed.com/2019/9/20/20873010/chicago-architecturebiennial-2019-must-see.

Figure 24: Teeter-Totter Wall by Rael Sam Fratello (2018), on the border between Sunland Park, NM., USA \& Ciudad Juarez, Mexico.

"Teeter-Totter." Architectural Digest. Accessed February 22, 2020. https://www.architecturaldigest.in/ content/trump-us-mexico-border-wall-architects-seesaw/

Figure 25: Gallery façade (1993) by Vito Acconci \& Steven Holl for Storefront for Art and Architecture, New York, NY., USA.

Gopnik, Blake. "The Storefront for Art and Architecture By Acconci and Holl Is the Daily Pic by Blake Gopnik." The Daily Beast. The Daily Beast Company, October 24, 2012. Accessed November 16, 2019. https://www.thedailybeast.com/the-storefront-for-art-and-architecture-by-acconci-and-holl-is-thedaily-pic-by-blake-gopnik.

Figure 30: The Ceiling display from the 2014 Venice Architecture Biennale: Fundamentals in Venice, Italy. Pirrone, Sergio. "The Ceiling." 2014 Venice Architecture Biennale. Central Pavilion. Accessed March 11, 2020. https://www.architecturalrecord.com/articles/3174-critique-rem-s-rules

Figure 31: Index of Architectural Elements (Exhibition/Exhibitionist) From The Knees Of My Nose To The Belly Of My Toes, Alex Chinneck, 2013

"From the Knees of My Nose to the Belly of My Toes." Alex Chinneck. Accessed November 16, 2019. https://www.alexchinneck.com/from-the-knees-of-my-nose-to-the-belly-of-my-toes.

Crystal Houses: MVRDV, 2016

"Crystal Houses." MVRDV. Accessed November 26, 2019. https://www.mvrdv.nl/projects/240/crystalhouses.

Umbrella Street: Quartier Petit Champlain, 2019

“Explore Canada on Instagram: 'Rain or Shine, Quebec City's Petit Champlain District Has You Covered! To Walk under These Colourful Umbrellas. Instagram. Accessed November 26, 2019. https https://www. instagram.com/p/BmZzo6EnPT0/?utm_source=ig_share_sheet\&igshid=1vmgjophxvnbs.

Yi Chen And Muchen Zhang: Guanglian Licc Cloud Center, 2019

"Guanglian Icc Cloud Center." Guanglian Icc Cloud Center - Yi Mu. Accessed November 26, 2019. http:// www.fenghemuchen.com/en/design/interior/2019/1008/96.html. 
Corridor House: Mos Architects, 2015

“House, No. 11, Corridor House." MOS. Accessed November 26, 2019. https://www.mos.nyc/project/ corridor-house.

Red River College Princess Campus-Roblin Centre: Cibinel Architecture, 2011

Wiebe, Jaclyn, Toban Dyck, Melissa Hryb, Jerrad Peters, Chris Hearn, and Samantha Bennett. “Winnipeg's Top 5 Architectural Wonders: Interior Edition." Spectator Tribune, May 21, 2013. Accessed November 26, 2019. https://www.spectatortribune.com/winnipegs-top-5-architectural-wonders-interioredition/.

Estiler, Keith. “Do Ho Suh's Immersive Fabric Homes Are on View at Museum Voorlinden." HYPEBEAST. HYPEBEAST, Accessed November 26, 2019. https://hypebeast.com/2019/5/do-ho-suh-museumvoorlinden-solo-exhibition.

Best Products Company, Inc.: Site “BEST Products." SITE. Accessed November 26, 2019. https://www.siteenvirodesign.com/content/bestproducts.

'Untitled (Stairs)': Rachel Whiteread, 2001

Pullen, Victoria Elizabeth. "Rachel Whiteread A Tate Britain.” victoria e pullen, November 13, 2017. Accessed November 26, 2019. https://victoriaepullen.myblog.arts.ac.uk/2017/11/13/rachel-whitereadtate-britain/.

Vessel: Thomas Heatherwick, 2019

“Heatherwick Studio: Design \& Architecture: Vessel." Heatherwick Studio I Design \& Architecture. Accessed November 26, 2019. http://www.heatherwick.com/project/vessel/.

Richard Serra

Rosina, Nick. “Sequence." Flickr. Yahoo!, October 4, 2011. Accessed November 26, 2019. https://www. flickr.com/photos/rlnv/6209758315.

Marsyas: Anish Kapoor, 2002

“Marsyas, Anish Kapoor, 2002." Columbia College. Accessed November 26, 2019. https://www.college. columbia.edu/core/content/marsyas-anish-kapoor-2002.

The Why Factory Is (W)Ego: MVRDV, 2017

Frearson, Amy. "MVRDV Presents a Hotel You Can Reconfigure at Dutch Design Week." Dezeen. Dezeen, October 24, 2017. Accessed November 26, 2019. https://www.dezeen.com/2017/10/23/mvrdv-wegohouse-reconfigure-dutch-design-week-2017-why-factory/. 
Off The Cuff: Diller Scofidio + Renfro, 2017

“Off the Cuff." DS R. Accessed November 26, 2019. https://dsrny.com/project/off-the-cuff.

Al Fayah Park: Thomas Heatherwick, 2010

“Heatherwick Studio: Design \& Architecture: Al Fayah Park." Heatherwick Studio I Design \&

Architecture. Accessed November 26, 2019. http://www.heatherwick.com/project/al-fayah-park/.

The Future Was Then: Daniel Arsham, 2016

Martell, Hayley. “The Future Was Then." Daniel Arsham. Daniel Arsham, February 2, 2016. Accessed

November 26, 2019. https://www.danielarsham.com/collection/the-future-was-then.

The Collage House: S+Ps Architects, 2015

Mena, Florencia. “Collage House / S PS Architects." ArchDaily. ArchDaily, April 24, 2016. Accessed

November 26, 2019. https://www.archdaily.com/786059/collage-house-s-plus-ps-architects.

Wastelandscape: Architect Clémence Eliard And Artist Elise Morin, 2011

Etherington, Rose. “WasteLandscape by Elise Morin and Clémence Eliard.” Dezeen. Dezeen, October

11, 2019. Accessed November 26, 2019. https://www.dezeen.com/2011/08/02/wastelandscape-by-elisemorin-and-clemence-eliard/.

Superkilen: Brash Danish Architects Big In Collaboration With German Landscape Architects Topotek 1 And Superflex, 2013

“Superkilen." arcspace.com. Accessed November 26, 2019. https://arcspace.com/feature/superkilen/.

Massimo Uberti: Neon Light Installation, 2014

“Massimo Uberti: Neon Light Installations: Light Architecture, Installation Art, Light Installation."

Pinterest. Accessed November 26, 2019. https://www. pinterest.ca/pin/504332858245743725/?lp=true.

Hh59 Zurich: Meyer Dudesek Architekten, 2015

HH59 Zürich. Accessed November 26, 2019. http://www.meyerdudesek.com/hh59.html.

Figure 33: Vessel (2019) by Thomas Heatherwick in New York, NY., USA.

Figure 34: Crystal Houses (2016) by MVRDV, Amsterdam, Netherlands.

Figure 35: From the Knees of my Nose to the Belly of my Toes (2013) by Alex Chinneck, Kent, UK.

Note: All other figures and images included in this document are of my own work. 


\section{Appendix}

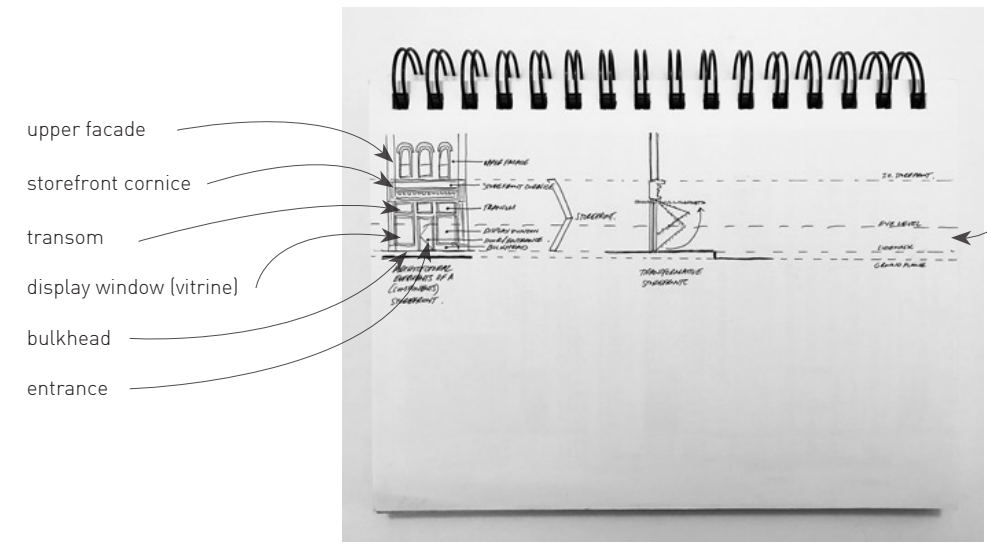

analysis of depths of

storefront through section
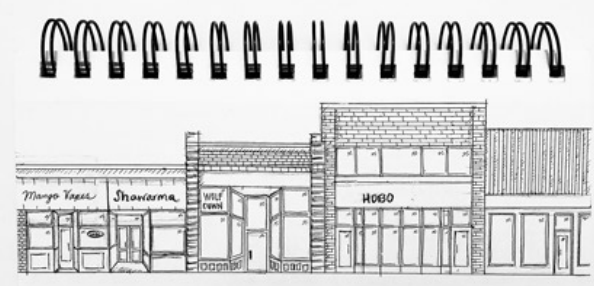

$r$

storefront drawing within

Deconstructing the Binary Vitrine

- exploring spatial conditions of

the vitrine in the museum and the built environment

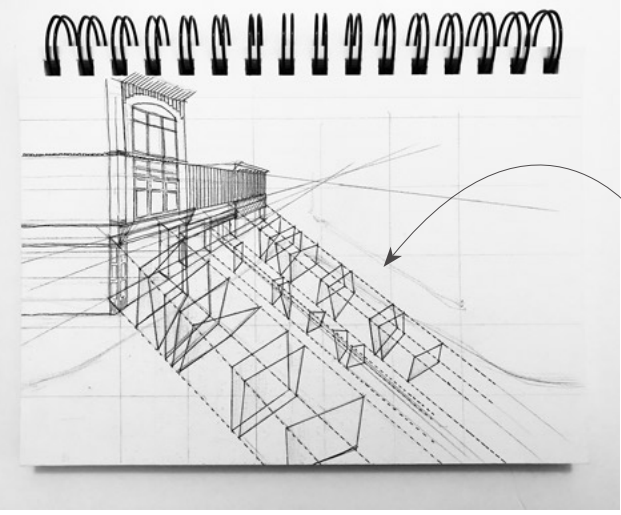

expanding the tectonic surface of the vitrine

Fig 54 Supplementary Sketches and Explorations 


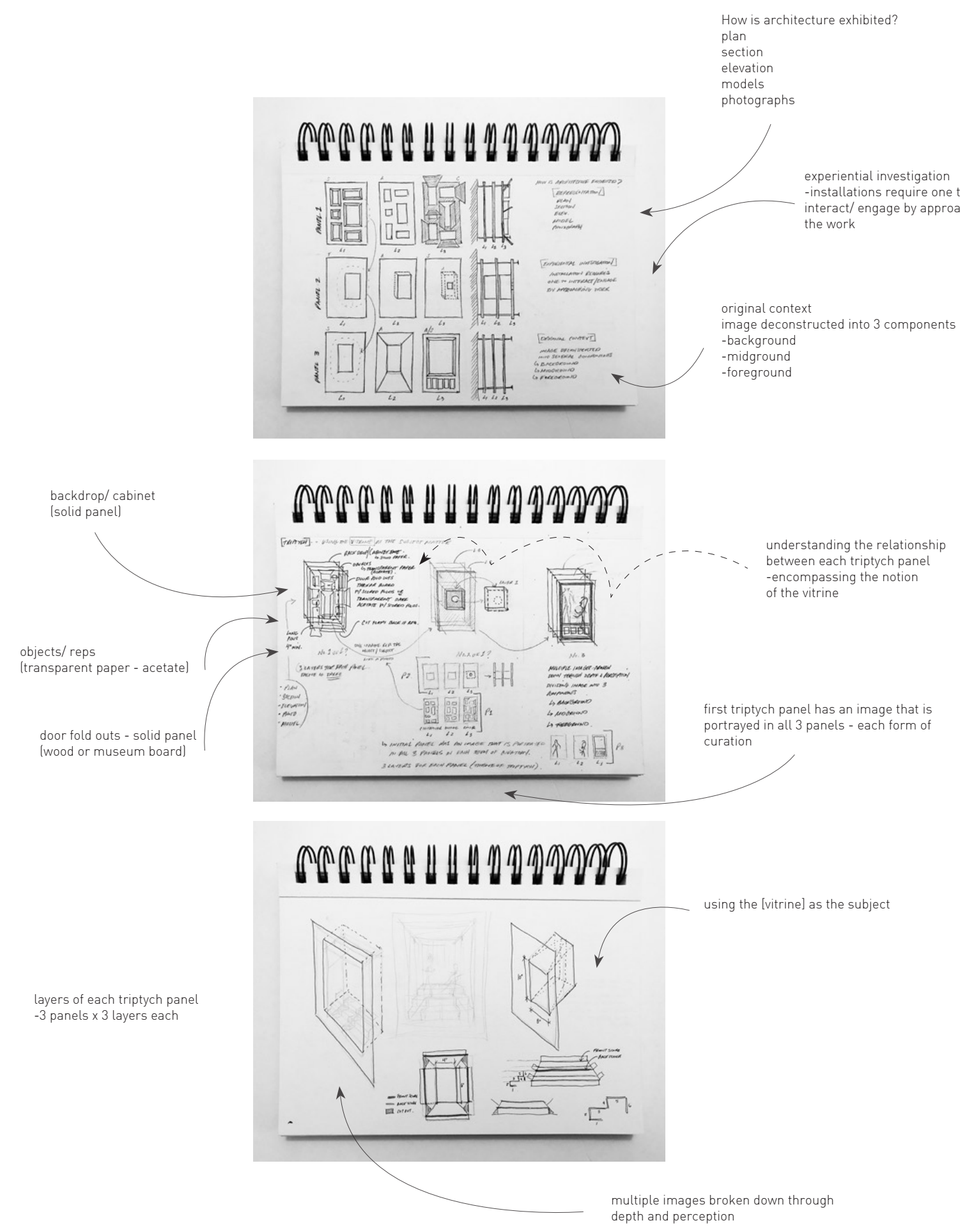

Fig 55 Supplementary Sketches and Explorations 


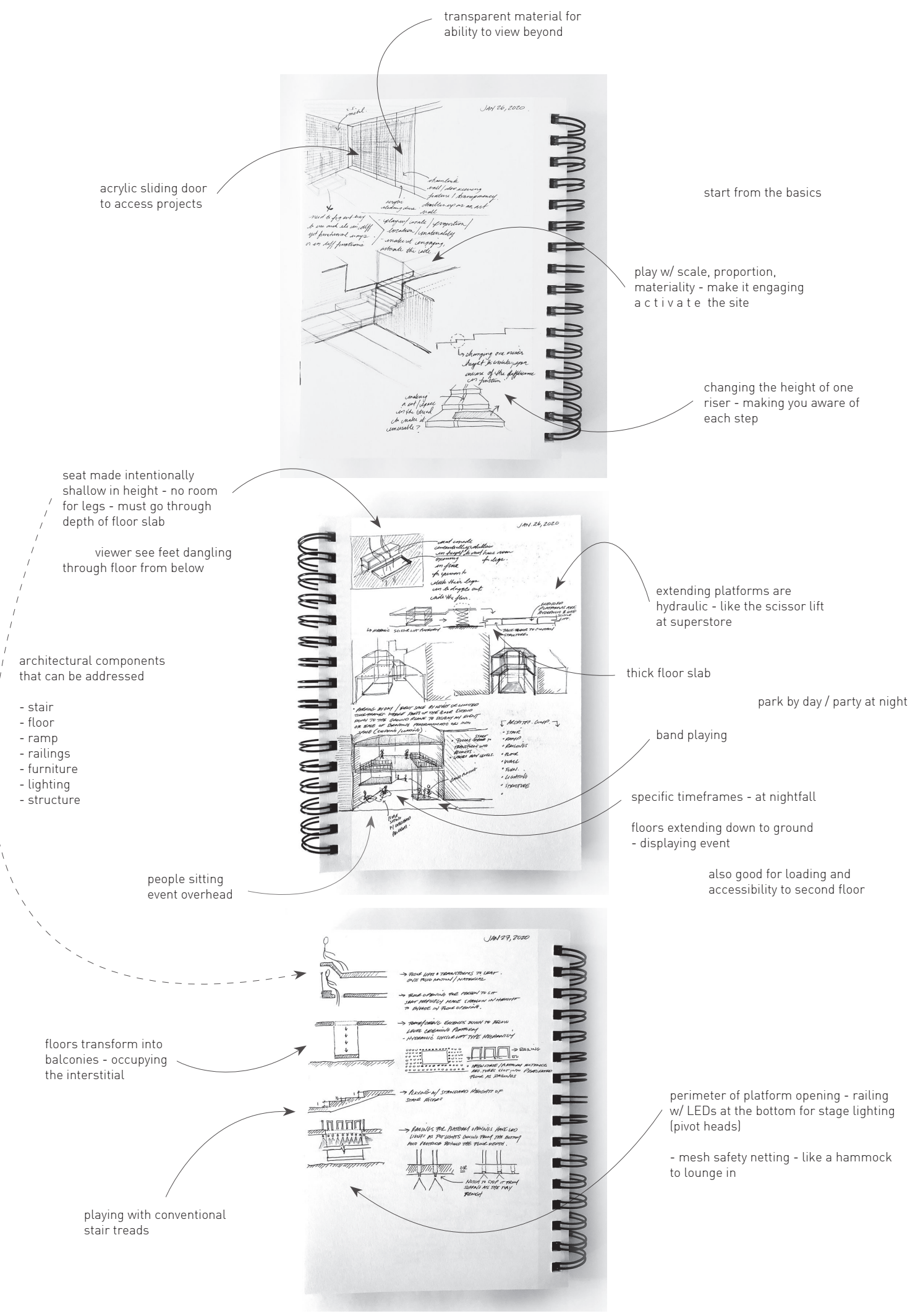

Fig 56 Supplementary Sketches and Explorations 


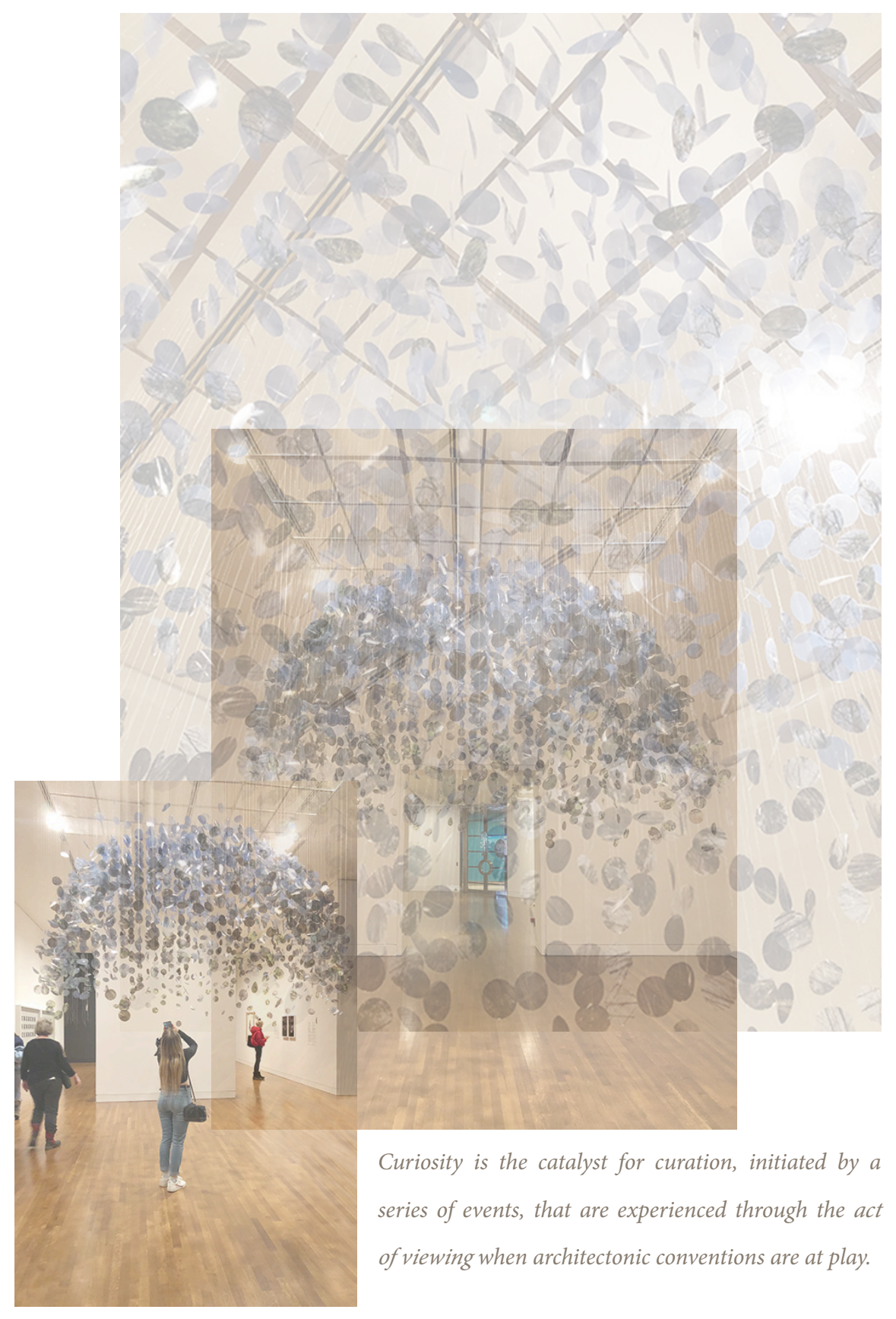

